\title{
MANAGING INTERPRETATION AT A UNESCO WORLD HERITAGE SITE: \\ A SUPPLY-SIDE PERSPECTIVE OF ANGKOR WAT TEMPLE, CAMBODIA
}

by

\section{Chanvirak Sarm}

\author{
A thesis \\ Submitted to the Victoria University of Wellington \\ in partial fulfilment of the requirements for the degree of \\ Master of Tourism Management
}

Victoria University of Wellington

2013 


\begin{abstract}
Interpretation and its relevance for visitor experiences have been discussed extensively but little attention has been paid to the management of interpretation by multiple stakeholders. UNESCO World Heritage Sites involve a number of different organisations but their interpretation management is not well understood. A lack of good interpretation management may lead to negative effects on heritage properties and people understanding about the heritage. This study aims to examine the structure of interpretation management and to identify the objectives in interpretation from various stakeholder organisations' perspectives. Other influential factors, for example decision making, are studied. Angkor Wat temple, a UNESCO World Heritage Site in Cambodia, is used as a case study.

Adopting the social constructivist approach for the current study strengthens the research method and data interpretation. The research takes a supply-side perspective; in-depth interviews were conducted with 22 representatives from UNESCO, the Ministry of Tourism, site management teams, tour guides and tour companies.

The findings suggest that interpretation is not yet managed successfully by organisations and tour guides. Tour guides are concerned about their lack of knowledge and language proficiency which impacts on their presentation. In addition, managing a different demand of group tour was found important for interpretation management. Tour guides had less involvement in making a decision about the development of interpretation-related projects. Some conflicts between the tour guides and site managers about decision making were identified. On the other hand, managing interpretation by organisations still requires interpretive facilities and visitor centres to enhance visitors' experiences at Angkor Wat temple.

This research contributes to the literature on interpretation and heritage tourism by identifying different interpretation management by multiple stakeholders. In addition to the academic study, the findings imply that relevant organisations need further improvement of interpretation management and visitor centres at Angkor Wat temple.
\end{abstract}




\section{Acknowledgements}

The completion of my master's thesis would not have been possible without the support and help from the following people.

Above all, I would like to thank my parents and my siblings for their spiritual support and timeless assistance.

This thesis would not have been possible without the help, support and patience of my supervisor Dr Julia Albrecht. Throughout the research process, my supervisor has been so supportive and remained encouraging till the completion of this thesis. Her wisdom, experience and encouraging supervision have lit my way to get my thesis completed.

I also wish to thank all members of the Tourism Group as well as the Student Learning Support Service (SLSS) at Victoria University of Wellington (VUW) for their support, encouragement and facilitation in the procedures needed to progress this thesis.

I would like to show my gratitude towards New Zealand Agency of International Development (NZAID) and New Zealanders who have provided me the scholarship. This scholarship not only provides me with education but also draws a meeting point for me and my wife, Nakry Sao. I might not have met her if we were not granted this scholarship together.

I am most grateful to Professor Ang Choulean and his colleagues who provided me with inspirational experiences and guidance in pursuing my postgraduate education.

Thank you to Bang Sopheak, Bang Sarith, Son and Dim's families and all my friends who offered me accommodation and transport during the stay in Wellington and Siem Reap.

Last but not least, I would also thank to all participants from UNESCO, the Cambodian Ministry of Tourism, APSARA Authority, GACP, WMF, I.Ge.S, tour guide teams and tour companies. Their involvement in this data collection is the most important input for this study. I would like to thank them all for their time and consideration in taking part in the interviews. 


\section{Table of contents}

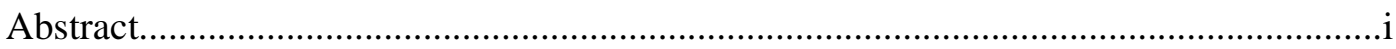

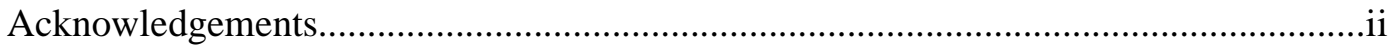

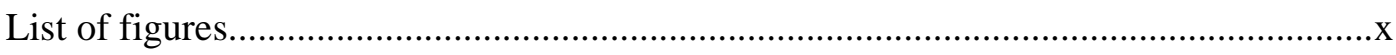

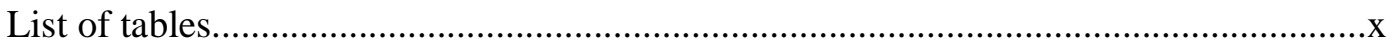

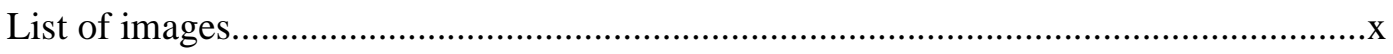

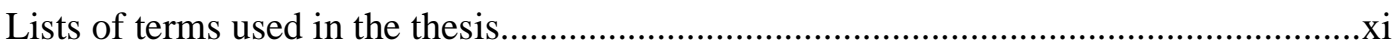

\section{1-Introduction...................................................................................................1}

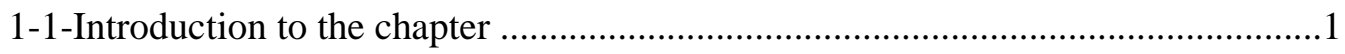

1-2-Researcher's interest in the topic.................................................................

1-3-From practical management of interpretation to academic research.................... 3

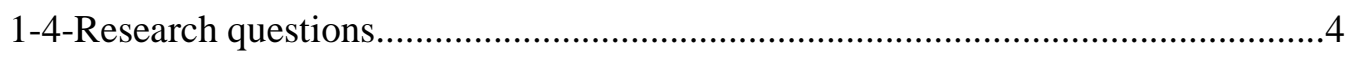

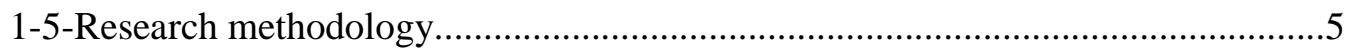

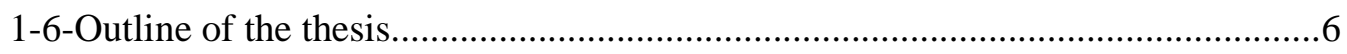

2-The research site and context..............................................................

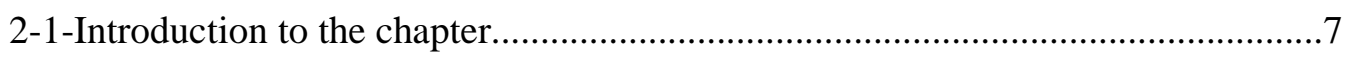

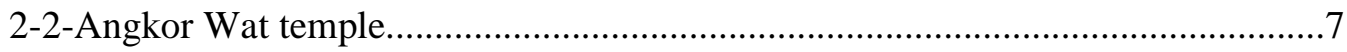

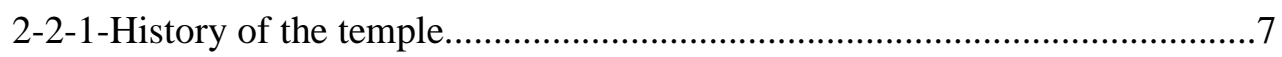

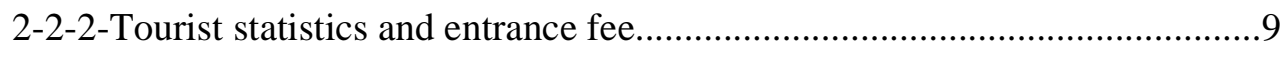

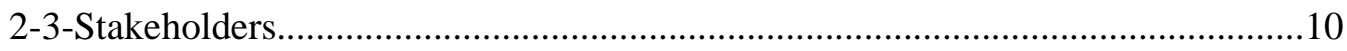

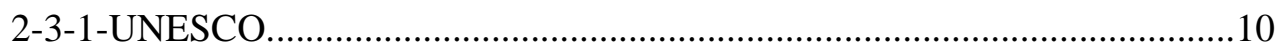

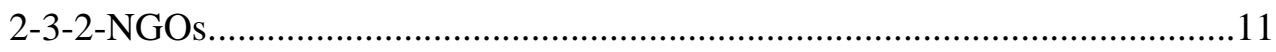


2-3-2-1-German Apsara Conservation Project.

2-3-2-2-Ingegneria Geotecnica e Structturale snc......................................12

2-3-2-3-World Monument Fund................................................................12

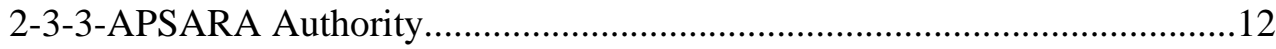

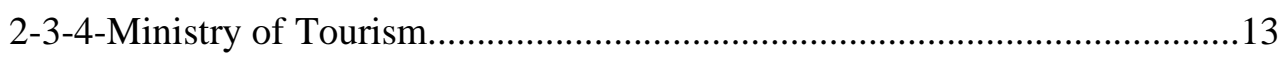

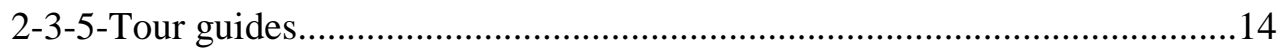

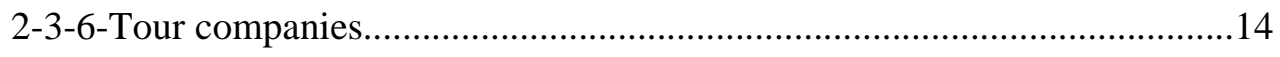

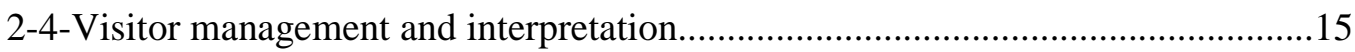

2-5-Multiple stakeholders in interpretation management at Angkor Wat temple.....16

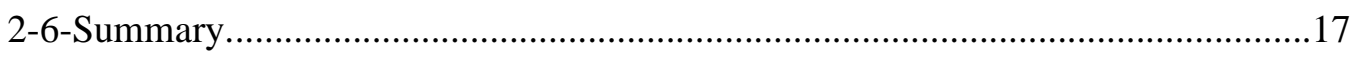

\section{3-Literature............................................................................................................18}

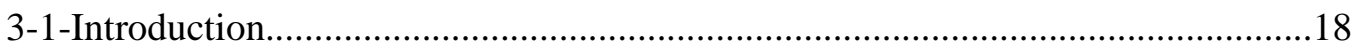

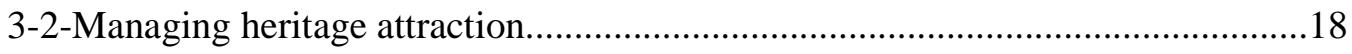

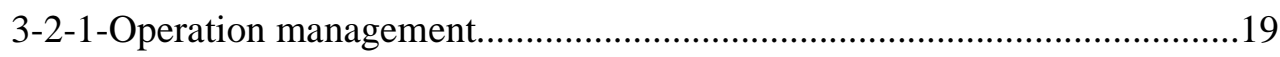

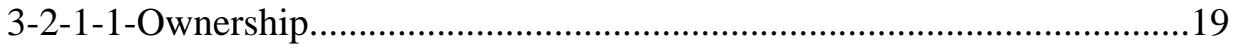

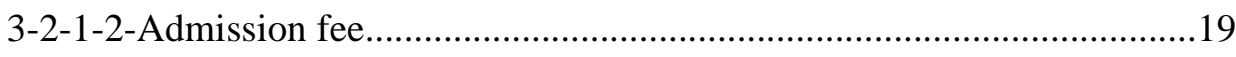

3-2-1-3-Key management challenges at visitor attractions...........................20

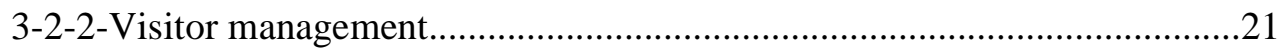

3-2-3-Non-verbal and verbal interpretation of attractions...............................22

3-2-4-Managing interpretation facilities....................................................23

3-2-4-1-Interpretation centres................................................................23

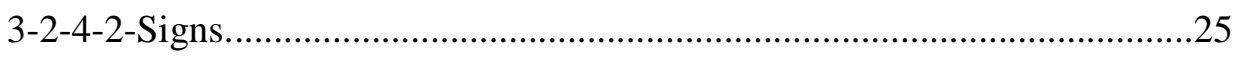

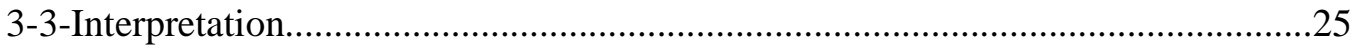


3-3-1-Definition and the aim of interpretation.

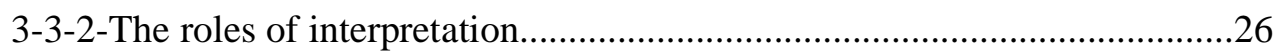

3-4-Stakeholders and join-management of visitor attraction...................................28

3-4-1-International organisation involved in management interpretation...........29

3-4-2-Managing interpretation at national level ........................................... 30

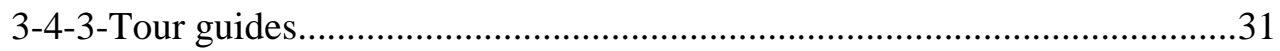

3-4-3-1-Factors that may impact on interpretation........................................33

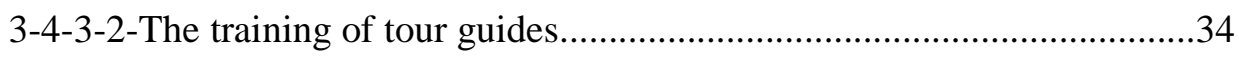

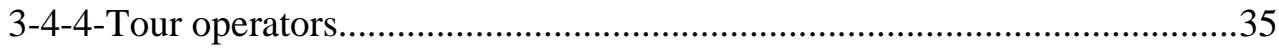

3-5-Multiple stakeholders in the management of heritage attractions........................35

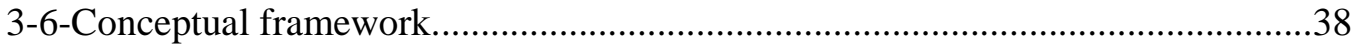

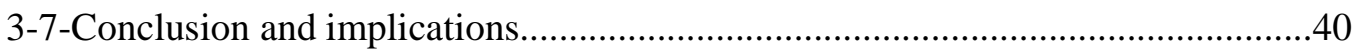

4-Methodology

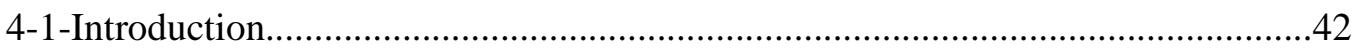

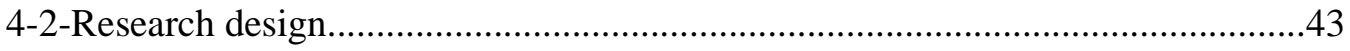

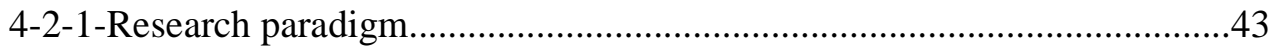

4-2-2-Case study research..................................................................... 44

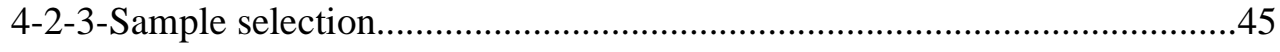

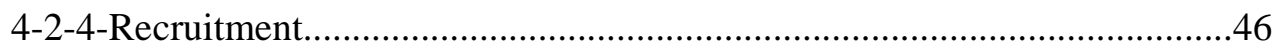

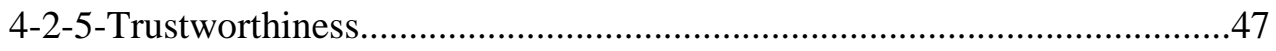

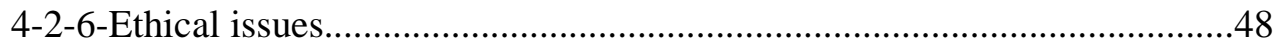

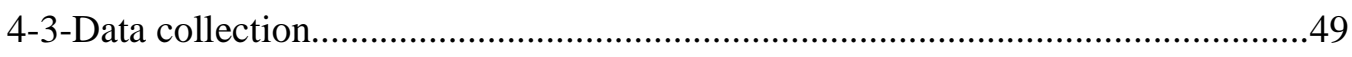

4-3-1-Interiview-primary data.................................................................. 49 
4-3-2-Secondary data.

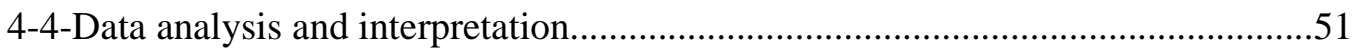

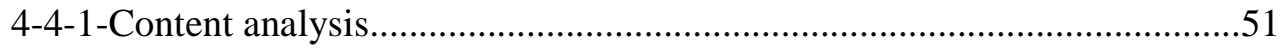

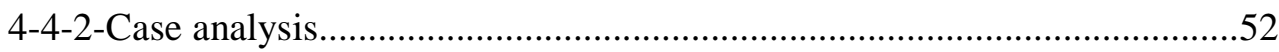

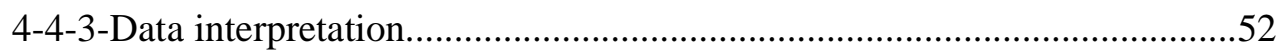

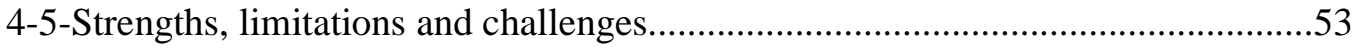

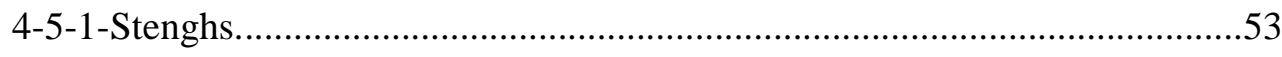

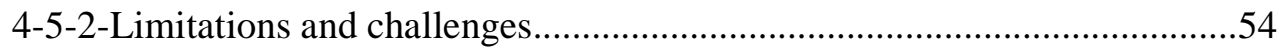

5-Findings.........................................................................................................56

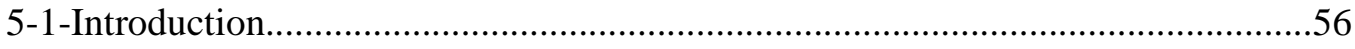

5-2-Responsibilities and interpretation management by organisations......................57

5-2-1-Involvement of NGOs in interpretation and visitor management.............57

5-2-1-1-The purpose of interpretation and dissemination of information.......57

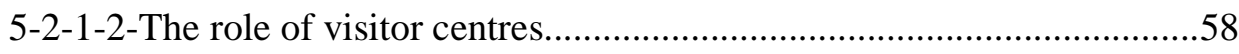

5-2-1-3-Funding for the visitor centres....................................................6

5-2-1-4-Responsibilities in visitor management and interpretation................60

5-2-1-5-The expectation of implication of interpretation..............................61

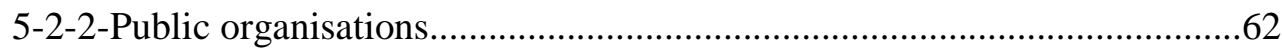

5-2-2-1-Plans for visitor centres and the role of visitor centres....................63

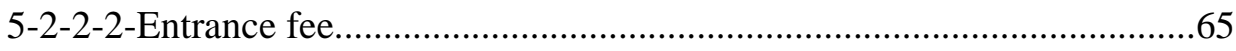

5-2-2-3-Training course.......................................................................67

5-2-3-The influence of languages on site interpretation and information...........68

5-2-4-Future perspectives for improving interpretation..................................69 
5-2-4-1-A key driver for heritage education. .69

5-2-4-2-The need for interpretation in visitor management..........................70

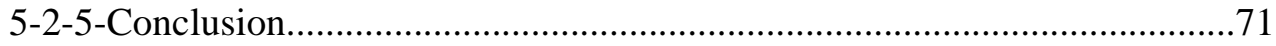

5-3-Managing interpretation by tour guides...................................................... 72

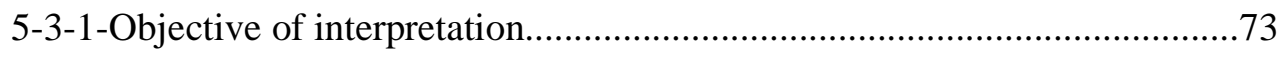

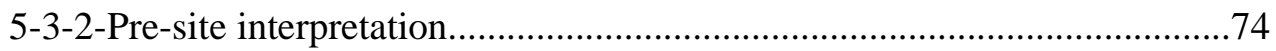

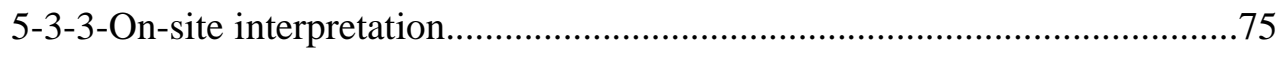

5-3-3-1-Influentual factors on interpretation..............................................75

5-3-3-2-Effective ways to manage interpretation for the group tours.............77

5-3-4-Issues related to tour guides in managing interpretation.........................79

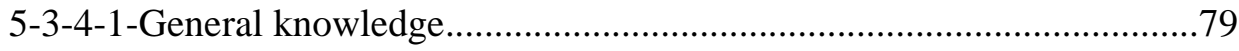

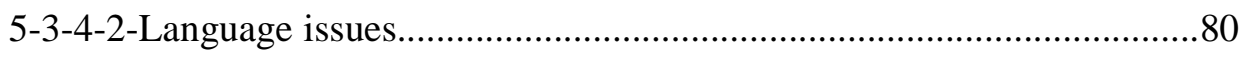

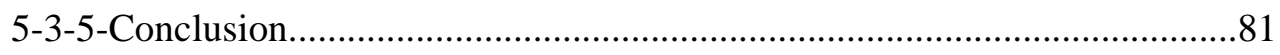

5-4-Relationships and communication of stakeholders in managing interpretation...82

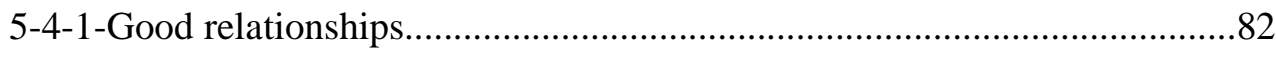

5-4-1-1-Site managers and international community..................................82

5-4-1-2-Site managers and Ministry of Tourism...........................................83

5-4-2-A conflict between site managers and tour guides................................84

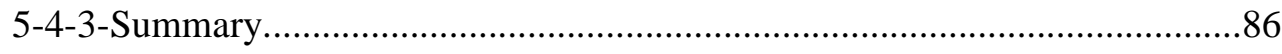

5-5-Conclusion of interpretation management by multiple stakeholders....................86

6-Discussion................................................................................................89

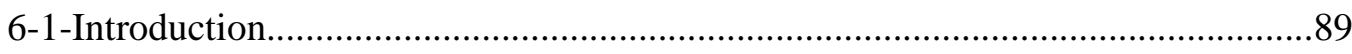

6-2-Stakeholders in managing interpretation at Angkor Wat temple.........................89 
6-2-1-Managing interpretation by organisations.............................................90

6-2-1-1-Managing visitor centres (APSARA and NGOs) ............................90

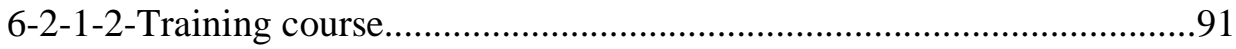

6-2-2-Managing interpretation by tour guides...............................................92

6-2-2-1-Managing interpretation for the groups of visitors...........................93

6-2-2-2-Language barriers and limited knowledge of sites............................94

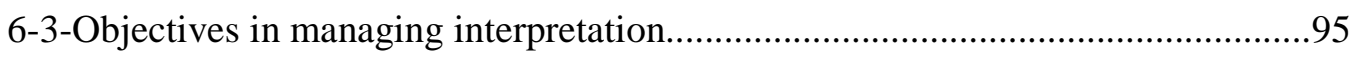

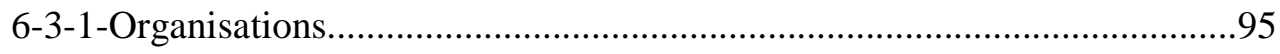

6-3-1-2-Understanding about conservation................................................95

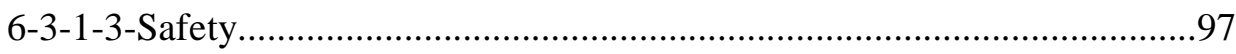

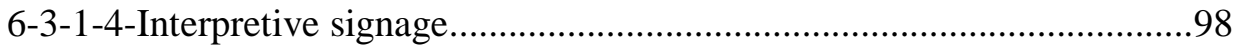

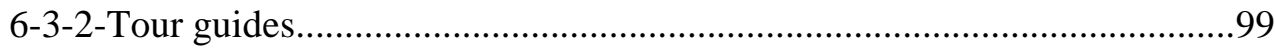

6-4-A variety of interpretation management by multiple stakeholders....................100

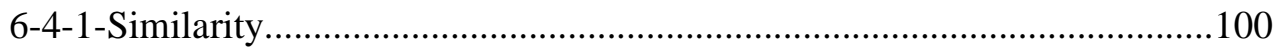

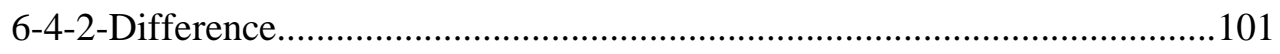

6-4-3-The impacts of multiple stakeholders on interpretation management.....103

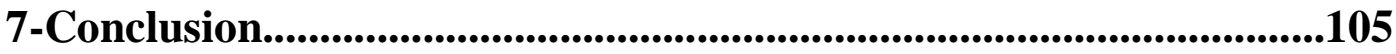

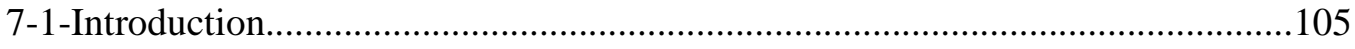

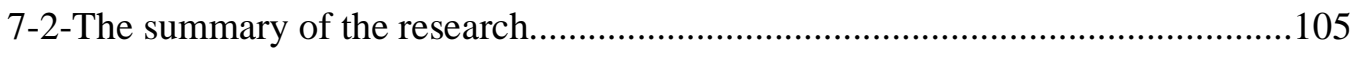

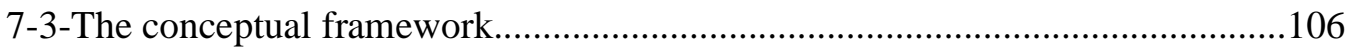

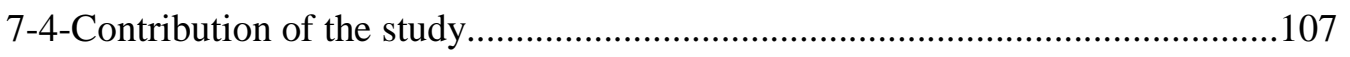

7-4-1-Contribution to academic research..................................................107

7-4-2-Contribution and practical implications...............................................108 
7-5-Limitations.

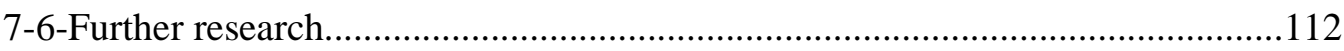

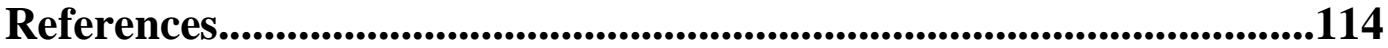

\section{Appendices .............................................................................................................118}

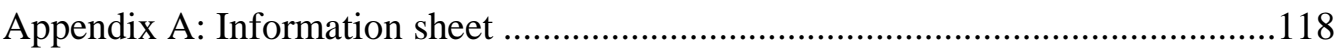

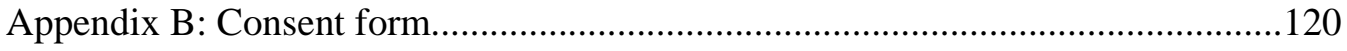

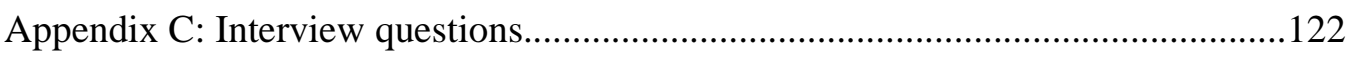

Appendix D: Pseudonyms of research participants............................................126

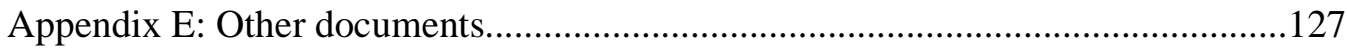




\section{List of figures}

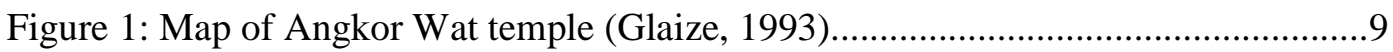

Figure 2: Multiple stakeholders in interpretation management at Angkor Wat.............16

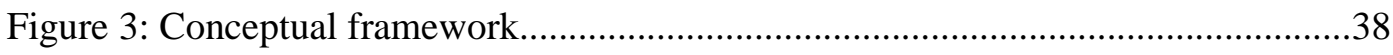

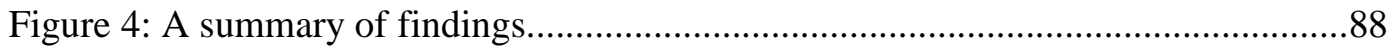

\section{List of tables}

Table 1: Number of visitors to Angkor Wat per day..................................................10

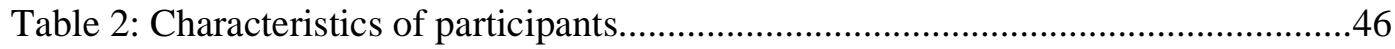

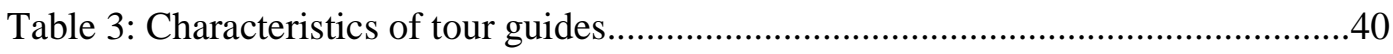

Table 4: Objectives in managing interpretation by organisations.................................96

\section{List of images}

Image 1: Angkor and Angkor Wat temple...........................................................

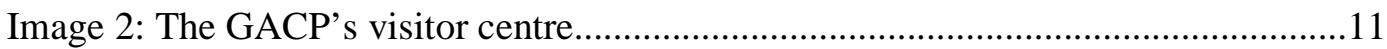




\section{List of terms used in the thesis}

AKW: Angkor Wat temple

APSARA: Autorite pour la Protection du Site et l'Amenagement de la Region

$$
\text { d'Angkor }
$$

GACP: German Apsara Conservation Project

ICOMOS: International Council on Monuments and Sites

I.Ge.S: Ingegneria Goetechnical e Structurale

MoT: The Cambodian Ministry of Tourism

UNESCO: United Nations Educational, Scientific and Cultural Organization

WMF: World Monuments Fund

TG: Tour guides

Khmer: Cambodian people or spoken language in Cambodia 


\section{Chapter 1: Introduction}

\section{1-1-Introduction}

This thesis is concerned with the management of interpretation at Angkor Wat temple, a World Heritage Site in Cambodia. The study examines the structure of managing interpretation and it is based on a supply side perspective. In-depth interviews with relevant stakeholders are conducted to explore how stakeholders manage their interpretation at the site.

Little attention has been paid to the management of interpretation by multiple stakeholders. In addition to previous studies, the current research tends to focus on two perspectives about interpretation management by organisations and interpretation management by tour guides on site. The current study will examine the differences of interpretation management by organisations and tour guides due to their objectives and responsibilities in managing interpretation.

This first chapter presents the background of the study, and provides an overview of the research to the understandings of relevant stakeholders in managing interpretation at Angkor Wat temple, Cambodia. The chapter also defines gaps in the interpretation literature. It further introduces the research questions and gives a summary of the methodological application for this study. The structure of this thesis is outlined in the last section of the chapter.

\section{1-2-Researcher's interest in the topic}

The selection of the research topic is based on the researcher's experiences. The researcher works at Angkor Wat temple in the role of a tourism manager. To improve visitor experiences at the site, tourist activities and their comments were recorded by the author. A small conversation between domestic visitors at Angkor Wat temple interested the researcher and then become a consideration for the research topic. The conversation was about the visitors' plan for their holiday the following year. 
Visitor A: Will we visit Angkor Wat again next year?

Visitor B: No, I won't come here again for just seeing such a stone building here.

Considering the conversation above, the researcher is interested in the response of visitor B why he does not plan to see the temple again. There could be many reasons that discouraged visitor B for making the next trip to Angkor Wat temple. Among these reasons the researcher was concerned about an availability of interpretive facilities provided at the site. According to the researcher's experiences, visitor facilities at Angkor Wat such as visitor centres, interpretive signs and information are still a major issue to encourage visitors to learn about the site or to visit it again. Without these facilities, tourists do not know how to visit the temple and they do not experience much in the site. Hence, visitor B may not want to visit the temple again because of inadequate information at the site.

Furthermore, appropriate behaviour is needed at cultural heritage sites. Angkor Wat temple is a cultural and historical site where it receives a huge respect from Cambodian people. Some visitors do not know how to behave and dress appropriately in the site because the site managers and tour guides probably provide a little information and interpretation of Angkor Wat to visitors. It is assumed that a lack of interpretation could have negative impacts on culture as well as heritage properties.

Having read through academic publications about interpretation, the author is very enthusiastic about this topic because he expects that this study will provide indication which contributes to his career. Interpretation plays a prominent role in visitor attractions. It is described as a vital mechanism for developing tourist sites in a sustainable manner (Hall \& McArthur, 1993; Kuo, 2002; Moscardo, 1998; Orams, 1996; Shackley, 1998) and enhancing visitors' experiences (Moscardo, 1996; Moscardo \& Ballantyne, 2008). Interpretation can be studied from demand side (de Rojas \& Camarero, 2008; Light, 1995; Poria, Biran, \& Reichel, 2009) and supply side. Taking a supply side perspective, the author intends to examine the management of interpretation by multiple stakeholders at Angkor Wat temple. He also expects that this study will contribute to relevant stakeholders in order to preserve the cultural resources at the temple and attract more visitors to the site. 


\section{1-3-From practical management of interpretation to academic research}

From a demand perspective, interpretation at Angkor Wat temple appears primarily as a task of tour guides. Generally, visitors believe that tour guides have a role in telling history about the temple to visitors. According to the authors' experiences, not all the visitors to the temple hire tour guides especially domestic visitors who may avoid from the cost of hiring and may favour an independent visit. It is common that international tourists go to Angkor Wat in a group and they usually hire a tour guide from a tour company because there is no tour guide available at the site. There are many tour guides who can speak different languages such as English, Chinese, Japanese, French, German, Thai, Vietnamese, Spanish, Italian and Russian. Some tour guides can speak more than one language.

In addition to the tour guides above, there are various institutions involved in managing interpretation. These institutions include United Nations Educational, Scientific and Cultural Organisation (UNESCO), Non-governmental organizations (NGOs), Autorite pour la Protection du Site et l'Amenagement de la Region d'Angkor (APSARA), Ministry of Tourism (MoT), and tour companies (see section 2-3). These organisations have different responsibilities in managing interpretation. At the international level, UNESCO and NGOs such as GACP, I.Ge.S, and WMF (see section 2-3-2) have indirect influence on the management of the site due to their concerns about conservation and protection of the temple. At the national level organisations such as APSARA and the Ministry of Tourism play important roles in developing visitor facilities such as visitor centres and interpretive signs. As indicated in the Angkor Management Plan (Howse, 2007), a need for interpretation centres is very important to develop the site in a sustainable manner. Hence, the management of interpretation at Angkor Wat temple consists of a complicated structure which calls for the current study. Chapter 2 provides the interpretation management structure and existing plans in more details.

The interpretation literature has failed to examine the different perspectives of multiple stakeholders in the management of interpretation. The literature seems to focus on individual institution or stakeholder such as tour guides (Christie \& Mason, 2003; Io \& Hallo, 2011), management of visitor attraction (Hall \& McArthur, 1993; Leask, 2010), visitor perception on interpretation (de Rojas \& Camarero, 2008; Hughes \& Morrison- 
Saunders, 2002; Randall \& Rollins, 2009). However, more than one stakeholder is involved in the management of interpretation at a world heritage site including international communities. Hence, the current study contributes to the literature in which relevant stakeholders involved in the management of interpretation at Angkor Wat are focused on.

Studies on visitor management and interpretation are conducted either from demand side (de Rojas \& Camarero, 2008; Poria, et al., 2009) or supply side perspectives (Christie \& Mason, 2003; Io \& Hallo, 2011; Kuo, 2002; Moscardo, 1998). Taking supply side perspectives the researcher was able to explore different management of stakeholders. Furthermore, the researcher had a chance to make a comparison of stakeholders in managing interpretation which was rarely found in the literature. Interpretation of attractions can be undertaken both verbally and non-verbally (de Rojas \& Camarero, 2008). Verbal interpretation refers to tour guides or on-site interpreters whereas interpretive signs, guide books, and printed materials are included in the nonverbal interpretation category. The present study will not look at guide books and printed materials such as brochures and leaflets because they will extend the scope of this research. Therefore, a lack of literature and minimal analysis of managing interpretation by multiple stakeholders in previous studies leave gaps for the current research.

\section{1-4-Research questions}

This study explores the management of interpretation at a UNESCO world heritage site. Taking a supply side perspective to investigate the management of interpretation at Angkor Wat, two main research questions were addressed:

(1) How is interpretation at Angkor Wat managed?

Who are stakeholders and what are their responsibilities?

What is the organisational structure of interpretation management at Angkor Wat? 
(2) What are the public and private stakeholders' aims and objectives in managing interpretation?

What is being interpreted? And how?

What issues drive decision-making in interpretation management by various stakeholders?

\section{1-5-Research methodology}

A social constructivist approach is adopted for the current research. Using this approach for the current study, the author is able to understand the meaning of the world by developing his experiences through multiple ideas provided by interviewed participants (Patton, 2002). To get some insights into the management of interpretation by stakeholders, semi-structured interviews were conducted. Participants constructed the meaning of a situation through questions developed by the researcher. When the researcher broadened the questions, participants shared their views and other social activities they had encountered (Creswell, 2007).

Semi-structured interviews were applied to gain the perspectives of participants. This type of interview was chosen because the research is concerned with examining the communication and expectation of multiple stakeholders in managing interpretation. By using open-ended questions, the researcher could develop the questions in a way that participants felt comfortable and provided the answers. Also, this interview style gave participants enough time to answer the questions whenever they wanted during the interview session.

To understand multiple stakeholders' views on managing interpretation at Angkor Wat, 22 interviewees were selected to take part in the project. These participants were from different organisations: one participant from UNESCO, three from NGOs, four from APSARA Authority, one from Ministry of Tourism, three from tour companies, and ten tour guides. Chapter 3 explains the methodology of this study in detail. 


\section{1-6-Outline of the thesis}

This thesis consists of seven chapters, including this introductory chapter which provides a background to the study such as the researchers' interest, the research context, research questions, methodological considerations for the research and an outline of the thesis.

Chapter 2 provides overall information about Angkor Wat temple and the management of interpretation by multiple stakeholders. Chapter 3 discusses a wide range of tourism literature about managing tourist attractions, interpretation and multiple stakeholders involved in managing interpretation at cultural attractions. The chapter concludes by introducing a conceptual framework which underpins the management of interpretation at a world heritage site. Chapter 4 illustrates the research methodology being applied in the current study. This chapter includes scientific research inquiry such as research paradigm, research methods, data collection and analysis. Chapter 5 presents the findings of the research. The three main themes addressing the research questions are listed in this chapter. At the end of the chapter, there is a diagram showing a summary of the findings. A discussion between the findings of the current research and literature is presented in chapter 6 . The final chapter concludes the main ideas which fit the research questions. From the outputs of this research, contribution to the study of interpretation is acknowledged. It also provides some limitations and recommendations for future research. Implications for stakeholders are outlined. 


\section{Chapter 2: The research site and context}

\section{2-1-Introduction}

This chapter provides an introduction to Angkor Wat temple and explains its relevance to interpretation. It also identifies the different roles of each stakeholder taking part in managing interpretation at the temple. A structure of managing interpretation at Angkor Wat is introduced. Finally, the management of interpretation at Angkor Wat is discussed.

\section{2-2-Angkor Wat temple}

\section{2-2-1-History of the temple}

\section{Cultural resources}

Angkor Wat is a large Hindu temple which covers an area of nearly 200 hectares in the Angkor region, Siem Reap, Cambodia. The temple was constructed in the first half of the $12^{\text {th }}$ century in Yasodharapura, the capital of the Khmer Empire known as Siem Reap province. Angkor Wat was in the reign of Suryavarman II and it is dedicated to the God of Vishnu. Apart from religious aspects, the temple is a fascinating example of decorations and Khmer architecture (Glaize, 1993). Hundreds of sculptures and carvings describe the long history of the temple and the country. These are the result of human power. The iconic view, history and religious status of Angkor Wat temple attract thousands of visitors and pilgrims around the globe (see section 2-2-2).

Inside the first gallery, there are a number of different scenes illustrating human life, heaven and hells, history, and war (see Figure 1). These scenes provide visitors with an opportunity to learn about the god legend, the king history and myths. Furthermore, the secret of the temple is uncovered to visitors through inscriptions, statues, sculptures and bas-relief of the temple. Unlike other historical sites, Angkor Wat is also a living site because it still earns respect from people today. Visitors travelling to Angkor Wat in February, March and April may occasionally see local residents performing rites and rituals at the temple. For religious reasons, Cambodian people wish to see the temple at least once in their life. Once an American visitor made a wish that her ashes be scattered 
on the causeway of Angkor Wat when she made a trip to Angkor Wat in 1936 (Glaize, 1993). Such enthusiasm for the Angkor Wat temple shows that the temple is not just a tourist attraction but also a religious and sacred place. To gain insight into various perspectives of Angkor Wat, visitors normally buy a guide book prior to their visit or plan to hire a tour guide from a tour agency.

\section{Becoming a UNESCO World Heritage Site}

After the civil war in the 1970s, political stability in Cambodia was unpredictable. To protect the temples from some illegal activities such as illicit logging and pillaging of artefacts at Angkor, in 1989 the former King Norodom Sihanouk made a request to UNESCO for their assistance. Because of its uniquely rich cultural and environmental heritage, Angkor was first inscribed on the list of World Heritage in Danger on December 14, 1992 and then was upgraded to the World Heritage List in 2004 (Howse, 2007). Angkor Wat temple is one of the principal monuments in Angkor which covers about $401 \mathrm{~km}^{2}$ of Siem Reap province. After Cambodia achieved full peace, security and political stability, the country became an attractive tourist destination in Southeast Asia. The most common place to visit in Cambodia is Angkor especially Angkor Wat temple which people recognise from the national flag of Cambodia.

\section{Image 1: Angkor and Angkor Wat temple}
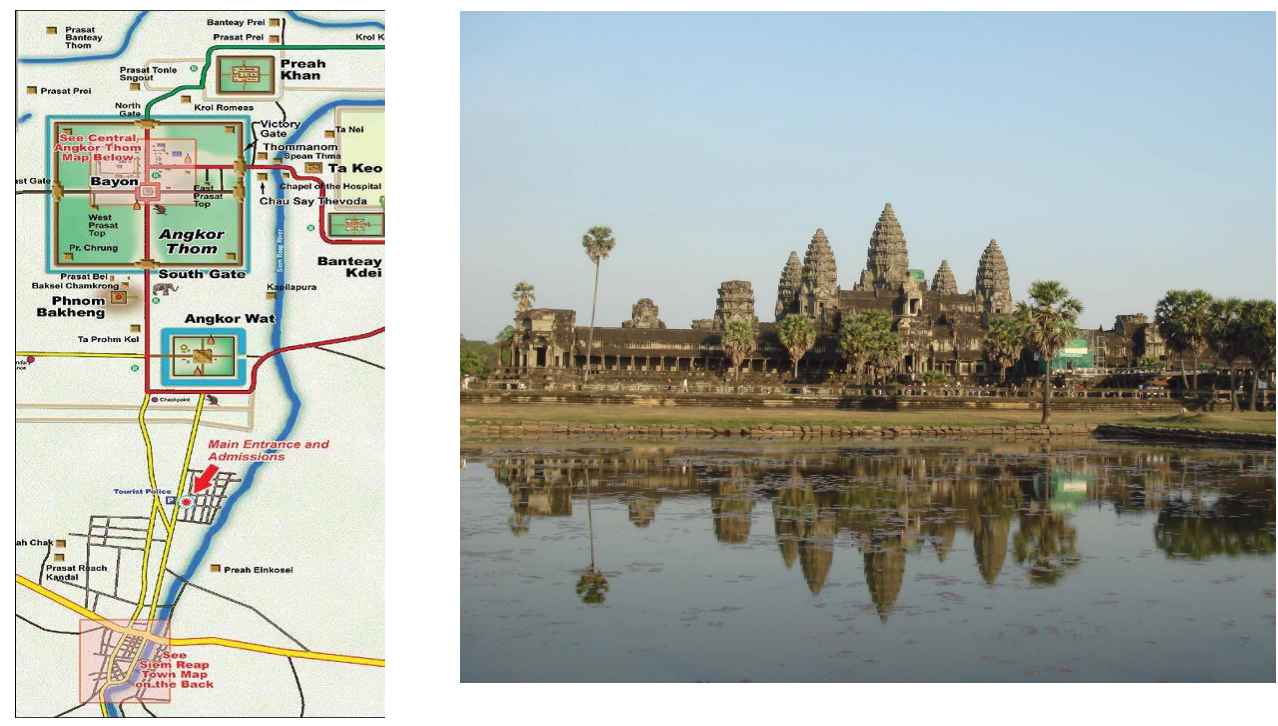

Source: Google image, 2012 \& Author, 2011 


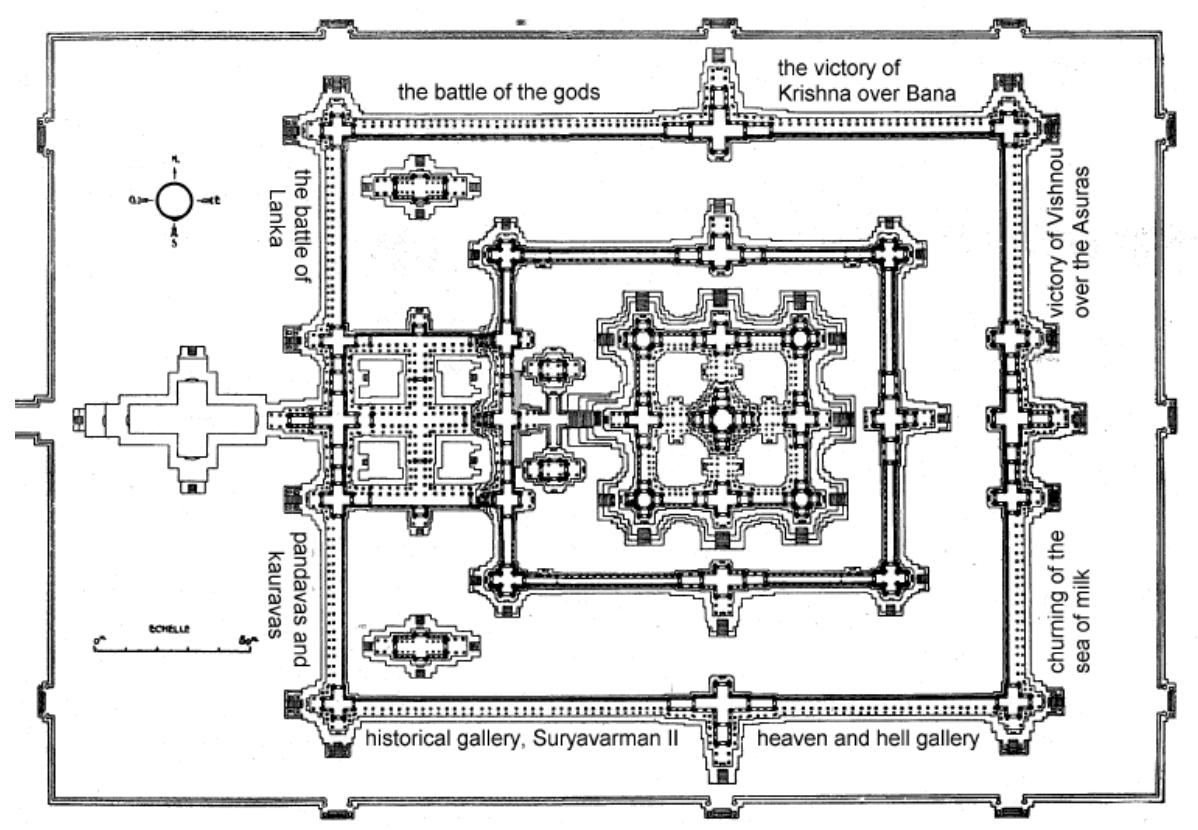

Figure 1: Map of Angkor Wat temple (source: Glaize, 1993, p.58)

\section{2-2-2-Tourist statistics and entrance fee}

Tourism is a priority sector for contributing to national economic development in Cambodia. There were almost 3,000,000 international tourist arrivals in Cambodia in 2011 (Ministry of Tourism, 2011). This figure increased by nearly 15\% compared to the year 2010, according to the report from the Cambodian Ministry of Tourism. Cultural tourism is known as the most significant target in which historical heritages in Siem Reap-Angkor has played a leading role. There are hundreds of temples in the Angkor area, Angkor Wat temple is always included in the programme tour. As can be seen from table 1, about 5,000 tourists visited Angkor Wat temple a day in 2010 and 2011. The number of Khmer and other visitors dominated the number of visitors from Asia. This number is also expected to grow in the near future. 
Table 1: Number of visitors to Angkor Wat per day

\begin{tabular}{|c|c|c|c|}
\hline Visitors & $\mathbf{2 0 0 9}$ & $\mathbf{2 0 1 0}$ & $\mathbf{2 0 1 1}$ \\
\hline Khmer & 1301 & 1829 & 1222 \\
\hline Japanese & 295 & 384 & 360 \\
\hline Chinese & 293 & 554 & 638 \\
\hline Korean & 298 & 651 & 791 \\
\hline Other Asian visitors & 262 & 395 & 416 \\
\hline Other visitors & 961 & 1268 & 1331 \\
\hline Total & $\mathbf{3 4 0 8}$ & $\mathbf{5 0 8 1}$ & $\mathbf{4 7 5 7}$ \\
\hline
\end{tabular}

Source: DCMHN, APSARA Authority, 2012

International visitors need to buy an entrance ticket to visit Angkor Wat. Visitors have three options to choose from. The ticket fee is 20 USD for one day, 40 USD for up to three days, and 60 USD for up to one week. With these prices, tourists can visit any temples in the Angkor area and can visit as many times as they want. Because of its attractiveness, some tourists visit Angkor Wat more than one time.

\section{2-3-Stakeholders}

\section{2-3-1-United Nations Educational, Scientific and Cultural Organisation (UNESCO)}

Since Angkor was inscribed in the world heritage list, United Nations Educational, Scientific and Cultural Organisation, the foremost international organisation provided the services of Standing Secretariat for the ICC-the International Coordinating Committee for the Safeguarding and Development of the Angkor site. On behalf of UNESCO, the ICC organises two meetings annually, once at the plenary level and once at the technical level. In the meetings both national and international organisations are able to submit their projects for conservation and development of Angkor. For instance, the APSARA Authority (see section 2-3-3), the national organisation, plans to have a visitor centre in Angkor, an approval from the ICC is needed. Approval will be granted if the visitor centre has benefits for the development of Angkor. Hence, the ICC a representative of UNESCO has the power to make a decision not just on visitor centre projects but also others related to the safeguarding of Angkor. 


\section{2-3-2-Non-governmental organisations (NGOs)}

In this study, Non-governmental organisations refer to international organisations taking part in conservation and restoration projects at Angkor Wat temple. There are three international organisations, namely GACP, I.Ge.S., and WMF that were interviewed for the current study.

\section{2-3-2-1-German Apsara Conservation Project (GACP)}

The protection and conservation of the reliefs and female pictures (Apsara) carved on Angkor Wat wall are the main objective of German Apsara Conservation Project. A majority of the financial support is from Germany and a very small part of it comes from visitor donations. There is a dozen locals and international experts working in the conservation project. Apart from their technical work, the project also has a small visitor centre which displays the issues of the stones and the need for protection. That is why the project needs the centre to explain the role of GACP in protecting the temple. Currently, there is a Cambodian interpreter working in the centre. She was trained by an international expert about how to interpret the project for visitors. In addition to the existing visitor centre, GACP also has many direction signs and information boards telling visitors how they should behave near the working and restricted areas.

\section{Image 2: The GACP's visitor centre}

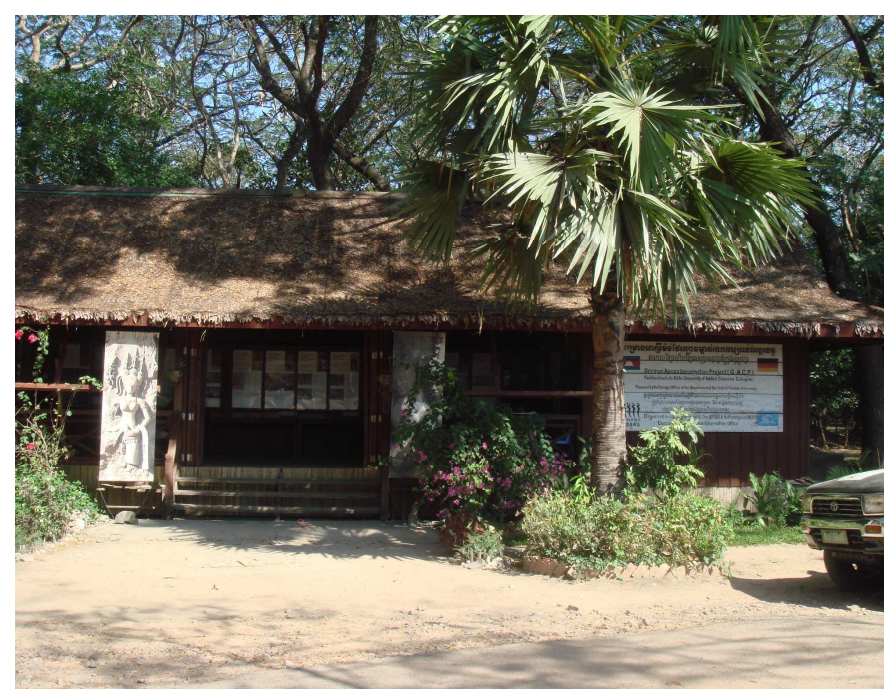

Source: Author, 2011 


\section{2-3-2-2-Ingegneria Geotecnica e Strutturale snc (I.Ge.S.)}

Ingegneria Geotecnica e Strutturale snc is the Italian government project for the safeguarding of Angkor. This project had an approval from UNESCO and the government of Cambodia to work on restoring some temples in the Angkor area including Angkor Wat temple. When conducting this research, the project operated on the balustrade of the cruciform terrace of Angkor Wat. Similar to GACP project, I.Ge.S. has its own visitor centre illustrating working activities but the centre does not have a permanent interpreter. According to the interview, sometimes the project manager presents their work to visitors and students who are interested in conservation and restoration of the temple.

\section{2-3-2-3-World Monuments Fund (WMF)}

World Monument Fund programmes receive financial assistance from the US. This project focuses on restoration of the stone roof above the Churning of the Sea of Milk gallery at Angkor Wat. Unlike the two organisations above, WMF does not have a visitor centre but it has arranged some interpretive signs and information boards to explain the overview of the project as well as the urgent need for restoration due to the severe conditions of the gallery. Another different way to present the project is on-site interpretation. The interpretation is based on a request made by a group of visitors or students who want to understand more about the restoration process. In general, the restoration is interpreted by experts from WMF.

\section{2-3-3-APSARA Authority and its ownership}

The establishment of Authorite pour la Protection du Site et l'Amenagement de la Region d'Angkor (APSARA) was a requirement of the World Heritage Committee. APSARA is a state party which has a legal profile, and has administrative and financial autonomy (Sihanouk, 1995). APSARA is responsible for the sustainable development of the Angkor site including Angkor Wat temple and the organisation ensures that the local community benefits from the development. The entrance fee received from the international visitors is under the management of APSARA who later contributes the 
fee for the development of the site. On behalf of the government, APSARA has cooperated with NGOs to rescue the ancient temples. Having a role in managing the site, APSARA also has another responsibility in informing visitors about the sites by providing information boards and interpretive signs.

APSARA Authority has strong power in managing the Angkor site however its management is still limited. According to the author experiences, APSARA Authority does not have tour guides for visitors because it is a responsibility of the Ministry of Tourism. Therefore, visitors need to look for their own guides prior to the visit at the Angkor site. In addition, visitors find it hard to get information about the site because the site does not have visitor centres. These limitations are also addressed in the Angkor Management Plan which has been studied by international consultants.

It was not until 2007 that APSARA Authority started to have the Angkor Management Plan (Howse, 2007). The plan was funded by New Zealand Agency for International Development. The two major issues related to conservation of monuments and sustainable tourism management are addressed in the plan. This plan helps APSARA Authority to improve its heritage management framework and strengthen its relationship with communities. The Angkor Management Plan is a public document which is developed in consultation with the community and stakeholders. The plan identifies some challenges in managing the heritage site and calls for actions to preserve the temples. These challenges include visitor management at the site, a lack of interpretation, a lack of collaboration between APSARA Authority and relevant stakeholders. The Angkor Management Plan provides APSARA with a consideration of visitor centres which are very important to improve visitor experiences and reduce negative impacts.

\section{2-3-4-Ministry of Tourism}

The Cambodian Ministry of Tourism has a major role in preparing a policy for tourism development in the country including the Angkor site. Because Angkor is the famous tourist attraction of the country, the Ministry of Tourism is concerned about the development and training of tour guides who work at the Angkor site. To enhance 
visitor experiences, the Ministry aims to develop the understanding of guides and their interpretation.

Providing tour guide training courses and granting licenses to tour guides come under the responsibility of the Ministry. About 3,000 tour guides have been trained for working in the region of Siem Reap province where Angkor Wat is located. The 360hour training course focuses on five main areas such as general knowledge, social knowledge, legal knowledge, skills, and site visit. In addition to this primary training, the Ministry also collaborates with APSARA to organise another three-week training course to enhance tour guides' capacity after they have some experiences at the site.

\section{2-3-5-Tour guides}

There are two types of tour guides, namely contracted and freelance, working in Siem Reap province. Tour guides who are employed by a tour company are called contracted tour guides whereas freelance guides are independent guides and receive temporary jobs from companies during the tourist high season. These tour guides are under supervision of the Ministry of Tourism. Tour guides are defined as people whose roles are to look after both national and international visitors and interpret relevant information such as geography, nature, history, culture, custom, society and economy of the visiting sites to visitors (Ministry of Tourism, 2009). To be a tour guide, students who graduated from high school and completed a degree in a second language, as required by the Ministry are eligible to apply. Once they are recruited by the Ministry, they need to take part in the primary training course (see section 2-3-4) and pass the course before applying for a tour guide license. Tour guides are also required to renew their license every two years.

\section{2-3-6-Tour companies}

Tour companies refer to private agents that arrange itinerary and package tours. Many tour programmes to Angkor Wat are similar to an itinerary suggested by Glaize (1993). According to his suggestion, a tour to Angkor Wat was arranged in different ways according to the length of stay in Siem Reap province. This means if visitors stay in the province more than two days, they are suggested to spend half a day at Angkor Wat 
because the temple has many things to enjoy and to be interpreted. Hence, the visiting programmes arranged by tour companies probably have an influence on the presentation made by interpreters. The longer visitors spend at the temple, the more visitors learn about the site through the interpretation.

Some tour companies have their own training courses for contracted tour guides. These courses normally introduce tour guides to visitor behaviour and its connection to interpretation. The companies understand that their clients have different interests when they visit the temple. It is important for guides to learn about visitors' needs in terms of interpretation.

\section{2-4-Visitor management and interpretation}

Visitor management and interpretive facilities are essential for Angkor Wat temple. Although there are some direction signs and information boards provided by APSARA Authority, they are still found to be inadequate for the current growth in visitor numbers due to the researcher's experiences. As indicated in the Angkor Management Plan 2007, the development of visitor management and interpretation was defined as a significant driver to enhance visitor understanding as well as appreciation of the site and, reduce the potential for the physical damage caused by over-use of the site. As the usefulness of interpretation for site management is proven, visitor facilities such as visitor centres and signage should be increased at Angkor Wat (Howse, 2007).

Visitors to Angkor Wat can hire private tour guides. The rate is approximately 20 USD a day and it may vary according to the language spoken by the tour guides. For example, Spanish speaking tour guides are more expensive than English speaking guides. Unlike other historical sites in the world, Angkor Wat does not have tour guides on standby for visitors. Normally visitors arrange tour guides before they travel to the temple. Interpretation made by tour guides is arragned in different ways. Some tour guides present an overview of the temple on a coach and then they give more details at every spot in Angkor Wat. In addition to interpretation, tour guides always give visitors their own time to have rest and take pictures if they wish. 


\section{2-5-Multiple stakeholders in interpretation management at AKW}

Figure 2 illustrates the overview of stakeholders taking part in managing interpretation at Angkor Wat temple. In general, the management structure consists of three main sectors namely international communities, public sector and private sector. Each sector has its own responsibility associated with interpretation (see section 2-3-1 to 2-3-6). The links from APSARA to UNESCO and from APSARA to the Ministry of Tourism serve different purposes in managing interpretation. For sustainable development and conservation of the site, APSARA needs to make a proposal for a visitor centre to the ICC, a representative of UNESCO. It means that being a World Heritage Site, UNESCO is also involved in the decision making for the development of the site. APSARA collaborates with the Ministry of Tourism to conduct training courses for local guides. The aim of these courses is to enhance the quality of tour guides in the Angkor area.

The three thick arrows indicate the three stakeholders from NGOs, APSARA and tour guides which have direct connection with the management of interpretation. The provision of visitor centres and interpretive signs fall under the responsibility of APSARA and NGOs for the purpose of conservation. In addition, tour guides act as site interpreters who have more flexible strategies to manage group tours and interpretation.

Figure 2 : Multiple stakeholders in interpretation management at Angkor Wat

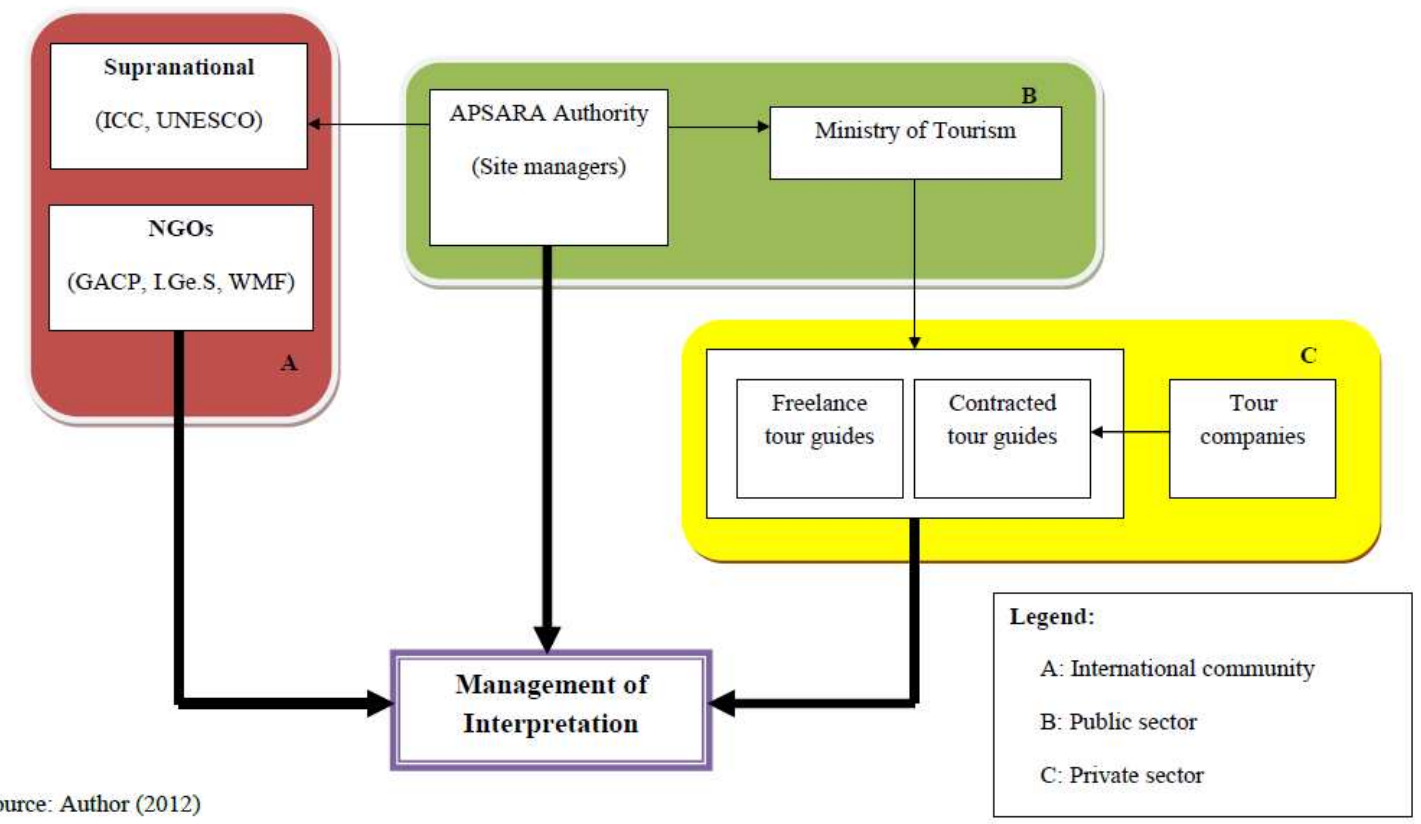




\section{2-6-Summary}

To sum up, the intention of this chapter is to help readers understand the context of interpretation at Angkor Wat. Although the roles of all above stakeholders are related to the management of interpretation at the temple, not all of them will be discussed in the same degree of depth in chapters 5 and 6. The scope of this MTM thesis makes it necessary to focus on those stakeholders that emerged as having direct influence on how interpretation is managed at various levels of governance in Angkor Wat. The tour guides emerged as significant due to their direct interaction with visitors whereas APSARA and the NGOs emerged as most significant for higher management levels that are detached from visitors. 


\section{Chapter 3: Literature}

\section{3-1-Introduction}

This chapter reviews the relevant literature from the perspectives of tourism and heritage management. The overview of the literature begins with a general perspective on management of heritage attractions and it concludes with the management of interpretation which is a part of visitor management. Reviewing the previous studies provides insightful ideas about how individual stakeholders manage interpretation. As a result, a conceptual framework is set up to underpin the examination of managing interpretation. This literature is organised purposely to address the three research questions (see section 1-4). The structure of the literature starts with a section of the management of heritage attractions by examining how the attractions are managed. This first section also includes visitor management which needs interpretation as a tool to tackle visitor impacts. The second section discusses interpretation and its role. The following section illustrates the objective and responsibility of stakeholders in managing interpretation. Their challenges in the management of interpretation will be identified in the third section. Drawing all ideas from the literature, conceptual framework is addressed in the final section.

\section{3-2-Managing heritage attractions}

Although managing heritage attractions is a complex task and responsibility for site managers, few studies have focused on the operation of heritage attractions (Leask, Fyall, \& Garrod, 2002; Leask \& Yeoman, 1999). Managers of such attractions need to solve major problems related to people and the site (Leask \& Yeoman, 1999). Site managers deal with their staff as well as visitor demand. In addition, they are also concerned about the sustainable development of the heritage sites. This section will discuss two critical issues in managing heritage attractions namely, operations management and visitor management. 


\section{3-2-1-Operations management}

\section{3-2-1-1-Public ownership}

An empirical study conducted by Garrod et al. (2002) revealed that visitor attraction owners and managers should pay attention to funding policy at the national level that leads to a reduction of visitor impacts and enhances sustainable tourism development. The authors stated that investing in conservation and development of visitor facilities such as interpretive centres, signs, parking, and cafe are more effective than spending on training attraction managers or staff. They gave an example of interpretation that can enhance visitors' awareness about sites as well as explain to visitors about their potential negative impacts and how to minimise or avoid such impacts. To some extent this finding could reflect the reality of ownership of visitor attractions in Scotland. However, a further study should be focused at heritage attractions in some developing countries where public sectors deal with both financial resources and human resources in their management. The management of heritage attractions still requires technical and financial assistance to operate the cultural heritage sites (Carter \& Grimwade, 1997). In general, UNESCO is always a good partner and consultants for those attractions listed as world heritage sites. Therefore, training site managers or staff may also be a good alternative for heritage attractions under public ownership.

\section{3-2-1-2-Admission fee}

Generating revenue at heritage attractions is complicated in regards to increase visitors' awareness. This can be explained by the fact that the admission fee at heritage attractions is flexible due to the policy set by the organisations who control the sites (Yale, 1991). Poverty and a lack of heritage awareness may be the key reasons why some governments allow free admission to residents. For some visitor attractions, visitors are required to pay an entrance fee which varies depending on the time of visit (day, weekend and season), category of visitors (age and purpose of visit), volume of visitors (individuals, group and family), and resources provided (whole facility or limited access) (Leask, et al., 2002). Hence, revenue from visitor fees at heritage attractions are critical to develop visitor facilities as well as to preserve heritage settings. 
Admission fee revenue was used to improve interpretation and educational activities (Garrod, Fyall, \& Leask, 2002). The researchers studied the management of visitor attractions in Scotland by examining the visitor impacts with admission prices. Their research relied on a postal survey of managers from 510 paid visitor attractions. Their findings suggested that admission fee may be allocated for developing the interpretive infrastructure of the attractions. They insisted that an admission fee may change visitor behaviour because visitors expect that the fee will benefit the heritage attraction. Thus, the visitors will behave responsibly at the sites. These findings might not be entirely true for some heritage attractions in developing countries where national visitors are exempt from paying an admission fee. It means that the attraction sites gather the admission fee only the international visitors. Thus, a small amount of entrance fee might not have an influence on visitor behaviour and contribute less to heritage attractions. The result of similar research conducted in developing countries might vary from Scotland in terms of low admission fees and the education level of visitors.

\section{3-2-1-3-Key management challenges at visitor attractions}

In addition to a study of the management of visitor attractions, Leask (2010) identified some key challenges that may influence the management of attractions. These include an increase in visitor expectations, imbalance within sector relating to funding and admission fee, a lack of skilled staff, conflicts of the objectives of stakeholders, and conservation of natural and cultural resources. These variables were used as a framework to develop a model for the effective management of visitor attractions (Leask, 2010). However, the management may be different according to the type of visitor attractions. For example, missions of individual attractions may vary because of resource availability for visitors. The care of the resources might not be the same in terms of public and private ownership (Garrod, et al., 2002). Therefore, future research into effective management should examine how individual visitor attractions can adopt appropriate management practices for their resources, visitors, and stakeholders. 


\section{3-2-2-Visitor management}

Visitor management at heritage sites has been concerned with the negative impacts caused by visitor behaviour and over-crowded sites (Mason, 2005; Shackley, 1998). In order to promote conservation and minimise negative impacts at heritage sites, the right visitor management strategies should be adopted (Kuo, 2002; Mason, 2005; Moscardo, 1998). These strategies can be considered as different forms of interpretation. The interpretation here refers to information given to visitors through visitor centres, exhibitions and interpretive signs.

\section{Hard and Soft Visitor Management Strategies}

Hard and soft approaches are recognised in visitor management (Kuo, 2002; Mason, 2005). Apart from using these approaches for minimising visitor impacts, they can also be considered a framework to enhance visitor experiences and educate them about the site. Kuo (2002) examined the process and purpose of visitor management and interpretation and how to increase their effectiveness. In this study Kuo (2002) suggested hard and soft management strategies to enhance the effectiveness of visitor management and sustainable tourism development.

There are three strategies discussed in the hard visitor management approach. The first strategy named physical management which focuses on an interaction between visitors and sensitive resources (Orams, 1996). For example using a fence to limit walking zones for visitors avoids to disturbance to the resources or old heritage settings. The second strategy is regulatory management which mostly related to regulations and rules. These rules and regulations are used to limit some activities such as access, times and numbers of visit. These rules include restrictions about inappropriate behaviour at the site. Some restrictions are perceived to have negative influence on visitors' experience and enjoyment. However, these restrictions were used in a form of interpretation or explanation to visitors in order to minimise over-use sites (Orams, 1996). The last strategy is an economic one. Prices are considered an effective method to manage visitor number at the site. Site managers can attract year-round visitors to the site by increasing or decreasing the prices in high or low visitor seasons. This strategy is normally used to control the number of visitors at the site. 
Kuo (2002) stressed that soft visitor management strategies are used to support hard management approaches. The author referred to soft management approaches such as educational forms that can improve visitor awareness about the sites. To enhance visitor understanding about the sites, the provision of interpretive facilities as well as interpreters play an important role in this regard. Information and educational directions provided through interpretive facilities at the site can help visitors to change their behaviour and to support sustainable development programmes (Mason, 2005). The information includes directorial interpretative information, behaviour interpretive information and educational interpretive information (Kuo, 2002). Directorial information aims to reduce traffic congestion, promote other visiting places, and care about visitor safety. Behaviour interpretive information, on the other hand, can be law enforced by law. The purpose of this information is to provide a guideline of appropriate activities and behaviour of visitors at the destination. The information also enhances visitors' awareness and understanding of the visiting sites. Last but not least, educational interpretive information refers to a selection of information or programmes which can be presented to visitors. It is a kind of communication approach that delivers messages about conservation to visitors. The expectation of site managers using this educational interpretation is to gain conservation support from the public.

\section{3-2-3-Non-verbal and verbal interpretation of attractions}

Interpreting an attraction can be divided into two major forms, non-verbal and verbal interpretation. Non-verbal interpretation is described as interpretive facilities provided at visiting sites such as visitor centres, on-site interpretive signs, leaflets and other printed materials (de Rojas \& Camarero, 2008). Visitors can see and use these facilities both inside and outside the attractions. The importance of non-verbal interpretation is to enhance visitors' understanding and show a wide range of possibilities that visitors can enjoy. Visitors' emotional experiences seem to occur before their arrival and continue until their presence at the attractions. Guide books, for instance, attract visitors by providing comments and suggestions about the visiting sites. Apart from marketing for the destination, the guide books have a vital role in completing visitors' expectations by interpreting physical assets at the sites to visitors before and during their visit (Beck, 2006). 
Verbal interpretation, on the other hand, does not only provide information to visitors but also improves their experiences and meets management objectives in terms of visitor behaviour and visitor respect of the site. Literature of verbal interpretation indicates that a tour guide is a key person who conveys information about natural and cultural heritage protection (Carr, 2004; Hall \& McArthur, 1993; Moscardo \& Ballantyne, 2008; Munro, Morrison-Saunders, \& Hughes, 2008). Verbal interpretation presented in these studies focuses on increasing visitors' awareness about conservation of natural and cultural resources. Visitors' understanding of the scarce resources leads to a reduction of negative impacts resulted from improper behaviour at the site. Additionally, verbal interpretation of attraction can encourage direct communication with visitors by provoking a discussion about the site through questions related to the sites. Instant responses provided by tour guides are more concise and effective than information provided by non-verbal interpretation.

Having understood verbal and non-verbal interpretation from the literature, the present research will not look at all aspects of non-verbal interpretation, pre-visit interpretive material in particular. For example, guide books and printed materials such as brochures and leaflets are beyond the scope of this research. Guide books such as Lonely Planet and World Heritage Guides are written by foreigners and they are not under supervision of government or site mangers.

\section{3-2-4-Managing interpretive facilities}

\section{3-2-4-1-Interpretation centres}

Interpretation centres or visitor centres are identified as setting factors that relate to the mental process involved in learning and understanding historic sites or museums (de Rojas \& Camarero, 2008; Moscardo, 1996). In a proposed model of mindful visitors to heritage sites, interpretation centres provide cognitive orientation to visitors (Moscardo, 1996). She states that the interpretive centres increase visitor attention and learning about the visiting sites. De Rojas and Camarero (2008) studied visitors' expectations, experiences and satisfaction which are related to cultural tourism and services provided by cultural organisations. Their findings suggest that the interpretive centre provided at the sites increase visitor satisfaction, because it generates emotional and cognitive paths 
for visitors. In general, visitors to cultural heritage sites seek experiences such as leisure, culture, education, and social interaction (Timothy, 2007). Therefore, visitor centres play a prominent role in increasing visitors' understanding and experiences at the visiting sites or museums.

Fallon and Kriwoken (2003) stated that visitor centres have three roles in addition to visitor experience enhancement. In terms of marketing role, visitor centres promote local products by providing orientation of the products to visitors. The visitor centres sometimes suggest relevant places for the next trip, where to visit and stay (Fallon \& Kriwoken, 2003). The second possible role of visitor centres is about minimising negative impacts caused by visitors at the sites. The visitor centres inform visitors about how to behave responsibly at a site. Sometimes, the centres can change visitor attitudes from undesirable behaviour to environmental and conservative manners. Thus, visitor centres can make a significant contribution to visitor management which was discussed widely in previous studies (Cros, Leask, \& Fyall, 2007; Garrod, Fyall, \& Leask, 2006; Mason, 2005; Shackley, 1998). The visitor centres may have another role as substitution. Because some cultural and natural heritage resources are considered vulnerable and are not accessible, the visitor centres will be an appropriate place to display and interpret the original materials or artefacts gathered from the sites (Fallon \& Kriwoken, 2003).

The planning and designing of visitor centres are important to meet the aim of visitor centres. A plan for a visitor centre should take into consideration public attitudes and expectations. Experiences and awareness about the visiting sites could be included (Moscardo, 1998). Fallon \& Kriwoken (2003) suggested that visitor centres should be designed in extraordinary buildings that could provide high technology and distinctive experiences, environment and imaginative experiences. However, the suggested designation for visitor centres could not be possible for some historical sites where revenue from visitors is still limited so they cannot afford such expensive centres. Fallon and Kriwoken (2003) reveal that participation of stakeholders in planning for visitor centres leads to the success of the tourism industry which is the target of the government. Therefore, the government may be an important actor to be included in the planning process for visitor centres. 


\section{3-2-4-2-Signs}

The use of signs at visitor attraction was discussed in the literature as a boundary between visitor management and interpretation (Kuo, 2002; Mason, 2005; Moscardo, 1998). In general, signs can be a picture or a short phrase that both national and international tourists easily understand and notice. Moscardo (1998) stated that interpretation enhances visitor experiences via signs provided at the visiting sites. She gave an example of crocodile warning signs used in national parks and other public areas in Queensland, Australia. The author believed that these signs give a safety message to visitors in order to avoid visitors from swimming in the river. To manage visitor impacts at visitor attractions, Mason (2005) discussed using signs as an interpretive mode or format. In his discussion, the signs referred to interpretive form in soft approaches and they were used to support the hard visitor management strategies (Kuo, 2002). Kuo (2002) stated that interpretation is a component of soft visitor strategies. Interpretation can provide visitors with information about welcoming message, safety and directions (Kuo, 2002). Signs play an important role in providing these kinds of information. Therefore, signs can be used as interpretive form in order to manage visitor impact.

\section{3-3-Interpretation}

\section{3-3-1-Definition and the aim of interpretation}

Interpretation is an activity process that connects a visitor's emotion and understanding to the resources of the sites (Hall \& McArthur, 1993). This process enables visitors to appreciate and learn about the places they visit (Moscardo, 1996). Tilden (1957) defines interpretation as "an activity which aims to reveal meanings and relationships through the use of original objects, by firsthand experience, and by illustrative media, rather than simply to communicate factual information (Tilden, 1957, p.8). Hall and McArthur (1993) further Tilden's definition by connecting it to a philosophy of heritage management. They stress that interpretation is used as a form of education to increase visitors' experiences at heritage sites and to support the heritage conservation. These experiences include appropriate behaviour and a reduction of negative impacts at the visiting sites. A definition indicated in the International Council on Monuments and 
Sites (ICOMOS) Charter for the interpretation and presentation of cultural heritage sites is quite similar to the concept of Hall and McArthur (1993):

Interpretation refers to the full range of potential activities intended to heighten public awareness and enhance understanding of cultural heritage site. These can include print and electronic publications, public lectures, on-site and directly related off-site installations, educational programmes, community activities, and ongoing research, training, and evaluation of the interpretation process itself.

ICOMOS, 2008, (p.4)

Studying a definition of interpretation is not the only way to understand the overview of interpretation because the definition may vary due to the objective of the interpretation. For instance, the aim of ICOMOS is to use the charter to protect and conserve the heritage settings. Interpretation might not be important if visitors have less intention to the heritage sites (Moscardo, 1996). It means that an effective of interpretation needs to be considered from the two aspects, heritage settings and visitor settings. According to the research questions mentioned in chapter 1, this research will investigate and concentrate on the management of interpretation rather than visitor settings.

Interpretation is divided into two types, one is personal interpretation provided by tour guides and another is non-personal interpretation which includes interpretive infrastructure, brochure and leaflets (Brochu \& Merriman, 2002). This classification clearly indicates that the objectives of interpretation might be different because of the organisations' goals. However, up to date studies show that the two main purposes of interpretation to be promoted are sustainability of the resources and visitors' experiences (Hall \& McArthur, 1993; Moscardo, 1998; Reisinger \& Steiner, 2006; Shackley, 1998; Timothy, 2007).

\section{3-3-2-The roles of interpretation}

Among other things, interpretation is an educational tool. Locals as well as visitors have a chance to learn about ecological, historical, and cultural resources at sites through the many methods of interpretation provided (Moscardo \& Ballantyne, 2008; Tilden, 1957). 
According to Timothy and Boyd (2003), there are two forms of education in visitation, formal and informal interpretive programmes. Formal education is similar to a given educational programme at schools and universities (Timothy \& Boyd, 2003). The programme tends to develop the process of learning by providing practical experiences to students. For example, some school curriculums have field trips to historical sites where students can gain a deeper understanding in their history and geography subjects. Informal education, on the other hand, refers to the provision of information to visitors at the sites where interpretation is conducted and offered. This form of education helps visitors to experience and get the real practices at the sites. Timothy and Boyd (2003) believed that the role of interpretation here is to increase the students' and visitors' awareness of the visiting sites which leads to understanding, enjoyment and responsibility. This literature review fits with the current study because Angkor Wat temple, a world heritage site, is not just a place for leisure activities but also a place for those who are interested in learning about culture, architect, and archaeology. Therefore, it is important to investigate how interpretation is formed to educate visitors at Angkor Wat temple.

Interpretation plays an important role for the sustainability of sites. Moscardo (1998) argued that an effective interpretation contributes to sustainable tourism and conservation (Bramwell \& Lane, 1993; Hall \& McArthur, 1993). Because of interpretation, visitors have opportunities to learn about history, environment, and culture (Moscardo, 1998). This process of learning may encourage them to visit the sites again which leads to economic sustainability. She explained that with these kinds of visitors, the visiting sites probably have less negative impacts. When visitors know the value of the site, they might appreciate it and help to protect its heritage. These visitors always behave in appropriate ways because they understand the impacts caused by the visitors.

Interpretation can provide efficient information to enhance the quality of visit. Interpretation has been used in many forms to inform visitors of what they can do and cannot do at the sites. Apart from reducing the negative impact on the site discussed above, interpretation provides a good information about the available options so that the visitors will make the right decision to match their visiting schedule (Moscardo, 1998). In addition, visitors may avoid dangerous activities that they are informed of through 
interpretive signs and boards. Visitors' safety during their trip may encourage them to visit the places again.

\section{3-4-Stakeholders and joint-management of visitor attractions}

Considering stakeholders is relevant to a topic in managing interpretation (Jamieson, 2006; McKercher, Ho, \& du Cros, 2005; Timothy \& Prideaux, 2004), because management of interpretation comes under the disciplines of heritage and tourism management. These two sectors consist of other relevant stakeholders concerned about the conservation and development of visiting sites. Jamieson (2006) gave an explanation of themes to be selected for interpretation by multiple stakeholders. Themes interpreted by UNESCO may differ from the one provided by the government and private sectors. Timothy et al. (2004) presented a need for international fund and technical assistance to maintain conservation and protection projects. The need normally occurs in developing countries where financial and human resources are poor. In addition to the issue of stakeholders taking part in the management of interpretation, McKercher et al. (2005) introduced a relationship between the stakeholders and their conflicts. These studies suggested that stakeholders have their own strategies and plans to develop interpretation. It is very important for the current study to investigate how individuals prepare for their interpretation management.

To have effective interpretation, stakeholders are required to have a plan for interpretation management. Interpretation has two important functions in visitor management and heritage management (Carter \& Grimwade, 1997; Hall \& McArthur, 1993; McKercher, et al., 2005; Moscardo, 1998). Moscardo (1998) suggested that mindful visitors require efficient interpretation that facilitates their trip and makes it more meaningful. In addition to Moscardo (1998), interpretation is used as a tool to protect and promote the cultural resources (Hall \& McArthur, 1993). A success of interpretation management needs a lot of works and helps from relevant stakeholders to create a plan for management. Jamieson (2006) suggested a number of critical questions for stakeholders before they prepare a plan for interpretation management. 
-What are the resources, themes, and subthemes to be interpreted?

-Why are these resources and themes being presented to tourists and what should the presentation accomplish?

-Who are visitors to the community? How can the theme be interpreted so they can understand and relate to it?

-How, when, and where are the interpretive programme and services presented?

-What will it cost, in terms of people, time, resources, and budget, to implement the plan?

-How will the parts of the plan be evaluated to see if all objectives are achieved?

Jamieson, 2006, (p.87)

3-4-1-International organisations involved in management interpretation

Based on a review of previous studies, international bureaucracies such as the International Union for the Conservation of Nature (IUCN) and United Nations Educational, Scientific and Cultural Organisation (UNESCO) have been involved in drawing public attention to diverse natural and cultural resources which are under threat (Hay-Edie, Howard, Martin, \& McCandless, 2011). In response to these concerns, international organisations find ways to develop frameworks for resource conservation. When discussing the development of the frameworks, collaboration between international and national guidelines needs to be addressed because nothing can be achieved without the active participation of stakeholders. These frameworks are introduced to local governments as guidelines to increase relevant stakeholders' awareness about conservation which results in minimising negative impacts.

Having a concern about conservation and protection heritage settings, the International Commission on Monuments and Sites (ICOMOS), on behalf of UNESCO, sets up a charter for the interpretation and presentation of cultural heritage sites. The objective of this charter is to communicate the meanings of cultural heritage sites to visitors and engage visitors in the protection and conservation of cultural resources (Araoz, 2005). 
This charter shows that UNESCO has paid attention to interpretation as a vital mechanism to increase visitor awareness and protect the heritage resources.

UNESCO assists some developing countries to improve interpretive programmes. Hawkins (2004) stated that some world heritage sites in developing countries do not have adequate resources, including financial and human resources to develop their interpretive infrastructure (Hawkins, 2004). UNESCO whose duty it is to monitor all world heritage sites, may make a decision on how they can help the countries to protect heritage resources. Ho et al. (2004) revealed that UNESCO sometimes either provides budget or technical staff to assist the world heritage site. These studies fit to the current research which is conducted in Cambodia, a less developed country. The involvement of UNESCO in development of interpretation is assumed to be important for the case of Angkor Wat temple which needs to be explored.

\section{3-4-2-Managing interpretation at the national level}

Central government plays a prominent role in creating legislation for the protection and management of cultural resources. The government is the highest level which can also review and amend existing legislation on framework for protection and management of natural and cultural properties (Hall \& McArthur, 1993). An example of this comes from New Zealand where legislation was amended for the purpose of conservation. The strategies that the government adopted included restrictions on the export of cultural property; the allocation of funds for training cultural conservators; and provisions for the protection of historical buildings and sites. As a result, a variety of legal acts such as Antiquities Act, Historic Places Act, Conservation Act, and Resource Management Act have been created for the purpose of conservation among other things. In addition to the protection and management of cultural property, the government of New Zealand also takes responsibilities for establishing collecting and interpretation centres (Butts, 1993). In this regard, Te Papa Tongarewa, the national museum, plays a role in collecting, preserving and exhibiting the cultural property.

The ownership of historical sites can be private and public (see section 3-2-1). The sectors may have different objectives in managing the sites but they have the same plan to facilitate the visits by providing visitor facilities (see section 3-2-4). According to Garrod et al. (2002), a majority of historical sites in Scotland are owned by the 
government. In order to increase the quality of visits and to gain support for conservation, the site managers consider the importance of interpretation. The investment in interpretation by the government met some shortages in finance. As a result, the sites owned by the government sometimes do not have adequate funds to improve visitor facilities.

\section{3-4-3-Tour guides}

Tour guides have been defined as information givers, leaders, mediators, culture brokers and entertainers (Cohen, 1985; DeKadt, 1979; McKean, 1976). Tour guides have also been described as people who interpret in an inspiring and entertaining manner, in the language of the visitors' choice, the cultural and natural heritage and environment (IATM, EFTGA, 1998 cited in Reisinger, 2006).

Tour guides have a role as educational agents who explain the real meaning of the resources at the site. Christie and Mason (2003) state that cultural and natural conservation to some extent are found hard to interpret in the classroom and students find them difficult to understand. However, if the interpretation could be made in the field, students have a chance to experience a site as an authentic learning experience. The success of interpretation here is to link visitors or students to the reality of the sites and make them feel enthusiastic about visiting the sites. The authors suggested that tour guides may have a relevant role in interpreting the sites in this way.

Another role of tour guides is to increase visitors' understanding by challenging their knowledge. As stated by Moscardo (1996), mindful visitors have high satisfaction upon the visiting sites. Visitors appreciate interpretive infrastructure that they are provided with such as visitor centres, interpretive signs and other media which convey the site information to them. However, not all facilities provided are efficient in terms of communicating with visitors because some interpretive infrastructure cannot deal with all visitors' doubts or questions. In this case, tour guides would play a prominent role in responding to questions. Unlike interpretive facilities provided at the sites, tour guides could challenge visitors' awareness with Q\&A about the sites. Hence, tour guides are more flexible with all questions raised by visitors than interpretive facilities. 
Io and Hallo (2011) believe that tour guides play an important role in visitor management. These two authors conducted research on tour guides' interpretation of the 20 heritage buildings located in Macao. Their findings reveal that tour guides interpreted only two or three attractive buildings among 20 heritage buildings in a world heritage site to visitors (Io \& Hallo, 2011). Selecting some buildings to be interpreted may result in confusion of the meaning of cultural heritage and under-used heritage sites. The authors explained that visitors might get the wrong perception about uncertain number of heritage settings situated in the heritage site of Macao. This may result in reducing visitors' authentic experiences at the heritage site. Another concern is about a balance between over-use and under-use of the site (Shackley, 1998). If the tour guides can make a connection between over-use and under-use of the site, a reduction of the negative impact can be expected. In this case, tour guides should make the most of interpretation by connecting one attractive heritage building to another, so that visitors will have chances to see the significance and value of the entire site of Macao. This interpretation does not only provide experiences for visitors but also has benefits for visitor management.

Little attention has been paid to research methodology for a study of managing interpretation by tour guides. The majority of literature either focuses on demand side (Randall \& Rollins, 2009) or supply side perspectives (Ap \& Wong, 2001; Christie \& Mason, 2003; Pizam, 1999; Reisinger \& Steiner, 2006). However, a study of tour guides' interpretation at heritage buildings in Macao, interview with tour guides, visitors and observations were used to collect data (Io \& Hallo, 2011). It is not necessarily logical to understand how tour guides manage their interpretation without also examining visitors' perceptions because guides may make ill-informed generalisations about visitors' opinions. For example, a study by Io and Hallo (2011) indicated that tour guides had wrong assumptions about sightseeing visitors. The tour guides perceived that the visitors may be less interested in heritage which led them to interpret limited heritage information for the visitors. In contrast to tour guides' assumption, visitors responded that they had wished to see many historic sites. Hence, the responses provided by tour guides and visitors were completely different. In order to gather accurate information about the management of interpretation by tour guides, future researchers should consider the research methodology used. Although examining 
both tour guides and visitors provides insightful information, it is not applied in the present study because of the research scope and time restrictions.

\section{3-4-3-1-Factors that may impact on interpretation}

Ap and Wong (2001) addressed two major issues, a lack of knowledge and language that have effects on the professionalism of tour guides. The findings revealed that guides had limited understanding of cultural and entertainment attractions in Hong Kong. Also, similar findings were found in a study by Io and Hallo (2011) in which tour guides were not aware of all heritage settings at visiting sites. In addition to the research on the local tour guides (Ap \& Wong, 2001; Io \& Hallo, 2011), limited knowledge of history, culture, and geography were identified as primary issues for guides touring their groups abroad (Yu, Weiler, \& Ham, 2004). Yu et al. (2004) studied Chinese-speaking local tour guides working in Australia. The researchers stated that Chinese-speaking tour guides struggled with cultural aspects and competencies which their Chinese visitors were seeking. A lack of knowledge about historical and cultural resources presented in the previous studies implies that tour guides need to have general knowledge of the visiting places because their interpretation is perceived as a tool for mediating cultural understanding (Yu, et al., 2004).

In addition to a lack of knowledge, poor language skills are identified as a problem for interpretation (Ap \& Wong, 2001; Yu, Weiler, \& Ham, 2002). Ap and Wong (2001) defined the language barrier of tour guides as an issue of professionalism in tour guiding. Tour guides are not able to interpret their knowledge about the sites as much as possible because their language use is limited. Yu et al. (2002) further a discussion by stating that a lack of language skills may impact on intercultural competence. The role of tour guides is to facilitate interaction between clients and hosts and to broker an intercultural experience that is non-stressful, interesting and rewarding for clients (Yu, et al., 2002). It is impossible for the visitors to communicate with the hosts and learn about the culture because of low level language proficiency. Ap and Wong (2001) suggested that guide training courses can improve the standard of language. In terms of interpretation they believed that the training courses also increase the quality of visitation to the cultural heritage sites. A language barrier is a common issue occurring 
in Asian countries where cultural heritage sites receive visitors from different countries and need foreign language speaking guides.

\section{3-4-3-2-The training of tour guides}

Christie and Mason (2003) discussed a variation of guide training courses in some countries such as the US, the UK, Canada, Australia and New Zealand. In their discussion, the authors highlighted the differences in requirements for being tour guides in each country. These include a professional education, general knowledge, communication skills, capacity of speaking foreign languages and health (Christie \& Mason, 2003). The researchers also noticed countries where the government provides a great deal of support for the training courses, for example, Canada because the government requires a standard of guiding tour. Although the countries have different visions for improving the quality of tour guides through training courses, they have the same purposes to develop guides' knowledge, skills, attitudes, and behaviour. The authors insisted that the course provides guides an opportunity to learn how to critique their own knowledge before they interpret it to their clients.

Training courses are vital to developing guides from basic understanding to theoretical base. Pond (1993), cited in Christie and Mason (2003), acknowledged that tour guides normally have basic understanding about the places they are touring but she strongly supports the training courses that increase guides' ability and effectiveness of interpreting. Knudson et al. (1995) agreed that good tour guides or interpreters should develop themselves by engaging training courses, including field courses, research, and theory.

The training courses are fundamental in increasing the professionalism of tour guides. Ap and Wong (2001) examined the nature of tour guides in Hong Kong by assessing the level of service standards and identifying issues that tour guides have met. Their findings indicated that tour guides need more training courses in order to improve their existing knowledge as well as language. The researchers made some comments that training courses are not just important to develop guides' abilities of interpretation but the courses may move tour guides from a basic level to a higher level. The authors explained that tour guides will have a chance to develop themselves from tour guiding 
to management level tasks. In terms of tour guides' income, they will also be well paid by tour operators.

\section{3-4-4-Tour operators}

Tour operators may have an indirect influence on interpretation made by tour guides. Little attention has been paid to an itinerary which is organised by tour operators. A finding from Ap and Wong (2001) indicated that tour operators have an influence on tour guide professionalism. Visitors might think that tour guides sometimes spend little time for interpreting the site and tour guides use the rest of the time for shopping where they can get a high commission. The study of Ap and Wong (2001) revealed that visitors complained about the unethical practices of tour guides who focus only on their personal income without presenting much about the value of cultural heritage sites. This action may make the visiting schedule a bit tight and visitors might not get enough explanation and information of the sites. Tour operators may be associated in this issue because they have greater power than tour guides (Ap \& Wong, 2001). These tour operators usually arrange itineraries which include historical sightseeing, shopping and other activities for visitors. Tour guides just follow the itinerary set by tour operators so they sometimes try their best to interpret the heritage sites. On the other side of the coin, one can argue that the issue may happen in some certain countries where Asian visitors are more interested in shopping and city visits than trips to historical places. Based on this reason, tour operators may satisfy their clients by reducing times for the site visits. This reduction results in inadequate time for tour guides interpreting the sites to visitors. Therefore, this literature provides insight for the current study to examine itineraries arranged by tour operators whether the itineraries are associated with interpretation by tour guide or not.

\section{3-5-Multiple stakeholders in the management of heritage attractions}

A conflict between stakeholders in tourism and heritage attractions was indentified in some case studies from many countries such as the UK, Australia, New Zealand, Hong Kong, Canada, and the US (Aas, Ladkin, \& Fletcher, 2005; Hall, 1999; Hall \& McArthur, 1993; McKercher \& Du Cros, 2002). Hall (1999) made a point that 
collaboration among stakeholders from various communities, conservation and nongovernmental organizations are needed in tourism planning. This requirement mostly concerns the impact of visitor and development issues on the heritage assets in the regions. Although collaboration of stakeholders is strengthened, conflicts are still found due to the different objectives of stakeholders. Conflicts between the stakeholders happening at heritage sites probably are common issues which concern UNESCO. For instance, as indentified in the objective of the Charter for the Interpretation and Presentation of Cultural Heritage Sites, stakeholders are encouraged to take part in developing interpretive programmes for the heritage sites (Araoz, 2005). Hence, this example shows a need for a smooth relation between the stakeholders in order to achieve the goals.

Ho and McKercher (2004) expressed three main scenarios that lead to conflicts between stakeholders in managing heritage sites. Active stakeholders from two sectors, cultural heritage conservation and tourism, were illustrated in a discussion. The first scenario is that the both parties, site managers from the conservation sector and tourism sectors, performed their own duties (Ho \& McKercher, 2004). This means site managers take responsibility for conserving the sites while tourism sectors only focus on the promotion of sites. The site managers do not acknowledge what the market demand is and the tourism sectors are not aware of conservation and the value of the cultural assets. The development of the site would be impossible if the two sectors did not try to understand the purposes of each other. Ho and McKercher (2004) suggested that communication, which was later echoed by Aas et al. (2009), should be built between the two sectors so that they can exchange their visions and find appropriate ways to develop heritage sites.

The second scenario is about an inadequate provision of services at the sites. The site managers simply presented and managed the assets while the tour operators brought in tourists and let visitors shape their own experiences (Ho \& McKercher, 2004). It is because of a lack of tourist facilities such as information, services and interpretive infrastructure at the sites. As a result, visitors hardly meet satisfaction about the services provided. The third scenario shows a big responsibility of site managers. In this scenario, Ho and McKercher (2004) explained that site managers often take over tourism tasks. The site managers develop cultural tourism without discussing with tourism experts whose studies focus on tourism management and market information. The authors suggested that help from tourism sectors is very necessary to successfully 
develop cultural products. A lesson from the three scenarios informs the current study about how to get success in managing interpretation by relevant stakeholders at a world heritage site. If the stakeholders serve the same purpose to increase visitors' awareness of the visiting sites and enhance the quality of visits, they need to build good communication together in order to provide efficient information to visitors.

Language and political issues could be factors that influence collaboration among stakeholders. Aas et al. (2005) conducted research about a collaboration approach to the relationship between heritage management and tourism development in Luang Prabang, Laos. They found that communication between UNESCO and the government agencies does not go smoothly because members from the government find it hard to communicate in English. The ability to use English may slow the process of working and can lead to misunderstanding. In addition, the working environment in Laos is not as good as in some developed countries. Stakeholders from UNESCO revealed that the government of Laos is centralised and difficult to work with in terms of making decisions. In general, Aas et al. (2005) found that the extent of international organisation collaboration with the government was minimal. The research conducted by Aas et al. (2005) provides a good example for developing countries where international assistance is important for developing historical sites. It provides an idea to examine how UNESCO works with the government of the visiting sites.

A contrast between stakeholders could be found when they hold an incorrect perception. Tour operators and conservators work at the same heritage sites. Tour operators require a good relationship with the conservation sector because they always bring tourists there. In contrast, conservators may have different perceptions. The conservation sector sometimes gets limited funds from the tourism sector for conservation purposes, so they do not value collaboration as much as the tourism sector does (Aas, et al., 2005). According to the authors, the conservation sector perceives tourism as harmful to heritage resources. If the stakeholders hold this kind of perception, they will not have a successful working relationship. 


\section{3-6-Conceptual framework}

The review of the literature provides insight into developing a conceptual framework which will be used as a guideline to explore the current research and as a primary structure to identify participants for data collection (see figure 3). This framework illustrates a relationship between stakeholders and their tasks in managing interpretation at cultural heritage sites. International and national stakeholders have different responsibilities and objectives to manage heritage sites in a sustainable manner. In doing so, interpretation is adopted as a tool to reduce negative impacts and increase visitors' awareness about visiting sites. International organisations such as UNESCO and ICOMOS pay great attention to the impacts of tourism on historical sites. Their concerns about visitors' impacts lead to the establishment of the Interpretation and Presentation charter (Araoz, 2005). This charter presents the importance of interpretation which can be used as a guideline for cultural heritage conservation and site management.

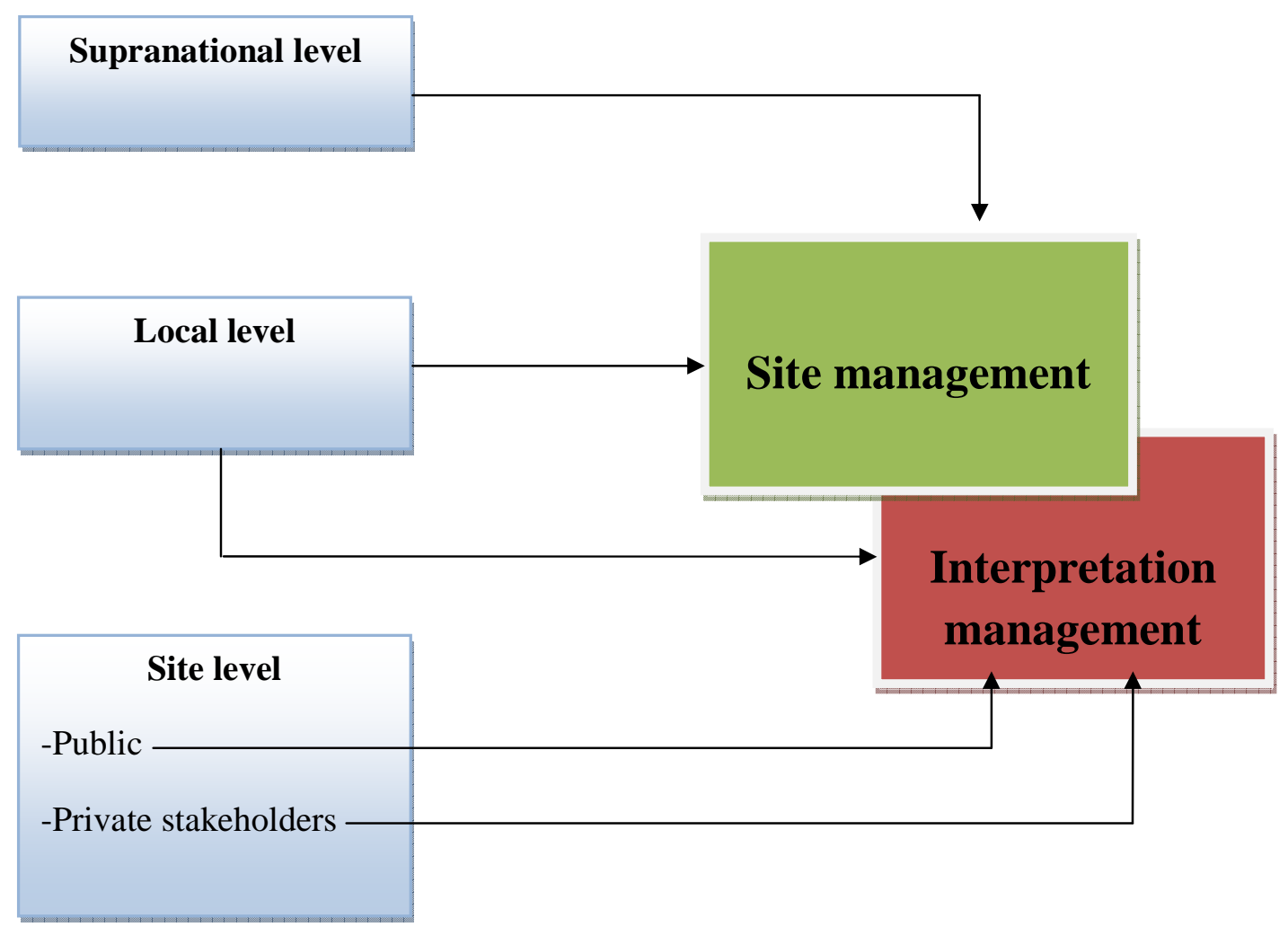

Figure 3: Conceptual framework 
To achieve sustainable development goal, local authority plays an important role in developing heritage management framework (Hall \& McArthur, 1993). Due to the scope of the current research, local authority here excludes local communities. The two aspects that support this framework are conservation and tourism development. These two aspects need to complement each other. Managing the heritage site needs to consider the conservation policy which was set up by the central government and also follows the guideline of UNESCO if the site was registered on the world heritage list. In addition to the conservation theme, interpretation of heritage sites is used as an exceptional solution to deal with visitor impacts. The local authority works closely with site managers to study the effectiveness of interpretation management and use the result of the study as benchmarking for tourism management. To manage the interpretation at cultural heritage sites, hard and soft visitor management approaches are adopted (Kuo, 2002; Mason, 2005). These approaches are used to inform heritage frameworks by increasing visitors' awareness about heritage as well as increasing heritage conservation support from the public.

The local authority also performs their duty for the purpose of building the capacity of local guides. The local authority implemented guidelines approved by the central government at the local and provincial levels (Dahles, 2002). For example, the guidelines indicate the role of training courses in developing interpretation at the site. The aim of the course is to provide local tour guides with basic knowledge such as national history, culture, and the arts. Students from high school level can attend the courses and they can become junior guides. These junior guides are officially recognised by local authority and they have an opportunity to develop their skills to senior and professional guides in the country according to the guideline.

The public sector encompasses organisations that own the heritage sites and also have important management roles. For example, in Scotland the government or state runs the historical sites. The sites' operations depend on entrance fees (Garrod, et al., 2002). The money generated from the fee is spent on human resource development as well as visitor facilities. Visitor facilities are found to be important in developing visitors' experiences so site managers are trained with particular skills to enhance the service quality. To do that, some site managers are trained to be site interpreters whereas the others are responsible for providing and designing visitor facilities including interpretive infrastructure. 
The private sector refers to tour guides and tour operators whose tasks are related to interpretation about historical sites. Tour guides play an important role in providing significant information about the visiting sites to visitors (see section 3-4-3). Compared to the management of interpretation by organisations, tour guides have direct communication with tourists and the guides have individual strategies to involve visitors in their interpretation. To manage interpretation, tour guides tend to enhance visitors' understanding and experiences about historical sites. Tour operators, on the other hand, have an influence on tour contents or presentation organised by tour guides (see 3-4-4). The tour operators usually need tour guides to follow the itinerary tour. This itinerary tour varies due to duration of visit and visitors' requirement during the visit. For instance, tour guides would interpret the site in more detail if they had adequate time in every programme existing in the itinerary. Therefore, effective interpretation also relies on the itinerary set by the tour operators.

\section{3-7-Conclusion and implications}

This literature chapter explores and assesses the previous studies about managing interpretation. The chapter also provides comprehensive insights not only into the management of interpretation but also into implications of the management towards visitor management and historical attraction management. As a result, a conceptual framework, as the outcome of reviewing the literature, is presented. The framework conceptualises ideas from the previous research and forms important components which need to be examined in the current study. The framework also provides ideas about relevant participants in managing interpretation for data collection.

Having explored the literature, the author is able to identify gaps in previous research. Very little academic research has been concerned with managing interpretation by stakeholders. A majority of studies focused on individual stakeholders such as tour guides, site managers and visitors' perspectives about tour guides. Others conducted research about sustainable development at visitor attractions by examining interpretation as a role in managing visitor impacts and resources. These studies cannot identify the possibility of conflicts that are caused by multiple stakeholders at the historical sites. These conflicts are considered an obstacle in managing interpretation. 
The use of research methodology has not developed much because some studies still adopted descriptive approaches and surveys for examining the questions. The following chapter will present why the current research adopted a qualitative approached to investigate the management of interpretation at a world heritage site. 


\section{Chapter 4: Methodology}

\section{4-1-Introduction}

The two research questions presented in Chapter 1 were used as guidance for the research process and methodology. Qualitative research is considered an appropriate approach for the current study. This approach enables the researcher to gain a deeper understanding of how individual institutions and tour guides manage interpretation at Angkor Wat. The study also employs a qualitative case study approach. It uses semistructured interviews and an analysis of secondary documents to examine the research questions.

It is necessary to present a need for this chapter in the current research. This chapter will help researchers to consider an appropriate way to design, analyse and present the research. The research design may vary according to the research typology. For instance, this study is in partial fulfilment of a master's degree in tourism management. Although the result of the study will not be presented in academic journals, it will be read by a small number of tourism scholars. Furthermore, the purpose of this research topic is to identify challenges in the management of interpretation at Angkor Wat. The author hopes that the results of this research and the resulting recommendations will contribute to the work of stakeholders and government. Thus, the current study needs to be academic and involve systematic research that includes research design, data collection, and data analysis.

A social constructivist approach will be presented in this chapter. According to Patton (2002), social constructivist researchers can tackle their research questions by asking interviewees about their views of working experiences. In addition, the chosen approach contributes to data interpretation (see section 3-2-1). Furthermore, semi-structure interviews were adopted for the current research.

This research methodology chapter outlines three main sections that guide the process of the study from pre-field work until data analysis. The first section about research design gives an overview of the theory applied in the current study. The second section discusses methods of both primary and secondary data collection. Finally, the last section presents how the data is analysed. This section explains how data was 
transcribed, the analytical framework, and it considers weaknesses and strengths of the research approach.

\section{4-2-Research design}

This section presents the social constructivist approach to this study. In addition, the importance of case study approaches is explained. The process of selecting interviewees and participant recruitment are also included. Trustworthiness and ethical considerations are discussed at the end of the section.

\section{4-2-1-Research paradigm}

Taking a social constructivist approach for the current study helped the researcher to understand the worldviews of interviewees (Patton, 2002). From this understanding, the researcher can find possible answers for the research questions according to responses from the participants. Interviewees participating in the current research were from different institutions such as NGOs, the governmental sectors, and private sectors. These interviewees stated their own different experiences in managing interpretation at Angkor Wat. As a result, the researcher is able to identify the complexity of the participants' views in order to explore the research questions (Creswell, 2007).

The social constructivist approach has implications for data interpretation (Creswell, 2007). Creswell (2007) expressed that participants in the research constructed the meaning of a situation that participants taking part and experiencing in their daily life and work. To get information from the participants, constructivist researchers capture specific contexts by using open-ended questions doing interviews (Guba \& Lincoln, 1994). The interviewees are encouraged to come back to the questions anytime during the interviews. Creswell (2007) made a point that social constructivist researchers can also use their own background and experiences to challenge the interviewees during the interviews. The researchers attempt to make sense of the data collected by interpreting the meaning that interviewees have about the world (Creswell, 2007). 
Understanding the perspectives of different stakeholders is vital for this study. Literature shows a provision of interpretation on sites varies from managing interpretation by tour guides. The tour guides have direct contact with visitors when guides interpret the background of the sites. The tour guides may be flexible in managing interpretation according to groups of visitors whereas site managers complete their duties by providing interpretive facilities. Hence, the understanding of how tour guides and site managers manage interpretation is necessary for the current research. In addition, the study also looks at other perspectives from UNESCO, NGOs and tour companies because the study took place in heritage sites and these relevant stakeholders probably influence tour guides and site managers.

\section{4-2-2-Case study research}

Qualitative case studies have been used to tackle research problems in different ways (Stake, 2005). Stake (2005) identified three important types of qualitative case studies namely an intrinsic case study, a single instrumental case study and a collective case study. The intrinsic case study presents an unusual or unique situation which is used to solve particular problems that are of interest to the researchers. A single instrumental case study, on the other hand, presents a problem or concern and the researcher then selects one bounded case to present the problem (Stake, 2005). In a collective case study, researchers look at one issue but they select multiple case studies to illustrate the issue. Creswell (2007) suggested that researchers should select an appropriate type of case study which provides useful information for the research. The type of case study selected will illustrate what kind and useful information is needed to address the research questions or issues. The single instrumental case study is used in the current research. The researcher focused on one issue of managing interpretation at a particular site, Angkor Wat. He investigated different views from NGOs, the government, and private sector on the management of interpretation.

The case study gives researchers and readers an insightful perspective through which to form appropriate research methods and how to apply it in empirical study (Creswell, 2007). The case study also helps researchers to learn a lot of experiences through a process from data collection to data interpretation (Stake, 2005). Within a case study report, the researcher acts like a teacher who tells readers about particular skills or tools 
being used to examined the research problems. Thus, the readers can understand the context of the study from the case study presented by the researchers. For example, the current research is probably new to many readers because Angkor Wat is a relatively new tourist destination and few studies have been conducted in that site. Presenting the case study of managing interpretation at Angkor Wat enables readers to understand overall management of interpretation at Angkor Wat. Furthermore, the case study contributed some ideas to the readers as to why the researcher employed the methods to tackle the research problems.

\section{4-2-3-Sample selection}

Patton (2002) stated that there is no rule for selecting a sample size in qualitative research. The sample size can vary due to the purpose of inquiry, what researchers want to explore, what can be done with available time and resources and application of theory that could make sense of the data. Participants in this research were purposefully selected (Patton, 2002), the aim of the research questions, the literature and the author's personal experiences with management of the site have informed the selection. These participants such as UNESCO, APSARA, Ministry of Tourism, GACP, WMF, I.Ge.S, tour operators and tour guides are involved in managing interpretation at Angkor Wat. Individual participants have various backgrounds and experiences in managing interpretation depending on their roles and duties. As a result, the author arranged different numbers of participants to be interviewed from each organisation.

As can be seen from the Table 2, tour guides including contracted and independent guides form the largest group of participants. This is because guides perform their roles as site interpreters whereas the site managers, APSARA, are responsible for improving interpretive facilities such as interpretation centres, signage and information boards at the site. Four officers from the Authority were appointed by their employer to be interviewed. Each representative from three NGOs, working for restoration and conservation projects was interviewed about how they run and manage the interpretation centres. At the Angkor Wat temple, a world heritage site, UNESCO has an important role in assisting site managers to create a tourism management plan which is a mechanism of the heritage management framework. Interpretation is identified as a key driver to develop a tourism plan. A participant from UNESCO was interviewed 
about how interpretation management is useful for the development of Angkor Wat temple. An officer from the Cambodian Ministry of Tourism was selected to participate in the interview. The Ministry is the only organisation that is involved in developing the capacity of tour guides and provides licenses to them. Three representatives from different companies, Angkor TK Tour, APEX Tour, and BFT Tour companies were recommended by contracted tour guides for interviewing purposes.

Table 2: Characteristics of participants

\begin{tabular}{|c|c|c|c|c|}
\hline Participant & The role of participants & Location & $\begin{array}{l}\text { Number of } \\
\text { participants }\end{array}$ & $\begin{array}{l}\text { Duration of } \\
\text { interview(s) }\end{array}$ \\
\hline UNESCO & $\begin{array}{l}\text {-Set up the policy for the } \\
\text { sustainable development of the site }\end{array}$ & $\begin{array}{l}\text { Phnom } \\
\text { Penh }\end{array}$ & 1 & $65 \mathrm{~min}$ \\
\hline $\begin{array}{l}\text { NGOs } \\
\text { (GACP, } \\
\text { WMF, } \\
\text { I.Ge.S) }\end{array}$ & $\begin{array}{l}\text {-Run interpretation centres } \\
\text {-Work on restoration and } \\
\text { conservation project } \\
\text {-Increase visitor awareness of } \\
\text { conservation and restoration }\end{array}$ & $\begin{array}{l}\text { Siem } \\
\text { Reap }\end{array}$ & 3 & $40-55 \mathrm{~min}$ \\
\hline $\begin{array}{l}\text { APSARA } \\
\text { Authority }\end{array}$ & $\begin{array}{l}\text {-Improve interpretative } \\
\text { facilities } \\
\text {-Develop capacity building in } \\
\text { interpretation }\end{array}$ & $\begin{array}{l}\text { Siem } \\
\text { Reap }\end{array}$ & 4 & $55-60 \mathrm{~min}$ \\
\hline $\begin{array}{l}\text { Ministry of } \\
\text { Tourism }\end{array}$ & -Offer guide training courses & $\begin{array}{l}\text { Phnom } \\
\text { Penh }\end{array}$ & 1 & $40 \mathrm{~min}$ \\
\hline $\begin{array}{c}\text { Tour } \\
\text { company }\end{array}$ & $\begin{array}{l}\text {-Arrange programmes to be } \\
\text { interpreted }\end{array}$ & $\begin{array}{l}\text { Siem } \\
\text { Reap }\end{array}$ & 3 & $20-25 \mathrm{~min}$ \\
\hline Tour guides & $\begin{array}{l}\text {-Interact with visitors through } \\
\text { interpretation }\end{array}$ & $\begin{array}{l}\text { Siem } \\
\text { Reap }\end{array}$ & 10 & $45-50 \mathrm{~min}$ \\
\hline & Total & & 22 & \\
\hline
\end{tabular}

\section{4-2-4-Recruitment}

The author used different approaches to recruit participants. Participants from UNESCO, NGOs, APSARA, and Ministry of Tourism were initially contacted by phone and e-mail to arrange a date and time. The purpose of the research and the study objectives were explained. The information sheet and further information were sent to them via email. Interview dates and places were arranged after employers accepted the project participation. 
To recruit tour guides the researcher had to go to Angkor Wat temple. Every third tour guide walking into Angkor Wat was approached as a potential interviewee. The researcher found an appropriate time to talk to the tour guides when they took a small break at a rest area in Angkor Wat. The information sheet was given to the tour guides. The tour guides provided the researcher with his or her contact in case they were interested in the research project. The researcher contacted the tour guides again for a date and meeting place to be interviewed when they finished their tour programme.

Participants from tour companies were recruited differently from the tour guides and other institutions. When conducting the interview with tour guides, the researcher enquired whether they were freelance or contracted tour guides. If they were contracted, they were employed by tour companies. Then, the contracted tour guides were asked for their work-place contact. Having the contact address, the researcher made a phone call to the tour companies by asking them about the possibility to participate in the interview. Among five companies recommended by the tour guides, three of them were happy to take part in the interviews whereas the other two were busy until March 2012 which did not match to the researcher's schedule. Thus, the researcher decided to interview three companies. The date and place for the interviews with tour companies were flexible according to the availability of the companies. These proceedings were approved by Pipitea Human Ethics Committee (see section 3-2-6).

\section{4-2-5-Trustworthiness}

There is a lot of discussion about the importance of trustworthiness in qualitative research (Davies \& Dodd, 2002; Guba \& Lincoln, 1994; Patton, 2002). The terminology used to explain validity and reliability of qualitative research are dependability, credibility, and trustworthiness.

Dependability refers to an examination of research processes and outcomes. It is possible to ensure consistency of data by looking through raw data collected before analysing (Guba \& Lincoln, 1994). In this present study, the researcher initially made a comparison between the raw data and research notes from the fieldwork and then he sent the final transcriptions to the interviewees by email. Having time to recheck transcription from both parties increases the researcher's confidence in the findings. 
Credibility or internal validity can be viewed from researchers' experiences and their belief in the value of qualitative inquiry (Patton, 2002). Because of extensive experiences, the author is familiar with the fieldwork which he could understand easily as a process for how to collect effective data and get the most in-depth answers. Furthermore, an appreciation of social constructivist approach which is a qualitative inquiry contributes to the reliability of qualitative research. Patton (2002) stated that social constructivists' findings clearly express how a person's own experiences and background affect others' understanding. Thus, taking social constructivists' theory for this study made sound of the data (Guba \& Lincoln, 1994) and made the findings more meaningful.

\section{4-2-6-Ethical issues}

Ethical approval was needed for this research before conducting an interview. Interviewees could be sensitive to questions related to social inequality (Silverman, 2009). The questions can also lead to some degree of risk for both interviewees and the interviewed organisations. Therefore, to keep the quality of data and to protect the rights of interviewees, researchers need to go through an ethics approval process before conducting fieldwork. The author of the current study applied for ethical approval from the Pipitea Human Ethics Committee at Victoria University of Wellington in early November 2011 and the application form was reviewed two times before getting approval.

Confidentiality and informed consent have been discussed in qualitative inquiry. In the interview process, researchers give their assurance that data gathered from interviewees will be protected. Pseudonyms are used instead of the actual name in order to protect participants' identities. This information was stated clearly in the consent form given to participants. Patton (2002) argued that some interviewees allow researchers to reveal interviewees' names in the report or publication. Informed consent, in this regard, does not necessarily imply confidentiality. The informed consent can mean that interviewees understand the advantages and drawbacks of having their real name reported.

In this study, informed consent delivered a clear message to participants about confidentiality. Participants' identities such as their name and contact details would 
remain entirely confidential. This personal information was not be revealed to anyone and was neither used in the interview transcription nor written in the report. However, the institution name and a pseudonym would be used instead. Even though the author made an effort to maintain participants' anonymity, they were still informed of the possibility of knowing their identity through the mentioning of their organisation or their statement. Furthermore, the data collected was securely stored. All raw data and audio recordings will be destroyed within two years after the conclusion of the research.

The information sheet and consent form were translated into Khmer to ensure participants understand the purpose of the research and the confidentiality. The information sheet was handed over and explained before the start of the interview. The author asked for permission to record the conversation and for a signature of approval from participants.

\section{4-3-Data collection}

\section{4-3-1-Semi-structured interviews-primary data}

To undertake this qualitative research, semi-structured interviews were used. The researcher conducted interviews with 22 participants from different institutions. The interviews took place in November and December 2011 and January 2012 which was the high tourist season in Cambodia. It was very challenging for the researcher because he received many meeting cancellations from the group of tour guides. However, the cancellations did not impact anything on the interview process.

There were four officers from the APSARA Authority, one officer from the Ministry of Tourism, one representative from UNESCO, three experts from international organisations working for restoration and conservation projects (NGOs), three participants from tour companies and ten tour guides who took part in the interviews (see table 2). Interviews were conducted in two regions, Phnom Penh and Siem Reap where Angkor Wat is located. Participants from the Ministry of Tourism and UNESCO were interviewed at their offices in Phnom Penh whereas the rest were conducted in Siem Reap. 
As can be seen in table 3, there are two different groups of national tour guides. The first group called contracted tour guides are employed by tour companies whereas the second group, freelance guides independently conduct a tour with visitors. In this study, there were seven freelance tour guides and three contracted tour guides (see table 3). The nature of the semi-structure interviews allowed the interviewer enough time to develop questions and get most of the answers. Participants, on the other hand, could understand the questions and provide insightful answers and recommendations (Guba \& Lincoln, 1994). The interviews were allowed to record. They were between 20 and 65 minutes based on the availability of participants (see table 2).

Table 3: Characteristics of tour guides

\begin{tabular}{|l|c|l|}
\hline Tour guide (TG) & $\begin{array}{c}\text { Numbers of tour } \\
\text { guides }\end{array}$ & Organisations the TG works for \\
\hline French speaking TG & 2 & Freelance TG \\
\hline English speaking TG & 2 & Freelance TG \\
\hline Spanish speaking TG & 2 & Freelance TG \\
\hline Japanese speaking TG & 2 & $\begin{array}{l}\text { One is freelance TG and one works } \\
\text { for the APEX tour company }\end{array}$ \\
\hline Thai speaking TG & 1 & Working for the TK tour company \\
\hline Chinese speaking TG & 1 & Working for the BFT tour company \\
\hline Total & 10 & \\
\hline
\end{tabular}

(Source: Author, 2012)

\section{4-3-2 Secondary data}

Both soft and hard copies of the heritage and tourism management plans for Angkor Wat temple were collected. Some additional information could be accessed online. The secondary data including data gathered online was used to prepare the collection of primary data and to add to it and clarify during the interpretation of primary data (Finn, Elliott-White, \& Walton, 2000). This means the researcher had a chance to identify which useful information was to be collected during the fieldwork. Documents related to the heritage management and tourism development of Angkor were found in APSARA Authority's library. In order to get this document, the researcher had worked 
with librarians and asked for their helps. In addition, the researcher received other relevant documents from interviewed participants. A full list of these documents can be found in Appendix E. These documents showed a number of stakeholders are involved in the management of interpretation. The documents were also used to address some gaps in managing interpretation at Angkor Wat. Additionally, the author used this secondary data as supplementary information to write up a descriptive case study. It is important to indicate at this point that some documents were in a report form, the report was collected from a seminar about the involvement of tourism stakeholders in developing tourism in Siem Reap. Some parts of the report were found relevant to the current study. To analyse the secondary data for this study, relevant information from the library and the participants' document was classified according to the mission of organisation toward the improvement of interpretation. Some important information was selected and used for the background of the research.

\section{4-4-Data analysis and interpretation}

English is the author's second language. He went through two processes before starting data analysis. Firstly, the researcher translated interviews into English before transcribing because a majority of the interviews were conducted in Khmer. Secondly, a proof reader was asked to check some quotes. When checking the quotes, both a proofreader and researcher made sure the quotes retained the original meaning. The constructivist perspective helped the researcher to identify multiple views of participants. The researcher was able to cluster and group the ideas viewed by participants during data analysis. In this data analysis section, content analysis, case analysis and data interpretation will be explained and discussed.

\section{4-4-1-Content analysis}

Content analysis known as qualitative data reduction was adopted in the present study. Content analysis is a process of searching core meanings appearing frequently in interview transcripts (Patton, 2002). Sometimes these core meanings are used to represent themes or categories. Finn et al. (2000) recognised content analysis as a means to reduce a large volume of interview transcripts. In the current research, interview 
transcripts were coded manually by writing notes. Using the literature and conceptual framework as a guide, the author clustered the notes based on two major categories, managing interpretation by organisations and tour guides. Institutions (NGOs and public sectors) were identified as sub-categories for the managing of interpretation by organisations due to their different responsibilities.

Coding procedures help qualitative analysts to develop a systematic framework for data analysis (Patton, 2002). To do so, the researcher identified themes by coding the transcripts for the second time in the categories. During this stage, the author read the transcripts many times and took notes on A4 paper. The notes focused on individual management of interpretation at Angkor Wat. Then, the researcher clustered the notes and created themes which addressed the research questions. Coloured pens and post-it notes were used to re-code the transcripts. Therefore, the main categories which were from the literature and the themes derived from the research questions. These themes were presented in the structure of the findings.

\section{4-4-2-Case analysis}

A case analysis was taken to identify emerging themes within individual interviews (Silverman, 2009). In each interview transcript, the author highlighted common themes which were related to research objectives. Then, he made a comparison between one case and another to see the similarities and differences of managing interpretation at Angkor Wat by stakeholders. From this point of view, Patton (2002) believed that comprehensive information could be gathered through this analysis process. The researcher put all themes on different sheets of paper where they were clustered under main categories, managing interpretation by organisations and tour guides. Some themes were cut out due to overlap and new themes were generated to identify a relationship between organisations and tour guides.

\section{4-4-3-Data interpretation}

Having discussed in section 3-2-1, an adoption of social constructivist approach explained how the researcher interpreted data and made sense meanings of the data 
(Creswell, 2007). According to Creswell (2007), constructivist researchers tend to look at a particular context which interviewees have learned in their life. Based on their experiences, the interviewees might view the world differently. Thus, the researchers are able to study historical and cultural settings of interviewees and the researchers will make an interpretation of what they find from the interviews. Guba and Lincoln (1994) stated that socially constructed people would not make a judgement on individual views or perceptions. Instead, they would study a diversity of perceptions and make comparisons to identify similarities and differences. In addition, the study may provide implications for the current research. Constructivists could also interpret factors that affect the differences but they would not evaluate participants' perceptions.

\section{4-5-Strengths, limitations and challenges}

\section{4-5-1-Strengths}

A qualitative approach was considered as appropriate for the current study. Within this approach, semi-structured interviews were used in order to address the research questions. Semi-structured interviews offered participants enough time to respond to the questions. Furthermore, they were able to go back and answer the previous questions. To discover unexpected answers and explore emerging themes, this semi-structured interview style worked very well to provide the researcher an opportunity to develop the interview questions. With ambiguous responses, the researcher was able to follow up the interview questions throughout participants' contacts provided on the consent form.

One of the strengths of the research design is inclusion of tour guides. A variety of tour guides speaking different languages were recruited. These tour guides who have experiences with visitors from different cultures shared a diversity of concepts towards managing interpretation at Angkor Wat temple. To examine influencing factors on managing interpretation, the contracted tour guides introduced a company they are working for to the researcher. This introduction provided the researcher a chance to explore how much impact the tour company has on tour guides in managing interpretation at Angkor Wat temple. 
The selection of the case study provides an opportunity to identify issues and remedies to achieve tourism development in the Angkor region. Angkor Wat temple is the most famous temple in the Angkor region and in the ten years prior this research it has become the most popular cultural tourism attraction in Cambodia as well as Southeast Asia. A growth in visitor numbers and a lack of interpretive facilities worry the government and international community including UNESCO. The current research explored every viewpoint of stakeholders involved in interpretation at Angkor Wat temple. The data could contribute to government policy and the implications of this study suggest some constructive ideas for developing visitor experiences through interpretation.

\section{4-5-2-Limitations and challenges}

Some limitations and challenges were identified in this study. Firstly, a gap in sample selection was found even though an appropriate methodology was adopted. As can be seen in table 2, only Cambodian tour guides were recruited. The method of selecting every third tour guide walking into Angkor Wat is unlikely to work well in this research because the recruitment did not include international tour guides such as Korean and Japanese tour guides. International tour guides have not gone through a training course conducted by the Ministry of Tourism. These international guides were expected to be interviewed because they probably have diverse methods in managing interpretation compared to national tour guides. However, adopting the methods of sample selection, none of international tour guides were interviewed.

Secondly, considerations of confidentiality could influence responses given by government officers. Because each organisation's name was allowed to be used in the report, these groups of participants may have been reluctant to provide clear data due to some degree of confidentiality.

Thirdly, an inadequacy of data provided by tour guides resulted from inappropriate time and places due to a difficulty of making appointments as the research was conducted during the high season in Cambodia. The researcher found that the interviews with tour guides were mostly conducted in the night after the tour guides had finished work. Tiredness could be a big concern that made tour guides not want to talk so much. Also, 
assigned places for the interview were at restaurants or hotels where guides' clients stayed. Although both researcher and interviewees felt uncomfortable with such places and times, they still believed that this was the only way to make the interview possible.

Fourthly, on-site observation of tour guides, when they are doing interpretation for their visitors, should be included in data collection methods. The observation may help the researcher understand a way that tour guides manage group interpretation. This probably makes the data more effective. This approach was not undertaken for the current research due to the scope of the research and time.

Fifthly, the language barrier is a problem for the researcher and it may affect interview data and transcription. Because English is a second language for both the researcher and international interviewees, the researcher found it difficult to develop questions in order to obtain insightful answers. Transcription was also very challenging for the researcher. Before transcribing the data, the researcher had to translate data which was interviewed in Khmer into English.

Last but not least, tour programmes set by tour companies were explained to have influence on the interpretation made by tour guides (Ap \& Wong, 2001). However, tour companies being interviewed have not indicated any factors that influenced the interpretation. The researcher decided to stop interviewing participants from the tour companies quickly. Therefore, the framework for the case study illustrated in the literature chapter is different from the one in the findings chapter because of the lack of information from the tour companies. As a result, the data from tour companies was not included in the findings chapter. 


\section{Chapter 5: Findings}

\section{5-1-Introduction}

This findings chapter is divided into five sections. It includes an introduction, a section on responsibilities and interpretation management by organisations, interpretation management by tour guides, relationships and communication of stakeholders, and the summary of findings. The main idea of organising this finding chapter derived from a research objective that tends to explore the management of interpretation at a UNESCO world heritage site from a supply-side perspective. Two main research questions (see chapter 1) have been addressed regarding to the research objective. Having gone through these questions and the conceptual framework (see figure 3), three themes are identified namely, managing interpretation by organisations, managing interpretation by tour guides, and their relationship in managing interpretation.

The first theme, managing interpretation by the organisation, presents the findings in four important sections. The first two sections will illustrate how international and public organisations manage interpretation at Angkor Wat. The following section will highlight both views from international organisations and the public sector about the influence of languages on interpretation and information. The final section of the theme is the future perspectives for improving interpretation at the site.

The second theme mainly focuses on tour guides whose interpretive content is completely different from the above organisations. The theme is classified into subthemes such as, the objective of interpretation, two chronological stages of tour management namely pre-site and on-site interpretation, and general knowledge and the second language use of tour guides.

Last but not least, a comparison between the site managers known as APSARA Authority and other stakeholders is the final theme. To manage interpretation at Angkor Wat, this comparison will indicate some strengths and weaknesses of multiple stakeholders through their communication and decision making.

Quotes in italics in this chapter are attributed to individual interviewees' pseudonyms and this conforms with the ethics addressed in chapter 3 . The name of the organisation 
is used in the quote. To make the findings more precise, a figure and a summary diagram are used to complete the meaning and to sum up what the researcher found.

\section{5-2-Resposibilities and interpretation management by organisations}

This section will examine how international organisations and the public sector manage interpretation at Angkor Wat. In the following discussion, the second language known to be an influential factor in interpretation will be included. The section will also highlight different views on how to improve the management of interpretation at Angkor Wat.

5-2-1-Involvement of NGOs in interpretation and visitor management

Although APSARA National Authority entirely governs Angkor Wat, there are several international projects working at Angkor Wat. Their missions are to conserve and restore Angkor Wat temple. These non-profit organisations include German Apsara Conservation Projects (GACP) funded by Germany, World Monument Fund (WMF) by the US and I.Ge.S. by Italy. Apart from their main task of stone conservation and restoration, they are also involved in interpreting and explaining the importance of their current projects at Angkor Wat to visitors (see section 2-3).

\section{5-2-1-1-The purpose of interpretation and dissemination of information}

The World Monument Fund (WMF) aims to reveal their concern about roof damage at Angkor Wat temple to visitors. The roof of the southeast gallery at Angkor Wat was badly destroyed by rain that could also lead to the destruction of the churning of the milky ocean. Having acknowledged the issue, the government of Cambodia approved the WMF's project to fix the roof. Because the churning of the milky ocean is known as one of the most attractive galleries at Angkor Wat, the WMF just closed only a part of the scene for roof restoration and left the rest open for visitors to go around. While visiting the gallery, tourists were informed of reasons of the closure for restoration as well as international views on preservation of the world heritage. 
We want them to know about the value of a project that needs millions of dollars to fix the roof of the temple. Furthermore, visitors are informed about what we are doing with the temple and how we care about a world heritage site that belongs to the international community because of its human and cultural values. (Naga-WMF)

In addition to the understanding of the roof restoration above, the international organisation always reminded visitors about their safety while walking around working areas. An accident possibly happens to visitors if they take less care of themselves. It would be the worst experience ever for visitors to the site if they were to have an accident. To enhance the quality of visit at the site, the international organisations placed some signs regarding safety. The two following quotes were taken from the interviews with two different international organisations.

It is a working area. Visitors could be harmed accidentally when they are in the place. We always have a sign that says Safety First. (John-GACP)

When we started the restoration project, we had to think of visitor safety and the fact that tourists want to see but they couldn't due to the closure of the site. (Vana-I.Ge.S.)

The international organisations' intention is to make visitors' trips at Angkor Wat more fascinating. They take visitors' safety into account by using signage to explain to visitors about the working areas. The two quotes above also have implications for the responsibilities of international organisations towards their working places although the entire Angkor Wat is under the supervision of APSARA Authority.

\section{5-2-1-2-The role of visitor centres}

A participant from the German Apsara Conservation Project (GACP) stated that the fundamental understanding of visitors about the project calls for the establishment of the current visitor centre. The GACP is funded primarily by the German Foreign Office working for conservation of Apsara, thousands of female figures being carved on Angkor Wat's bas-relief and walls. It was not until 1995 that this international organisation began the project at Angkor Wat to secure the endangered Apsara and bas- 
relief areas caused by erosion. The representative from GACP expressed that the visitor centre has an important role to illustrate activity pictures to visitors as well as explain to them about the urgent need for conservation. The presence of a visitor centre could also help visitors to enjoy the site by reducing their frustration caused by a temporary closure of Angkor Wat. When tourists understand that the closure is for conservation purposes, disturbance will not happen in working areas.

[...] we need to inform people who visit this temple not only about our work but also about the reasons why we set up the GACP project. [...] It is my opinion that we need to inform the visitors that they need to know about the problems and of course we also wanted to explain what we are doing in general and how we are doing it to inform about conservation. Usually the people are annoyed that they cannot take a nice picture because of the scaffolding. You have to explain to them why the scaffolding is necessary and explain to them what is conservation and why it has to be done. So, this is one of the most important items. (John-GACP)

Because working areas are restricted to visitors, the visitor centre is only a suitable place where visitors are informed about a number of working sites at Angkor Wat and ongoing projects. Information about methods being used for restoration and conservation project also exist in the visitor centre. (John-GACP)

Our aim is to inform visitors about the restoration we are doing. We point out the place we are working on and the methods we are using. As you know visitors are not allowed to go in the working areas. If they really want to see how the project is going, they are able to go the centre. (Vana-I.Ge.S.)

It is important that international organisations explain their projects to visitors. When visitors understand about the conservation projects they will not interrupt the working site. In addition, the organisations offer the visitor centres for visitors who wish to know more about the conservation projects. Therefore, individual international organisations have their own visitor centres which interpret the process of conservation. 


\section{5-2-1-3-Funding for the visitor centres}

International organisations operate their visitor centres out of individual funds from Germany and Italy. They do not actually get benefit from an entrance fee that is in the control of APSARA Authority, a representative of the government. A German interviewee from the GACP revealed that the visitor centre gets support from Germany and other institutions.

In general we don't receive money from entrance fees. We have to find the funds by ourselves. Up to now the government of Germany is supporting the projects with others, with our foundations for example, with universities for example. (John-GACP)

\section{5-2-1-4-The responsibility in visitor management and interpretation}

Direction signs being used by international organisations show visitors where they should go without disturbance to the working areas. If there is no sign telling visitors where to go, visitors will walk through the working areas. To avoid this annoyance, visitor flows have been managed by having visitors follow direction signs provided on the sites.

When we close the site for maintenance, we use direction signs which show visitors the entrance, exit and possible ways to go. (Naga-WMF)

All the international organisations agree that the basic information to be informed to visitors is the background of the project. The owner of the project, project partners, period of the project, funding and the purpose of the project are an essential overview for visitors about the project. This kind of information usually has been seen on a wooden board standing close to the working areas.

The board at the working areas displays information about the collaboration between the government of Cambodia and Italy. It also includes an involvement of UNESCO in the project. On top of that, the period of the project, amount of funding, and technical description are written clearly on the board. (VanaI.Ge.S) 
Information about conservation or restoration provided to visitors could be changed regarding the phases of the project being done. It means that the completion of each phase of the project needs to be informed to the public. Thus, visitors are able to identify the condition of the temple before and after restoration. The below quote from the interview with a WMF participant whose mission is to fix the roof of the churning of the milky ocean at Angkor Wat.

The pre-restoration information is about the effects of rainwater from the roof on the carvings and the duration of the restoration. Also, we highlight the urgent need for the restoration. We don't actually have any details about the techniques to repair the roof, but we have pre-restoration and post-restoration pictures so that visitors can make a comparison. (Naga-WMF)

An inclusion of pictures in the information is also a good way to help visitors understand what happens to the restricted areas. Some particular places in Angkor Wat where public access is forbidden due to the ongoing restoration process, conservators copy or take a photo of the original scenes and print it with information. This kind of information enables visitors to learn about the working areas.

Because the visitors could not see the original scene of the Churning of the Ocean of Milk on the wall of Angkor Wat, our organisation duplicated the real scene on a plastic board for visitors to see. (Naga-WMF)

Although visitors are not allowed to go into the working areas, information about the areas and duplication of the places were arranged purposely to contribute the knowledge of the current site to visitors.

\section{5-2-1-5-The expectation of implication of interpretation}

A good collaboration between international organisations and other stakeholders is likely to lead to better interpretation in the future. Tour operators and tour guides have direct contact with visitors. They have a chance to tell visitors about the situation of Angkor Wat and how to protect the temple. An interviewee responded that good communication between conservators and tour guides through a knowledge exchange would result in successful interpretation. Furthermore, he is aware of a need for 
updating the organisation's website to enhance the quality of interpretation. He stated that the improvement of the website could attract more visitors to Angkor Wat.

To improve the information that people provide at the site and to find the possibilities that more visitors are coming. This is also one thing that we should go to the tour operators and talk with them about conservation. Also, we should have a workshop for tour guides. it is important that the visitors are being informed about the problems of the temples as well and the possibilities to protect them. It would be a nice thing but it is a wish. To improve for example it is a long point we have been discussing always when we have our annual meeting to improve the website. But maybe when I am retired, I have a little bit more time. (Naga-WMF)

Successful management of interpretation also refers to a good relationship between the international organisations and site managers. The site managers of the APSARA Authority plan to have a main visitor centre for the Angkor site in the near future. A participant from the GACP found that an improvement of interpretation would not be successful unless all relevant organisations working at Angkor Wat assist site managers. He also revealed that he is happy to help the new visitor centre and provides important documents if the site managers requires them.

Of course if they make a request of our project participation at the main visitor centre we are happy to help to join and we will find the possibility. (JohnGACP)

\section{5-2-2-Public organisations}

Public organisations refer to the government institutions that take part in managing interpretation. In the current study, these institutions are defined as the APSARA Authority and the Ministry of Tourism. APSARA known as the Authority for the protection and management of Angkor takes control of managing the entire Angkor site including Angkor Wat. The Ministry of Tourism, on the other hand, is responsible for the development of tourism in Cambodia. The training and development of tour guides is also under supervision of the Ministry. The Ministry and APSARA are specifically working on developing the capacity of tour guides in Siem Reap region where Angkor 
Wat is situated in. This section will examine the management of interpretation by public sectors. An interview from these two institutes will be included, even though the number of interviewees from the APSARA dominates Ministry of Tourism.

\section{5-2-2-1-Plans for visitor centres and the role of visitor centres}

Since Angkor Wat was inscribed on the World Heritage list and it was promoted as a tourist destination, interpretation was identified as a limitation (see section 2-3-3). A lack of visitor centres is the main reason for this and the government is still considering to have the centres. The whole Angkor archaeological park covers about $400 \mathrm{~km}^{2}$ of the Siem Reap region. It exists a number of ancient temples including Angkor Wat. Participants stressed that neither Angkor park nor Angkor Wat have a main visitor centre. All visitors just go straight to the temples they wish to see and they depend on information provided at the site.

We don't have a visitor centre at Angkor Wat. We plan to have a main welcome centre for the whole Angkor region first. (Mara-APSARA)

An interviewee from APSARA provided the reasons why there is no visitor centre at Angkor Wat. The APSARA Authority was initially established in the 1990s. Conservation was the prior project whereas tourism development came in as a second priority. The growth of visitor number was still limited and the negative impacts were not a big concern. However, APSARA had not neglected tourism development, they thought about having visitor centres for the Angkor park as well as Angkor Wat. According to the participant, a reduction of negative impacts would likely be if there was the visitor centre.

We thought about having the centre since we created APSARA Authority. But, we prioritised the monument conservation because tourism development at that time wasn't as good as today. Now an increase in the number of visitors results in both positive and negative impacts. Thus, we hope that visitor centre would help us in reducing the negative things. (Mara-APSARA) 
Although Angkor Wat does not have a visitor centre, an officer from APSARA acknowledges that the centres play a prominent role to inform visitors about Angkor Wat and increase their awareness of preservation.

The centres contribute knowledge to visitors and help them to understand Khmer civilisation and heritage. People won't naturally start to protect and conserve something unless they know and love it. (Reahu-APSARA)

Another role of the visitor centres is to entertain children accompanied by their parents. Unlike adult visitors, children like doing something fun and they are not really tolerant of a lengthy period of talk. Interpretation should be provided in simple ways that fit with children's behaviour (Mitsche, Reino, Knox, \& Bauernfeind, 2008). The interpretation, in this sense, should be activities that are relevant to the aspects of Angkor Wat temple. Thus, the children and the whole family will appreciate their trip at Angkor Wat.

We need to be aware of visitors who come here with a family. Some children who come along with their family don't really like listening to history. We should find a way that can draw children's attention to the temple. It could be a game where children are asked to find something interesting on the temple, for example animals. Children will simply know and understand the temple as well as enjoy their holiday like mature visitors. Keep in mind that we want all visitors to spend an enjoyable time in our temple. So, I think the Interpretation Centre will play an important role in interpreting our temple. (Mara-APSARA)

Moreover, the visitor centre will be a right place to explain international visitors about Khmer cultures. Angkor Wat is a new tourist destination in Southeast Asia, few visitors, especially those who are non-Asian visitors, have known about its history, culture and architectural structure. These visitors may find themselves hard to understand other cultures. Because of this concern, the APSARA officer perceived that the visitor centre will do a good job in explaining to international visitors about the cultures at the destination.

Tourism in Cambodia is a new destination for western visitors on the one hand and on the other hand, these visitors find it hard to understand our cultures. 
Therefore, the interpretation centre will play a very good job in explaining the aspects of the site. (Dara-APSARA)

Last but not least, 'Do' and 'Don't' signs are used to inform visitors about how they should or should not behave in the temple. At religious and heritage sites like Angkor Wat temple, some activities are strictly forbidden. These signs illustrate in different forms sometimes in a picture or a short phrase in English.

We have different kinds of sign in Angkor Wat temple saying that "No hat, No smoking, No climbing, and so on...”. (Devi-APSARA)

Having many restricted signs in Angkor Wat does not really make visitors feel happy with the visiting site. Visitors may have this kind of perception when they are not allowed to do many things in the temple when they pay for the entrance fee. One of interviewees from APSARA stated that:

Visitors won't be happy with some words like Not doing this Not doing that. Instead, they prefer an explanation why they can't do it”. (Reahu-APSARA)

The interviewees from the APSARA Authority demonstrated their responsibility in the establishment of a main interpretation centre. They acknowledged that the centre will provide an opportunity to visitors to learn about Angkor Wat temple before entering the site. In addition, the participants explained their future management plan which included a consideration of visitors coming with a family. Considering about how to manage the interpretation centre, visitor management will be used as an additional tool to inform visitors and explain to them how to behave at the site. The use of visitor management tools can be done in both the interpretation centre and on-site. Therefore, interpretation management of APSARA will ensure positive visitor experience and less negative impacts at the site.

\section{5-2-2-2-Entrance fee}

In the 1990s, little money was generated from the entrance fee because Angkor Wat temple in Siem Reap is a young tourist destination. Development of the whole site depended heavily on international finance. It was not until the 2000s that the tourism situation improved due to the income from entrance fees. A rise in the number of 
international tourist arrivals to Angkor Wat reflects a change in generating money from entrance fees especially the entrance tickets sold to international visitors. Total ticket sales to Angkor Park including Angkor Wat have soared to 47 percent between 2001 and 2005 (Howse, 2007). Since then, the international donors lessened their funds and APSARA continues developing the site by using revenue from the entrance fees.

International visitors need to pay the entrance fee which depends on the number of days they visit Angkor. By law, Cambodian visitors have been exempted from the fee because the they cannot afford the fee due to their low income (Ang, Thompson, \& Prenowitz, 1998). In contrast international visitors have to pay their entrance fee when they want to see the Angkor Wat temple. Normally, visitors can just pay for a one-day pass to visit the temple. They can get different categories of pass if they tend to visit other temples for more than one day. The entrance fee varies according to the number of days that international tourists want to visit the site (see section 2-2-2).

The entrance fee is believed to be spent on the development of the site including interpretive facilities. An interview conducted with participants from the APSARA office indicated that the money from the entrance fee absolutely has been spent on direction signs, signage, and information boards.

Of course, the expense of improving facilities at Angkor Wat including staff salaries comes from the ticket fee. This is quite different from several years ago when we depended heavily on international donations. (Mara-APSARA)

The participant also reported that it is very expensive to have a visitor centre and now it is not a suitable time to have this centre. That is the reason why the site does not have the visitor centre.

It costs a large amount of money to build a Welcome Centre. There would have to be an interpretation centre, auditorium, a new ticket booth, and so on. (MaraAPSARA)

One of the APSARA officers stated that the income from the entrance fees should be enough for improving visitor information at the site. This participant also suggested that APSARA has to provide much of the information on the site to visitors because Angkor Wat does not have visitor centres. They will not be satisfied with the current service 
when they know that their spending on the entrance fee does not contribute much to the development of information on the site.

There is little information about Angkor Wat. Being a management of APSARA, we have to focus on interpretation because visitors value our heritage. That is why they take a long journey to see our temples. We receive about 20USD from each visitor for a one-day ticket. Therefore Angkor Wat should provide enough information to the visitors to make the fee worthwhile. (Reahu-APSARA)

The income from the entrance fee is transferred directly to the Ministry of Finance (Ang, et al., 1998). APSARA can make a request to the Ministry for the expenses on the operation of the organisation as well as the improvement of the site including interpretive facilities and other infrastructure.

\section{5-2-2-3-Training courses}

An officer from the Ministry of Tourism explained how they organise guide training courses to meet the growth in the number of visitors to Cambodia. Because there are visitors from different countries to Angkor Wat, tour guides have been recruited and trained to meet the demand.

Our plan to have the training course relies on a demand of tour guides in the market. Before coming up with this plan, our Department and Statistic Department discuss how many tour guides we need to train and what languages we require. (Tom-MoT)

Apart from its own role to supply interpretive facilities on site, APSARA collaborates with the Ministry of Tourism to conduct another training course which provides additional knowledge and understanding of the site to tour guides. This training course is arranged after tour guides having gone through the first training course that was organised by the Ministry of Tourism. This course increases the guides' understanding about the rules of visitation at the heritage sites. It ensures the guides have enough capacity to work in the Angkor region. In addition, tour guides are also taught expressions in foreign languages. 
We provided a three-week training course for them on the rules and regulations of the site. The course also included the common language use that is important to communicate with visitors. (Tom-MoT)

5-2-3-The influence of languages on site interpretation and information

Languages being used to inform visitors may affect the understanding of the readers. The native and international languages are generally seen on information and interpretive boards at Angkor Wat. Every information board is written in Khmer and the second language spoken by the international donors is also written on the board. Understanding information provided on the board is very important. Some visitors cannot understand the meaning of the information due to several reasons. Different backgrounds and the level of their education is the first issue. Translation made by second language speakers is another problem. Last but not least, the technical vocabularies being written on the information board are also a concern. To deal with these problems, both international experts and site managers believe that simple language use could help many visitors approach the meaning of information.

We want readers to understand the information. They feel bored if they can't catch the meaning. Even some visitors from English speaking countries don't really understand the technical terms used on the board. We have to think about the translation into other languages and make it easy for readers. So, it would be better if both academic people and high school students can read and get to the meaning of the information provided. I can assume that it is hard to produce information boards. (Naga-WMF)

Too many languages being used on one information board confuses readers and they lose interest more quickly. It is not exactly an issue for developed countries where audio materials function in many languages for international visitors. At Angkor Wat, however, this more advanced technology has not yet been applied. There is no digital information on the site except information provided on the boards. At least four languages were written on one information board. Sometimes, many languages on one board discourages visitors from reading the information. It is difficult for the site management authority to reject the usage of other languages because Angkor Wat 
temple has received donations from these countries. Also, a number of visitors from the countries have grown rapidly because of diplomatic ties. The APSARA officer stated that a further language to be added after Khmer should be English because it is used globally in communication. With just these two languages on a board they could become more attractive to readers.

There are four languages written on the information boards. [...] the ambassador of France asked me to use French as a way to provide information.[...] The highest number of visitors to Cambodia in that time was Japanese. Why hadn't Japanese been used. At the present time, the number of Korean and Chinese visitors replaces Japanese. Why don't we use these two languages too? To meet the French ambassador's request, I decided not to ignore French but I had to add others like Khmer, English, and Japanese. However, I still believe that Khmer and English are the most important. We can't put too many languages on an information board. (Reahu-APSARA)

The two quotes above illustrate the influence of language in the interpretation context. If the language is unclear and complicated, visitors will not be interested to read the information provided. Therefore, site managers need to be aware of language use that can enhance visitors' understanding of the site.

5-2-4-Future perspectives for improving interpretation

Interviewees from international organisations as well as the APSARA Authority presented their future perspectives towards conservation of Angkor Wat temple through interpretation as a means for change. The development of the heritage site results from appreciation of the site and a reduction of negative impacts.

\section{5-2-4-1-A key driver for heritage education}

Interpretation is the essence of heritage education (Knudson, Cable, \& Beck, 1995). Low-educated people may have less understanding of their own cultures. Cambodian people are considered in this group. This group is expected to be educated about their heritage and how to protect it. So, the education through in-depth interpretation could 
lead to appreciation and understanding of the site. A representative from UNESCO believed that education should start with youth who are the next generation for future development of Angkor Wat.

Once you educate youngsters so that they understand the site and why the site needs to be preserved, this can only lead to the better interpretation of the site and the future needs of Angkor [...]. This is a very sensitive and very important point. Education is very important. (Jim-UNESCO)

An officer from the APSARA Authority had a similar opinion to the UNESCO officer. This participant expressed that educating children is a good way to raise children's awareness about heritage including Angkor Wat.

It is not too late to start thinking about children. UNESCO has come up with the same idea that we need to teach children and have them know about heritage. The programme is called the Tool Kids Programme that helps children learn about the usefulness of our ancestors' heritage. (Mara-APSARA)

The participant from APSARA explained how the interpretation will be managed in the future. The Authority organised some programmes that related to heritage education for children. Then, they will communicate with the local schools in order to promote the programmes. Heritage booklets for children such as drawing books, colouring books, and other materials will be distributed to children to enhance their knowledge about heritage (see Appendix E). In general, the books focus on Khmer heritage including Angkor Wat temple. This plan shows that APSARA is finding a way to increase people's awareness of conservation and heritage by starting with the younger generation.

\section{5-2-4-2-The need for interpretation in visitor management}

Interpretation is one of the important tools to achieve successful visitor management. An explanation of the negative impacts on the temple is needed for low educated people. Because some Cambodian visitors have high appreciation of loving their temple, they sometimes attempt to touch the sculptures and other carvings. According to monument experts, touching the sculptures causes erosion because of the sweat from 
visitors' hands. A participant from APSARA stated that interpretation and precise explanations are needed to help people understand about the issues. The APSARA officer acknowledged that site managers need to be more patient especially working with local people.

I agree that it is hard to work with visitors. For example, Khmer visitors see Angkor Wat in different ways. They wish to see this heritage at least once in their life. It means they perceive Angkor Wat as a sacred place. [...] Because of their appreciation of Angkor Wat, Khmer visitors always touch the sculptures to have a sense of being at the place. This behaviour indicates that these visitors have misunderstood about touching sculptures with admiration. So, we have to work hard on this and go on explaining to visitors what they should and should not do at Angkor. (Mara-APSARA)

To improve the interpretation management in the future, APSARA paid attention to domestic visitors who require a longer education time. APSARA stated that being a manager, we need to be patient and work closely with visitors in order to reduce negative behaviour on the site.

\section{5-2-5- Conclusion}

It can be concluded that managing interpretation at Angkor Wat temple presents in different ways due to individual management of international organisations and the APSARA Authority known as the public sector. There is currently no visitor centre at Angkor Park as well as Angkor Wat. The visitors heavily depend on existing information on the site. Although there are visitor centres run by the GACP and the I.Ge.S, these two serve visitors aim to educate visitors about the conservation and restoration projects. The visitors are not able to experience the whole site through these visitor centres.

To manage interpretation at the site, each institution is based on its own finance. The two visitor centres run by the international organisations do not benefit from entrance fees. They have to find the money from somewhere else to support the centres and other visitor facilities. The site management Authority, on the other hand, allocates the money from the entrance fees for the development of signs and information boards. 
Even though the purpose of managing interpretation by the organisations is based on a common idea about preservation and heritage awareness, international organisations seem to have further aims regarding the quality of visit. Through the interpretation, visitors would change their behaviour at the site. They will not feel annoyed about not being able to access working areas where conservation and restoration works are in progress. They will also keep themselves safe from danger that could happen accidentally near the working areas.

Language use for both interpretation and information boards is related to the understanding of visitors and their willingness to read information. Findings from international organisations and APSARA suggested that simple and correct vocabulary leads to the precise understanding of visitors. Too many languages on one information board results in visitors not wanting to read.

Interpretation is expected to be a key component to approach a successful heritage education and visitor management. Interpretation is used as a tool to increase children's awareness of heritage in Cambodia. Ethically, children are convinced to love their own cultures and history in other word about conservation. Another expectation is about a reduction of negative impacts of the temple. Because some visitors to Angkor Wat do not know about acceptable behaviour at the heritage site, interpretation plays an important role in this regard.

\section{5-3-Managing interpretation by tour guides}

This section explores a different level of interpretation management, the management of interpretation at Angkor Wat by tour guides. The tour guides whose nationality is Cambodian are involved directly with visitors by telling them about history and other relevant information at tourist destinations (Ministry of Tourism, 2009). The qualified tour guides are licensed by the Ministry of Tourism. They are divided into two different levels such as regional-level tour guides, working for some particular areas; and national-level tour guides, working for all tourist destinations in Cambodia. After completing the training courses offered by the Ministry of Tourism, some of them are employed by tour companies known as contracted tour guides while others have to look for visitors by themselves and are referred to as freelance tour guides. According to the 
scope of study, managing interpretation by the regional tour guides working in the Angkor region including Angkor Wat will be examined. The study included both contracted and freelance tour guides who are able to speak English, French, Thai, Japanese, Spanish, and Chinese.

\section{5-3-1-Objective of interpretation}

The aim of tour guides' interpretation is to give visitors a sense of places which they would probably visit again.

The purpose of interpretation is to make the visitors feel that they have some connection with the places and want to come back again in the future. I want to make them feel that it was a short stay so they should come back again. (Vicheka-Japanese Speaking TG)

Conservation of the site is one of the objectives of interpretation. One of the tour guides makes a point that through his interpretation visitors could take part in preservation and protection of Angkor Wat temple. In order to get help from visitors, the initial need for the tour guides is their high understanding of the heritage and how to preserve and conserve it.

We need to preserve the world heritage site. As local people of that world heritage site, we are determined to look after our temples. We need to know what to do and what not to do. When we know what to do with the world heritage site, we can help inform our visitors about that so, they can help preserve the temples as well. (Kakada-French speaking TG)

The quotes above express the different objectives of interpretation conducted by tour guides. Their interpretation sounds to attract visitors to come to Angkor Wat temple again. Visitors taking part in heritage preservation with locals is also a wish of tour guides. 


\section{5-3-2-Pre-site interpretation}

It is very crucial to have visitors known about general information of Angkor Wat temple before arriving there. Tour guides are very flexible in managing interpretation. Some informants explained that they prefer to inform visitors about Angkor Wat at the hotel whereas some do this on the way to Angkor Wat. Others provided the information to their clients at the entrance of the temple and they also gave more detail about the history of Angkor Wat at each spot on the site. There are two main reasons that explain why tour guides have to inform visitors before they reach the site. The primary reason is related to a number of visitors in a group that tour guides find themselves hard to manage them at the site. Secondly, visitors are easily interrupted by other groups of visitors on the site. It is really hard for visitors to concentrate on the history of the temple being interpreted by their tour guides.

With big groups of tourists, I often provide information about the site before they get to the site otherwise other groups of visitors will disturb them and I will brief them a little bit more while we arrive at the sculptures... (Makara-Chinese speaking $T G)$

One believed that interpretation made on a bus is more useful than that on site. This is because on the site, visitors easily get annoyed from foot traffic at the temple as well as crowds of visitors.

It is a little difficult but there is nothing we can do. It is congestion. Usually I have already interpreted about $70 \%$ of the site to Japanese tourists on the bus and the remaining $30 \%$ I would do at the site. If we totally interpret the site at the galleries, it might be difficult for our visitors to listen to us because there are other tour guides and tourists over there. To avoid this disturbance, we do that on the bus. (Mesa-Japanese speaking TG)

The travelling time and the distance between the hotels and Angkor Wat are very significant. Normally it takes about 15 minutes by bus from the city to Angkor Wat. Some tour guides managed this time wisely and took this opportunity to give their visitors some useful information like a distance from the hotel to Angkor Wat. They also can explain about culture and regulations at the site, and residents living around the temple. 
Usually, it takes about 15 minutes from the hotel to Angkor Wat temple. Therefore, on the bus I tell them about the population at the temple, dos and don'ts at the temple and I also brief the tourists about the history of Angkor Wat and I will complete it when we reach the destination. (Vicheka-Japanese speaking $T G$ )

The flexibility of tour guides in interpreting the site depends on a number of visitors in the group, congestion at interpretive spots, and the distance between the hotel and Angkor Wat temple.

\section{5-3-3-On-site interpretation}

Throughout the interviews, a majority of tour guides acknowledge that managing interpretation for a large group of visitors is very challenging. Tour guides need to be aware of characteristics of the group. These include the number of visitors in the group, ages of visitors, and children accompanied by their parents. When the tour guides know the background of their group of visitors, they have different tactics to manage interpretation effectively. In this study, the tour guides have experience in walking with various groups.

\section{5-3-3-1-Influentual factors on interpretation}

It is not an easy task to walk such a large group of visitors. The primary issue given by tour guides is about their voice projection. Visitors, sometimes, cannot get what tour guides interpret because the tour guides do not project their voice well. The second problem is the repetition of what is being interpreted. Some visitors in the group do not always follow tour guides and when they are back to the group, they ask the tour guides to interpret history again.

The influence of voice on the interpretation

One of the English-speaking tour guides explained that her voice cannot reach all visitors in a large group. Another point is that she cannot get to know all the visitors in 
the group. She is willing to walk with a small group of visitors rather than a big one because of her voice.

I could not facilitate a large group of tourists because I have a soft voice so not every tourist could hear me. I could use something to help my voice projection but I don't want to. I could remember all the names of my tourists if they come in 10 or 15 and I believe that I might not remember the names of thirty tourists. I'd rather have a small group and give them a quality experience. (MineaEnglish speaking TG)

However, the voice is sometimes interrupted by other tour guides who are talking to their clients.

It is hard to project my voice so that every single visitor can hear me when I walk with a big group. If we interpret loudly, other tour guides will do the same. (Sophea-Spanish speaking TG)

A few tour guides use loud hailers to make their voice louder which is not allowed in the sacred place, Angkor Wat.

Some tour guides use loud hailers while doing their interpretation and this disturbs other people and tour groups. (Pheak-Thai speaking TG)

\section{Repeating interpretation}

Tour guides and visitors sometimes feel annoyed with repetition of the interpretation requested by some visitors in the group. It normally happens when a minority of the group walk out for taking pictures while others listen to the tour guides. When they are back to the group, they ask the tour guides to repeat what they have said.

Some visitors in a group leave the group to take photos and when they come back, they ask us to interpret the same thing that we already did to the whole group. It is difficult. We need to be careful with big groups. (Seiha-French speaking $T G$ )

The repetition of the interpretation is also a case for visitors in their old age. It is normally about hearing problems. They always repeat the same questions to the tour 
guides and they sometimes easily get confused with what the tour guides have told them.

Old tourists often have hearing problems so we need to repeat our interpretation and they often ask the same questions more than once. Some tourists also get confused with our schedule of appointment places and time due to their hearing problems. (Seiha-French speaking TG)

It is also important that tour guides consider controlling their voices at moderate level. A low volume of voice might affect the quality of the interpretation. It means visitors cannot hear what tour guides interpret and sometimes they will not pay attention to the interpretation any more.

\section{5-3-3-2-Effective ways to manage interpretation for the group tours}

Having identified some challenges in interpretation management, some tour guides implicitly suggest remedies for these issues. These include the allocation of time, understanding about visitors' backgrounds, comparative interpretation, attractive games, children's motivation and flexibility of interpretation.

Firstly, the allocation of the time is a good way being used to inform visitors. To avoid the repetition of interpretation, tour guides divided the time during the trip at Angkor Wat into an interpretation time and a time for visitors to enjoy themselves for instance taking photos or having a break. They believed that the clear arrangement of the time enhances the quality of interpretation more effectively and avoids repetition of the same questions to the tour guides.

I understand people have different preferences so I ask them all to spend time listening to my interpretation and walking with me around Angkor Wat before I allow them to spend time on their own looking at the sculptures and taking pictures. I then assign a meeting time and place. (Minea-English speaking TG)

Secondly, the necessity of understanding visitors' background is also important. Tour guides are not able to interpret the Angkor Wat temple to visitors within three or four hours as this huge temple has many relevant things to be told. Knowing visitors' aims 
enables guides to select a suitable topic to fulfil their visitors' needs. Therefore, the talks should be more selective.

Different backgrounds of tourists require different interpretation on the site. For example, tourists who are architects are interested in how the temples were built. (Kakada-French speaking TG)

Thirdly, an analogy between the Angkor Wat story and the real existence need to be taken into account. Some people do not like complicated interpretation about myths and history due to their knowledge and preferences. Children, for instance, prefer a simple talk that is easily understandable. To do so, talent tour guides try to compare between the carving statues on the temple galleries and the existing nature around.

I allow them to be exposed freely to things they like. Later I engage them with the sculptures of animals through showing them real animals that they see in real life, for instance monkeys. They want to see the monkeys on the wall of the temples. (Minea-English speaking TG)

Fourthly, tour guides need to be more creative in order to deal with children. To encourage children taking part in the interpretation, guides played games with them. The topic of the games is related to Angkor Wat where children are able to remember the funny activities. Playing the games is also a way to draw children's attention to the interpretation. As a result, the children will not annoy their parents and others. Consequently, the whole group is able to concentrate on the interpretation.

I tell the fairy tales and ask them to find the characters in the fairy tales on the sculptures. I want kids to be interested in the site because they would not remember things I told them. Second, kids like people to appreciate them, so the games would make them happy after I admired how smart they were to successfully find the characters on the sculptures. This game also helps their parents to have their own time besides just watching their kids all the time. I try to make the family have full concentration on my interpretation and a good time visiting Angkor Wat that's why I created the games for their kids. (MineaEnglish speaking TG)

Lastly, the meaningfulness of interpretation relies on the real situation. It does not really mean tour guides have to talk all the time. Visitors want to do something else during the 
tour or they are annoyed because of their kids. They will not pay attention on the talk. Flexibility and consumer demand are important in these circumstances. Tour guides should stop interpreting and think of a way to make the whole tour happier.

We need to be considerate. If their children are crying, the parents pay attention to their children. We should not interpret the site to them. [...]. They mostly want to see and take pictures of the sculptures. We not only interpret the site to them but also fulfill their needs. (Seiha-French speaking TG)

The success of interpretation management needs to consider some relevant points such as time management for every single interpretive spot, a reduction of the same interpretation themes, interpretive topics, and tour guide techniques in interpretation.

\section{5-3-4-Issues related to tour guides in managing interpretation}

An officer from the Ministry of Tourism and tour guides perceived that two factors have an impact on interpretation. These factors are general knowledge and the language use.

\section{5-3-4-1-General knowledge}

Interpretation at Angkor Wat is not just a talk about the history of the temple but related information is also included. Residents still pay respect at Angkor Wat temple because it is a religious building. It is also known as a living site because of a relationship between local people and the temple. This related information is also important apart from the history of the temple. However, few tour guides have deep understanding about the information to be explained to visitors. A majority of them interpret only the history of Angkor Wat.

Most of the tour guides usually interpret the history of Angkor Wat temple, which is not completed information. Angkor Wat has more than what is being interpreted. Intangible heritage should be added in the interpretation of Angkor Wat as we know that without peoples' belief the temples could not be constructed. Furthermore, local residents still respect the temple as a holy 
place. This relationship between the people and the temple would be worthwhile to inform visitors. (Kakada-French speaking TG)

Tour guides acknowledge that their big concern is about their general knowledge. They also perceive that a lack of general information leads to difficulties in interpretation when conducting a tour.

I know that my general knowledge is not good yet. It's sometimes an obstacle for interpretation of the temple. Acknowledging this drawback, I'm trying to learn and do more research. (Kakada-French speaking $T G$ )

An officer from Ministry of Tourism agrees with the tour guides that there is a limitation of knowledge among tour guides. He insists that students holding a high school certificate are eligible to apply for tour guide training. So, they probably do not know much apart from what they have been trained to do in a short training course.

Another factor is about their knowledge. Because our recruitment policy is looking for students whose academic level is from high school. (Tom-MoT)

Guides and the officer from Ministry of Tourism revealed that general knowledge is very important to enhance the quality of interpretation.

\section{5-3-4-2-Language issues}

The effective interpretation depends on language proficiency. Tour guides working in the Angkor region where Angkor Wat is located start to learn language based on the tourist market. They learn the language in a very short time in order to meet the market demand. Vocabulary and pronunciation are not enough for efficient communication with visitors within this short period of study. Sometimes tour guides cannot give a clear explanation or answer which they are communicating in a second language.

My French language is limited [...] I sometimes learn new words from my tourists and use them later for the next group. Because I understand that my French is not perfect, I normally ask my tourists if they understand my interpretation. (Seiha-French speaking TG) 
We are Khmer, and Spanish is not our native language. Sometimes I don't understand their questions but I honestly inform tourists that I don't understand. I keep learning the language although I am working now. (Thanu-Spanish Speaking TG)

Conversely, one of the tour guides stated that having a good level of language proficiency is not what a tour company is looking for. This Japanese-speaking guide compared a good language proficient tour guide and a guide whose language is not good. Although some tour guides are limited in their spoken language, they are able to make fun for visitors. A way how to entertain visitors is more important than language proficiency. This is one of the criteria to select tour guides to work for tour companies.

I think language is not everything. [...] They might not know how to entertain the visitors. If we know how to manage visitors, the company will provide us more groups. (Mesa-Japanese speaking TG)

\section{5-3-5-Conclusion}

To sum up, managing interpretation by tour guides completely differs from managing by organisations at Angkor Wat due to several reasons. Firstly, the guides have direct communication with visitors while the organisations, site managers in particular, do not. Working with visitors is very challenging especially a group with a combination of children and mature visitors because of their different preferences. The tour guides do not only focus on the interpretation but also visitor demand. The visitor demand and interpretation are two different things, but the two are interrelated. If the visitors are not satisfied with something that happened during the tour, visitors will not concentrate on interpretation. Visitors turn to be happy when tour guides provide a meaningful interpretation and fulfil visitors' needs.

Secondly, time management is very crucial for the trip to Angkor Wat temple. Generally, a visit to Angkor Wat is one of the programme tours. If the tour guide cannot allocate the time wisely, their interpretation will not cover all necessary information of Angkor Wat within a limited time. Well-organised guides divide what is to be interpreted into stages, pre-site and on- site interpretation. 
Lastly, the most challenging aspect for the tour guides is a response to visitors. Unlike managing interpretation by organisations, the tour guides have to answer to visitors' questions. Interpreters need to know a lot of things related to Angkor Wat. Otherwise visitors will miss important information. This may result in unsuccessful interpretation. Poor language proficiency of tour guides is found to be the main issue influencing interpretation. It is because visitors sometimes do not understand what is being explained by the tour guides.

\section{5-4-Relationships and communication of stakeholders in managing interpretation}

This part of the finding chapter is mainly discussing a way that stakeholders communicate with each other. Some conflicts that resulted from multiple stakeholders will also be identified. Furthermore, their involvement in decision-making for development of interpretation will be examined.

\section{5-4-1-Good relationship}

\section{5-4-1-1-Site managers and the international community}

Even though APSARA is responsible for the management of Angkor Wat, they still need international cooperation and assistance from UNESCO in particular. They have an annual international meeting that discusses and decides on something to be improved on the site. This collaboration can be seen from the example of the interpretation centre project.

[...] an approval from UNESCO is needed if we want to construct an interpretation centre. Since our temple was inscribed on a World Heritage List, we have to follow the UNESCO guidelines. Not only interpretation project but other projects have to go through the international meeting, ICC. (MaraAPSARA)

All information boards at Angkor Wat temple are supposed to be the same in format as well as colour because Angkor Wat is a world heritage site. International organisations 
and site managers, the APSARA Authority always reach an agreement of having standard signage and information boards at the site. Thus, this format and colour interpret Angkor Wat as a world heritage site which visitors should be aware of and respect the site.

Because APSARA has a big role in managing the whole site, all requirements need to be discussed with them. For instance, the format of information boards and language are used on the information board. (Devi-APSARA)

The officers from APSARA revealed that they always respect their international partner especially UNESCO in order to develop on-site interpretation.

\section{5-4-1-2-Site managers (APSARA) and Ministry of Tourism}

APSARA working closely with the Ministry of Tourism developing the understanding of regional tour guides in Siem Reap, where Angkor Wat is. These tour guides were trained and licensed by the Ministry but they need to participate more in a seminar conducted by APSARA. An officer from the Ministry of Tourism claimed that the seminar aims to improve the interpretation skills of tour guides.

Tour guides need to join a seminar that is prepared by APSARA and Ministry of Tourism. [...] we are working with APSARA Authority on how to upgrade the level of tour guides at the site. (Tom-MoT)

An interviewee from APSARA believes that the seminar provides further knowledge to tour guides. The tour guides may learn new information presented in the seminar. This information includes archaeological discovery and anthropological research at Angkor Wat. Through this seminar, tour guides are expected to gain new knowledge adding to their current interpretation.

Usually we help Ministry of Tourism by sharing results from our research in the seminar. Hopefully, tour guides will find these results useful for their interpretation. (Dara-APSARA)

The two participants from Ministry of Tourism and APSARA accepted that they have good collaboration in organising tour guide training courses. 
5-4-2-A conflict between site managers and tour guides

It was not until 2011 that site managers, the APSARA Authority got an audio-guide investment project at Angkor Wat. This new project has two conflicts. The project worries tour guides about their future jobs. The involvement of tour guides in this project is also another issue.

The objective of the investment is to improve the interpretive infrastructure and the quality of interpretation at the site. There are two kinds of tools being introduced to visitors. One is audio guides which independent visitors, without tour guide, can listen to the history of Angkor Wat. Another one is voice transmission tools that tour guides use to talk to their visitors in a group and individual visitor in the group can hear their guides voice through earphones. The voice transmission tool can reduce some voice in Angkor Wat temple. In a contract signed by a private company and APSARA, it is indicated that it is the visitors' choice to rent the tools or not. Tour guides, however, are not satisfied with this new investment because they are concerned about their future employment.

If visitors use audio-guides, there is only one job for the one who designs the tool. I think we will lose our jobs because of these new audio-guides. (SopheaJapanese speaking $T G)$

An officer from the Ministry of Tourism also supports tour guides' opinions. He furthers that the investment should not threaten tour guides careers because they need money.

I think it is not good for having these facilities. Tour guides aren't satisfied with this project. We are developing country and our government policy is to alleviate poverty. It is not a right time to have such audio-guides because many tour guides still need jobs. (Tom-MoT)

However, according to an interviewee from APSARA, the aim of introducing the interpretive tools at Angkor Wat is to enhance the quality of interpretation. Because many tour guides try to project their voice for their own visitors in the groups, some visitors cannot hear what is being interpreted. In this case, a voice-transmission tool can help visitors to concentrate on their own tour guides and also reduce the noise in the temple. 
The first purpose is to reduce noise and increase the quality of visit in the temple. Tour guides should use a voice transmission tool and each visitor can hear the voice from their own earphone. Secondly, we plan to have a script written by academic historians and then we will record their voice in the audio guides. (Mara-APSARA)

Again, the APSARA officer expresses that diversification of interpretation is very significant to match visitor demand. So, visitors have alternative ways to enjoy a variety of service provided at Angkor Wat. The officer suggests that tour guides should know visitor needs and preference.

[...] this kind of audio guide provides visitors an option if they don't need tour guides.[...]It seems to me that the tour guides don't understand the market. Well, some visitors like reading guidebooks rather than walking with tour guides. These independent visitors maybe choose an audio guide as it is more convenient and cheaper. (Mara-APSARA)

A tour guide criticises APSARA about an involvement in decision making of introducing the audio guide project at Angkor Wat. He reveals that the decision made by the Authority is too fast and it affects the current price being sold in a package tour. The interviewee explains that when tour guides and visitors in a group are required to rent voice transmission tools, an additional price needs to be included in the package. He urges APSARA to inform tour guides as well as tour companies at least a couple of months before implementing the project. With this suggested time, tour guides should be invited to the meeting before deciding on the existence of audio guides in Angkor Wat.

We were not invited into the discussion whether the new project is good or bad. We were asked to implement the project after they reach the final decision. (Tola-English speaking TG)

[...]I think that the information should be released in 2 months, so that we are able to get things sorted. Very often the Authority announces information at the last minute. (Menea-English speaking TG) 


\section{5-4-3-Summary}

The findings highlight good and unusual communication among the stakeholders. Both international organisations and Ministry of Tourism have a tendency to develop interpretation at Angkor Wat because of a need for quality visitation and preservation of the site. The most obvious achievement of the existence of information boards and training courses for tour guides, has clearly demonstrated that the above institutions work closely with site managers from APSARA. To improve interpretative facilities at Angkor Wat, however, some challenges, resulting from lapses in communication between APSARA and tour guides, have been found. The primary issue comes from the impact of the development of interpretive facilities on guide occupations and the second problem is about a lack of democracy in decision-making.

\section{5-5-Conclusion of interpretation management by multiple stakeholders}

This section concludes the finding of managing interpretation by multiple stakeholders. The conclusion is presented in the figure 4 listed from the international organisations to the private sector. Each institution provides its strategy toward achievement of managing interpretation at Angkor Wat. However, some drawbacks have been found from the interviews among the stakeholders. Management of interpretation varies according to the objective and the responsibility of the relevant stakeholders. Interpretation at Angkor Wat is also influenced by communication between multiple stakeholders.

Again, international organisations have been discussed earlier in the previous section. In the green box A, there are UNESCO and the other three NGOs namely, GACP, WMF, and I.Ge.S who focus on conservation and restoration projects at Angkor Wat. Two of the three projects have their own visitor centres. These centres specifically present only selective information about the project and they attract visitors who are interested in conservation areas. The visitor centres are run on donations supplied by their respective countries. Furthermore, interpretive signs and boards have been arranged to enhance the quality of visits as well as for visitor safety.

Box $\mathrm{B}$ illustrates the role of APSARA in managing onsite interpretation and a good relationship between APSARA and international stakeholders is illustrated in box A. 
APSARA is the only public sector that controls Angkor Wat temple. Inside box B, there are two small boxes that show different levels of management of interpretation at Angkor Wat. Policy and decision makers who are involved in developing the site are from management groups. These groups work horizontally and vertically with site managers and international organisations to achieve managing interpretation on site. Because Angkor Wat was inscribed in a world heritage list, all development projects have to discuss with UNESCO including a project for the construction of a welcome centre. Also, the management group has a good relationship with NGOs and they always meet an agreement on a standard of interpretive facilities at the site. Management groups provide capacity building for site managers to develop interpretation schemes on the site. These site managers play an important role in increasing visitor experiences through interpretive facilities and information provided on the site because Angkor Wat does not have visitor centres. The facilities include direction signs, information boards, and signage.

Freelance and contracted tour guides in box E represent the private sector. These tour guides have gone through an interpretive training course provided by the Ministry of Tourism. The guides are under supervision of the Ministry who license guides to work on the site. In addition, a pink arrow connected between boxes $\mathrm{B}$ and $\mathrm{C}$ shows a good relationship between APSARA and the Ministry to strengthen tour guide capacity. APSARA understands that tour guides are key interpreters enhancing the quality of interpretation of the site. Thus, additional training courses for guides are found as good ways to improve their interpretation. Unlike managing interpretation by organisations, tour guides need to be talented and flexible. Managing interpretation by tour guides is very challenging because they have to understand visitor demand and how to select appropriate interpretation for visitors. A red arrow links between B and E illustrating some conflicts between APSARA and tour guides. Misunderstandings of the two parties about the audio-guide project and a lack of participation in the decision making process are a clear example of the conflicts. Site managers' tendency to improve interpretive facilities makes tour guides unhappy because they are worried about redundancy due to the replacement of the audio guides. Furthermore, there is no involvement of tour guides in decision making about having audio guide projects at Angkor Wat. A lack of democracy in decision making causes great tension among tour guides. 
Figure 4: A summary of findings
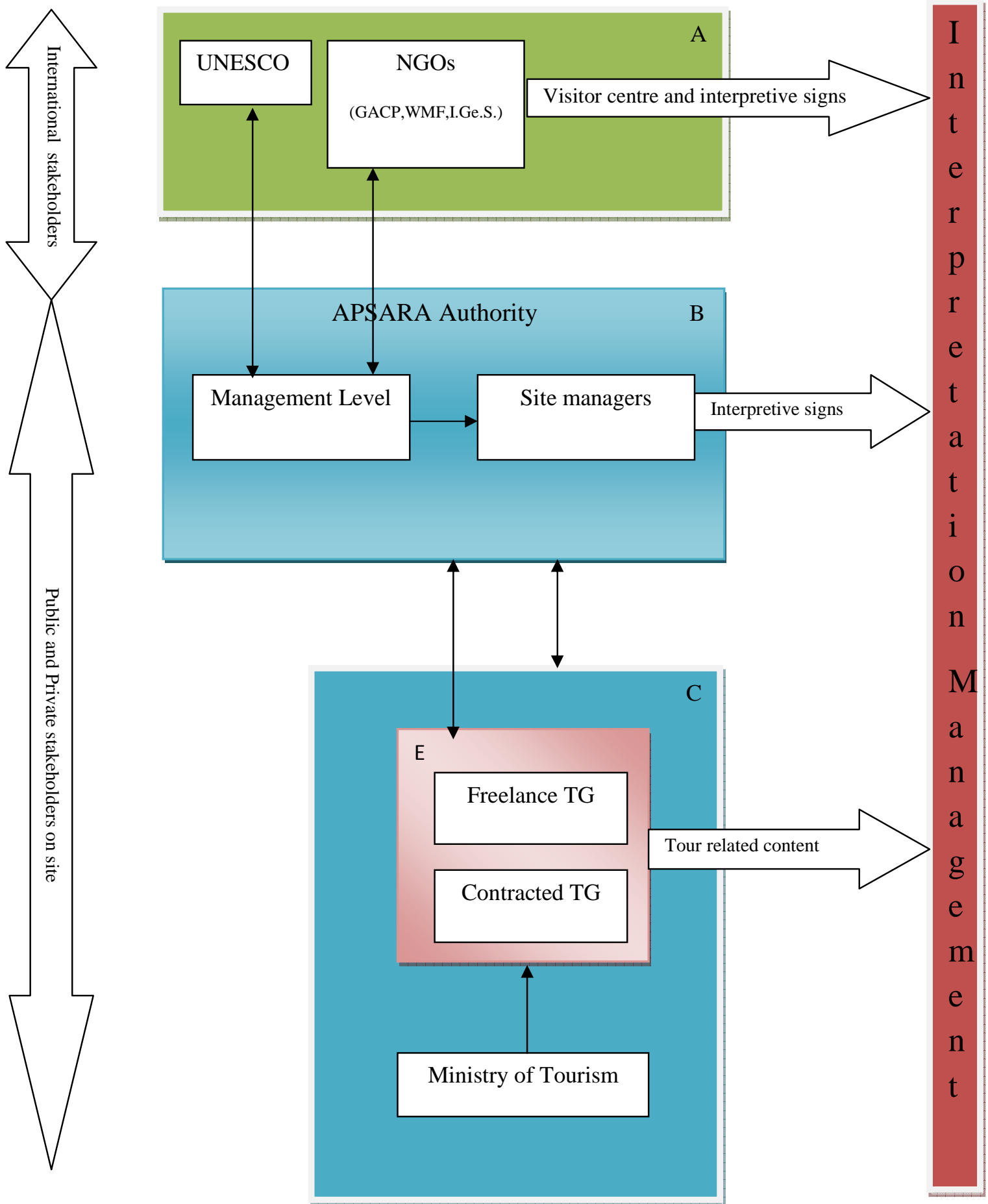


\section{Chapter 6: Discussion}

\section{6-1-Introduction}

The aim of this chapter is to address the two research questions presented in chapter 1. In this discussion chapter, the findings in chapter 5 will be connected to the literature presented in chapter 3. Some themes that emerged in the findings chapter have been discussed in the broader tourism literature, such as interpretation for managing cultural resources (Garrod \& Fyall, 2000; Tilden, 1957; Timothy, 2007), interpretation and sustainable tourism development (Leask, 2010; Moscardo, 1998), the tour guides' interpretation (Ap \& Wong, 2001; Io \& Hallo, 2011; Yu, et al., 2004), and stakeholders in managing interpretation (Aas, et al., 2005). Having gone through the discussion chapter, practical management implications, recommendations, suggestions, and further research will be presented in chapter 7 .

The organisation of this chapter is divided into three main sections. The first section will illustrate the key stakeholders taking part in managing interpretation at Angkor Wat temple. The stakeholders presented in this discussion chapter mostly have a responsibility to improve the management of interpretation at the temple (see figure 4). Managing interpretation by organisations including the APSARA and NGOs is distinguished from managing interpretation by tour guides. The differences between the organisations and the tour guides have been found through their particular roles and objectives in managing interpretation. Secondly, the stakeholders' objectives in the interpretation will be identified. Finally, a comparison between the management of interpretation by organisations and tour guides will be discussed.

\section{6-2-Stakeholders in managing interpretation at Angkor Wat}

This section will illustrate how different stakeholders manage interpretation at Angkor Wat temple. Not all stakeholders presented in the findings are discussed here because some of them have less actual attachment to the management of interpretation. For instance, the tour companies being interviewed do not provide any evidence related to interpretation and they have no influence on interpretation made by tour guides (see section 3-5-2). Similarly, the perspectives from UNESCO have not been included in this 
chapter because the site is under supervision of APSARA Authority. UNESCO would consider the interpretation project if APSARA proposes it.

6-2-1-Managing interpretation by organisations

\section{6-2-1-1-Managing visitor centres (APSARA and NGOs)}

It costs a lot of money to construct a visitor centre. The findings indicate that APSARA needs a large amount of money to build a visitor centre. An officer from APSARA reported that a majority of revenue from the entrance fee was spent on conservation and maintenance project and the rest was used to improve tourist facilities in Angkor Wat as well as human resource management. The officer believed that the revenue was allocated for primary purposes rather than for the construction of a visitor centre. Leask et al. (2002) stated that heritage sites necessarily need financial support for preserving and restoring ancient buildings. They furthered the discussion by saying that conservation is the main objective for heritage site management (Leask, et al., 2002). Therefore, the expense on a visitor centre is very challenging for APSARA when this organisation prioritises conservation projects.

Entrance fee policy set by the government and new tourist destinations may influence the expense on the visitor centre. The government provides their citizens free entrance to Angkor Wat because of the poverty in the country (Ang, et al., 1998). Thus, the revenue from the entrance fee is from international visitors. However, international tourism receipts at Angkor Wat are still low because Cambodia is a new tourist destination. These two factors could be a case that APSARA on behalf of the government cannot afford the construction of a visitor centre.

There are two visitor centres run by the NGOs. These centres purposely serve visitors who are interested in conservation and restoration work. One visitor centre belongs to the GACP project which is responsible for preserving carvings and bas-relief at Angkor Wat. Another centre is under supervision of the I.Ge.S project, restoring Kada Ben of Angkor Wat. The findings revealed that the owners of these two visitor centres used their government budget and international donations to build the centres. These international organisations use the centre as places to explain to visitors about the projects and the reasons why Angkor Wat needs conservation. Inside the centres, there 
is an exhibition of photos showing the process of conservation. Hence, apart from information about conservation, the centres are not appropriate places for visitors to get general information about the site.

\section{6-2-1-2-Training courses}

Tour guides need training courses to develop professional tour guiding. Interviews with tour guides revealed that training courses play an important role in improving their existing knowledge. Normally the basic training courses are arranged for new entrants and the courses are officially organised by the Ministry of Tourism due to a market demand for tour guides. In addition to the basic courses, there are on-going training courses which are organised by the Ministry and site managers, a representative from APSARA. Tour guides probably know that a basic training course could not help them much in interpretation of the site so that they need more training courses. These additional courses are expected to get in-depth understanding on how to manage the tour guiding and entertain visitors. Ap and Wong (2001) also found that additional training courses would benefit both tour guides and visitors. They furthered the discussion by saying that a first training course provided too general information of the site which visitors could access this information through different forms of media without tour guides. However, additional training courses may provide tour guides with updated information from the new discoveries made at the historical site. The additional training courses can upgrade the status of tour guides which move them from the simple guides who received low paid to professional guides or interpreters (Ap \& Wong, 2001). This is another way to motivate tour guides in their careers as well as to strengthen their capacity. Another implication for visitors is that they would appreciate their experiences at the site because of the highly qualified tour guides.

The benefits of the training course are considered by the site managers. Site managers politically tend to engage tour guides in a seminar or training course in order to convey information about conservation and protection to tour guides and to visitors. Some scholars believed that professional interpreters or tour guides who have gone through several training courses have a strong potential to convince and educate visitors (Ap \& Wong, 2001; Moscardo, 1998) for the sake of sustainable development of the site (Christie \& Mason, 2003). For the case of Angkor Wat temple, APSARA sends their 
experts and site managers to facilitate a training course which is organised by the Ministry of Tourism. Lectures given by the experts are mostly related to development and conservation of Angkor Wat temple. This action clearly shows that site managers or experts take the opportunity to explain to the tour guides about conservation work. Hence, it is important for site managers or other relevant institutions to consider about training courses as a means to develop tour guides' capacity and move them from a basic level of tour guiding to management level.

Foreign language competence is another important subject in the training course curriculum. In some developed countries, tour guides are recruited based on their language qualification (Christie \& Mason, 2003). However, Cambodian tour guides whose language is at a foundation level are recruited because of the market demand. Their language barrier sometimes has an influence on knowledge being shared to the visitors. These visitors expect to gain more information from the tour guides through communication. The visitors may not be happy with tour guides because of difficulties in communication between them. It is clear that guide training courses in Cambodia normally include language sessions which focus on language used for communicating with visitors. This finding is in line with the previous study by Ap and Wong (2001). The researchers believed that language is a means to enhance the quality of interpretation. This means that visitors are able to understand the tour guides' explanation of the visiting sites. Therefore, guide training courses should contain both interpretive skills as well as language use.

\section{6-2-2-Managing interpretation by tour guides}

Understanding the visitors' demand and the knowledge of the site are the key components of managing interpretation content by tour guides. Contributing the knowledge of the site to visitors is an important role of tour guides (Christie \& Mason, 2003). The transformation of the knowledge may be made in different forms due to the level of visitors' education. Understanding the background of visitors may help tour guides know what kind of interpretation they should provide. To increase visitors' experiences and enhance the quality of visit, interpretation provided by tour guides are flexible according to their visitors' demands. In addition, lack of knowledge and a language barrier indicated in the findings are the main issues in managing interpretation. 


\section{6-2-2-1-Managing interpretation for the groups of visitors}

Good interpretation management requires tour guides to understand visitors' preferences about the site and use the right technique to interpret the site. According to the interviews with tour guides, visitors in the group do not totally follow the tour guides. Because individual visitors have different preferences, they sometimes find things that interest them in Angkor Wat without concentrating on the presentation. Tour guides should also reflect on their ways in interpreting the site in addition to the observation of visitors' attitudes. Sometimes the contexts interpreted by the guides do not interest visitors and make visitors feel bored and confused. Tour guides should also consider techniques that can draw visitors' attention to the interpretation. Tilden (1957) stated that using a good technique to interpret the site does not only attract visitors' attention but also helps them to understand the interpreted content more easily, for example the use of pictures or maps during the interpretation.

A key contribution of this research is providing insights into how tour guides manage interpretation and presentation for the group of visitors at Angkor Wat. McKercher and du Cros (2002) stated that visitors to cultural heritage sites do not require the same information. The visitors may or may not be interested in the presentation and interpretation made by the tour guides. Some visitors want to spend a longer time on looking at carvings and sculptures whereas others prefer taking photos (see section 5-33-2). The visitors' preferences are very challenging for guides in the management of interpretation. Furthermore, the findings are consistent with the results of a previous study (Io \& Hallo, 2011). Tour guides do not spend a long time on presentation or interpretation because a long presentation can make visitors feel bored. That is the reason why the tour guides at Angkor Wat do not present the entire information of the temple at the site. Alternatively, they arrange some parts of interpretation on the bus and they will finalise it once they arrive at the site (see section 5-3-2). Thus, tour guides can avoid long interpretation which leaves visitors free to walk around the site and take pictures as they wish. Observing the site could give a compliment for interpretation made by the tour guides and would increase visitor understanding of the site.

In addition to Io and Hallo (2011) and McKercher and du Cros (2002), the current findings confirmed that illustrations and explanation technique are part of the management tools of interpretation. The findings specifically focused on children 
travelling with their family. Managing interpretation for these groups of visitors is very flexible. Tour guides need to know the nature of children such as their needs and interests. The tour guides reported that children do not really like listening to the history. They would be interested in a discussion about animals and flowers. The tour guides attempt to connect what interests the children to the presentation of Angkor Wat (see section 5-3-3-2). Visuals are found as attractive tools to explain the carvings and sculptures on the temple walls. The current research seems to inform the sixth principle of interpretation which is studied by Tilden (1957). Showing pictures and pointing out the nearby environment to explain to visitors are kinds of education through interpretation (Tilden, 1957).

\section{6-2-2-2-Language barriers and limited knowledge of sites}

Misinterpretation and misunderstanding of the sites are caused by language barriers and a lack of knowledge in cultural understanding. A language barrier is known as the major issue in communication and presentation of the site (Yu, et al., 2004). Since tourism in Cambodia has opened to the world, thousands of tourists from different countries visit Angkor Wat. A growth in visitors to the destination requires more tour guides. To meet the market demand, the Ministry of Tourism organises a training course for new local guides whose language proficiency is not good enough for communication with visitors. The findings showed that tour guides sometimes do not understand the visitors' questions because of their language problems. To give the visitors answers, tour guides ask them to repeat the questions again (see section 5-3-4-2). Although tour guides attempt to answer the questions from visitors, sometimes uncertain answers will be given. This uncertainty may lead to misinterpretation and misunderstanding about the site (Smith, 2001; Tilden, 1957).

In addition to the language barriers, the general knowledge of tour guides about the site is also discussed extensively in the literature (Io \& Hallo, 2011; Yu, et al., 2004). The tour guides in the interviews acknowledged that their ability to present the site is limited. According to officers from APSARA and the Ministry of Tourism, interpretation should include additional information about culture and people with which the site is associated. Their opinions support the study of Kundson et al (1995) cited in Moscardo (1998). Only presenting the history sometimes makes visitors feel 
bored and they will not be interested in the interpretation anymore. A lack of knowledge of tour guides about the entire site can discourage visitors whose expectation is to gain further interpretation of the site rather than history written in guide books ( $\mathrm{Yu}$, et al., 2004). In addition, the visitors would appreciate the tour guides who have a wide general knowledge about the site. So that, visitors are able to question the guides and build communication with the tour guides. This is what Tilden (1957) called provocation which is the aim of interpretation. The present study shows that training courses are very important to develop the capacity of tour guides and these courses will enhance the quality of interpretation at Angkor Wat.

\section{6-3-Objectives in managing interpretation}

To address the second research question, this section discusses the aims of organisations and tour guides in managing interpretation at Angkor Wat. This section illustrates a variety of objectives which are indicated by multiple stakeholders. Again, not every single stakeholder has been discussed. Some stakeholders do not have explicit objectives for the management of interpretation because they have no knowledge of interpretation and its benefits. For example, tour companies concentrate on taking care their customers and improving their service. Therefore, objectives in managing interpretation from NGOs, UNESCO, APSARA Authority and tour guides will be discussed. It would be better for the author dividing the section into two main categories, the objective of managing the interpretation by organisations and tour guides.

\section{6-3-1-Organisations}

\section{6-3-1-2-Understanding about conservation}

Conservation and preservation of cultural heritage are the prime objectives that site managers encourage visitors to understand. Cultural conservationists and site managers are more concerned about visitors who unintentionally cause damage to the sites (Shackley, 1998; Timothy, 2007). Moscardo (1996) stated that visitors' appreciation of the cultural resources could reduce negative impacts on the sites. These mindful visitors 
learn about the values of the site through tour guides as well as interpretive facilities provided at the site (Moscardo, 1996). The current finding is in line with the previous studies. The NGOs working for restoration and maintenance of Angkor Wat temple attempt to inform visitors about the current situation of the temple that needs immediate rescue (see table 4). Information boards and signs are used to explain to tourists about the conservation project and ask for their cooperation.

Table 4: Objectives in managing interpretation by organisations

\begin{tabular}{|c|l|}
\hline $\begin{array}{c}\text { Interpretation } \\
\text { management by } \\
\text { organisations }\end{array}$ & \multicolumn{1}{c|}{ Objectives } \\
\hline NGOs & $\begin{array}{l}\text { Conservation and restoration of Angkor Wat temple } \\
\text { Visitor safety }\end{array}$ \\
\hline UNESCO & Heritage education \\
\hline APSARA Authority & Heritage education \\
\hline
\end{tabular}

(Source: Author, 2012)

Interpretation is known as an education form to increase visitors' awareness of conservation (Garrod \& Fyall, 2000; Millar, 1989; Tilden, 1957). If high levels of accessibility to the site can lead to cultural assets becoming damaged, conservation requirements are needed in a heritage management plan. Garrod and Fyall (2000) explained that education plays an important role in achieving accessibility in this regard. The understanding of visitors about the significance of the site and why it is conserved are very essential for managing the site. Interpretive techniques such as onsite interpretation, media and publications are an effective mechanism for preventing cultural assets from the negative impacts. The interviews with a representative from UNESCO and APSARA indicated that educational interpretation of the heritage is needed for the site management (see table 4). These two experts acknowledged that Angkor Wat temple is being damaged due to a growth in tourist arrivals. They believed that sustainability of the site depends heavily on education forms such as educating visitors, local people and children (see section 5-2-4-1). It is likely that the results of the current study support the literature in some respects. Cambodia is a developing country where heritage education is required because local people seem to have less knowledge 
about heritage conservation and tourism. The education for children who are the new generation for sustainable development of the site should not be neglected. Providing adequate interpretive facilities at Angkor Wat temple educate visitors and increase their awareness of the site. Having gone through this discussion, this present study contributes to the development of interpretation at Angkor Wat temple and helps site managers to rethink the role of interpretation in educating people.

\section{6-3-1-3-Safety}

Not much literature has been discussed about the safety of visitors as a result of interpretation. Interpretation is known as a tool for managing natural and cultural resources at visitor attractions (Kuo, 2002; Shackley, 1998; Timothy, 2007). To be able to manage the resources, Timothy (2007) stated that visitors need further understanding about the meanings of conservation and restoration. Interpretation plays an important role in this regard (see section 5-5-2). Increasing visitors' awareness of conservation will minimise negative impacts caused by thousands of visitors (Shackley, 1998). It is likely that interpretation has only been used for managing the resources. In addition to the literature, findings suggested that when visitors understand about conservation, they will be careful during their trip. According to interviews with international organisations, visitors to Angkor Wat stood far away from working areas where experts were restoring stones. Having kept themselves far away from the restricted areas, visitors will not disturb the working areas and they will not be injured in some cases. The interviewees explained that a concern for visitor safety is one of the international organisations' aims (see table 4). To avoid visitors encountering a risky situation, interpretive facilities such as information boards and signage were provided around the working areas. Therefore, interpretation is used as a means to increase visitor safety at Angkor Wat.

Few studies have focused on visitor safety because of the research sites. Some heritage sites are opened entirely to the public whereas others allow visitors to see some parts of heritage attractions due to maintenance reasons (Shackley, 1998). For researchers studied at the sites without any maintenance, they probably did not concentrate much on benefits of interpretation for visitor safety. An exception to this is a study by Moscardo (1998) whose research included visitor safety in sustainable tourism development. 
Therefore, the findings give a new light for future research conducted at world heritage sites.

\section{6-3-1-4-Interpretive Signage}

Interpretive signage has been used to increase the sustainability of visitation. Giving visitors knowledge about the sites is very important. Moscardo (1998) explained that information can enhance visitor experiences and reduce negative impacts. Providing information signs informs visitors what the sites can offer and what are the possibilities that visitors can and cannot enjoy (Moscardo, 1998). The author found that the information gives visitors options so that they can make best choices about what they do and where they go. The current study indicated that there are different signs being used at Angkor Wat such as direction signs, 'Do' and 'Don't' signs, and information boards. Direction signs are used to direct visitors to the entrances and exits.

Interpretive signage is very useful for Angkor Wat temples. An interviewee from APSARA revealed that Angkor Wat is a new tourist destination for international visitors in terms of cultural understanding. Some activities, behaviour, and clothes are restricted. The participant stated that site managers expect visitors to know about the restriction guidelines. However, the provision of interpretive facilities at the sites is still needed. Shackley (1998) and Moscardo (1998) made a point that interpretive signage plays an important role in explaining the impacts of other cultures and offensive behaviour for the destination culture. The use of signage is a part of visitor management but it was also discussed in the context of interpretation that explains the reasons why visitors need to respect the site (Moscardo, 1998). So that visitors will learn about the new culture and come to respect the site accordingly. Therefore, the use of interpretive signage can be seen in the context of visitor management and interpretation management.

Information signs are very crucial for independent travellers. Poon (1993) estimated that the number of independent travellers will increase compared to the traditional package tours. The independent travellers are very flexible and need more education (Poon, 1993). These kinds of visitors have a high expectation about the provision of information on the site. To match this future market, the site managers working at 
Angkor Wat should study what kinds of information and signs to be provided for independent visitors as well as other visitors in general. Considering Poon's perspectives of independent tourists, the improvement of interpretive structure is very important for the case of Angkor Wat because the current interpretation of the site heavily depends on the tour guides.

Little attention has been paid to drawbacks of signs. It is not necessary to have many restricted signs at the heritage site. These kinds of signs may impact visitors' perceptions when they are at the visiting site. An officer from APSARA explained that visitors are not illegal people whose activities are always forbidden. The expectation of visitors is to gain experiences from the sites through explanation and interpretation (Hall \& McArthur, 1993; Moscardo \& Ballantyne, 2008). Additionally, the officer suggested that it would be better if site managers could give reasons or explanations instead of providing restrictions at the site. Hence, this suggestion should be taken into account for practical management of interpretation as well as for future study.

\section{6-3-2-Tour guides}

Tour guides aim to increase visitors' awareness of the sites and develop conservation ethics. According to the current research, tour guides entertained visitors and made them appreciated the Angkor Wat temple. The guides also transferred knowledge about preservation of the site to tourists (see section 5-3-1). These findings come closer to the previous research (Ap \& Wong, 2001; Christie \& Mason, 2003; Cohen, 1985). Cohen (1985) stated that tour guides do not just entertain visitors but they also provide visitors with an understanding of the site and its culture (Ap \& Wong, 2001). Providing information and knowledge to visitors will change their behaviour and the perception they had before arriving at the site. In addition, their positive attitude and understanding about the site can achieve important aims of sustainable tourism development and promote a conservation ethic.

If there is a gap between the objectives of tour guides and organisations, the gap may lead to unsuccessful development of the sites. This could happen in countries where freelance tour guides are licensed to work in the sites. These freelance guides are not under any specific tour companies and they work independently. These freelance tour 
guides probably do not always have an explicit objective apart from earning money through guiding tours. It can be explained by the fact that, tour guides may aim to satisfy their customers' basic needs rather than focusing on visitors' awareness of the site. The aim is not wrong or right but depends on tour guides' perceptions. If they perceive that they are a part of improving interpretation at the site, their objective may include visitor's awareness and sustainable development of the site. That is the reason why APSARA and Ministry of Tourism conduct guide training courses in order to increase their knowledge about the site. Training courses being discussed in section 6-21 may provide a good solution and facilitate tour guides to understand about their roles and the objectives of interpretation. Therefore, to differentiate between the aims of interpretation, future research on freelance guides and the organisations' aims of interpretation should be conducted.

\section{6-4-A variety of interpretation management by multiple stakeholders}

This section primarily gives an explanation about similarities and differences of managing interpretation by organisations and tour guides at Angkor Wat. Then, the impacts of multiple stakeholders on the interpretation management will be presented.

\section{6-4-1-Similarity}

Enhancing visitors' experiences at the world heritage site is the general purpose of the stakeholders. Tour guides are key players to contribute knowledge such as culture, history, architecture and information of Angkor Wat to visitors. Tour guides provide the visitors an opportunity to learn some aspects of the historic site (Garrod \& Fyall, 2000). In the current research, tour guides expressed different ways to manage various groups of visitors in order to increase visitors' knowledge about Angkor Wat, in other words, to enhance the quality of visit. Similarly, APSARA and NGOs working for conservation at Angkor Wat, also focus on visitors' experiences. Because Angkor Wat is not known by many people, information and signs are very important to inform them. Providing signs and information boards on the site are vital for visitors to understand the significance of Angkor Wat. In addition, visitors also learn about appropriate behaviour which is 
needed at the site. It is assumed that the arrangement of the signs and information boards facilitate visitors to experience most of the site. Therefore, visitors' experiences are the main objective of the stakeholders.

\section{6-4-2-Difference}

Site managers are more concerned about sustainable development of the site than tour guides. This is reflected in their objectives and approaches to interpretation management (see table 4). In addition to improving visitors' experiences (see above similarity), interpretation has been known as an important key to develop tourist attractions in a sustainable way (Garrod \& Fyall, 2000; Moscardo, 1998; Shackley, 1998). Their studies illustrate some issues caused by visitors and the authors seem to focus on interpretation as a management tool to solve the problems. Providing interpretive signs are a good way to reduce negative impacts resulting from visitors. Of course, tour guides can explain and interpret things that could harm the site to visitors but they can only inform some groups of visitors who hire them. In contrast, a message from signs and information boards managed by APSARA and NGOs do not only deliver to visitors but also to all members of the public who wish to know about the site. Another example from the present research shows that the guide training course conducted by APSARA and the Ministry of Tourism aims to explain to the tour guides about their role in developing the site. The training course also helps tour guides to understand the value of interpretation which increases visitor awareness and minimises negative impacts. Designing informative signs and organising training courses are a kind of strategy in managing interpretation which is a response to site damage concerns.

Managing interpretation made by tour guides is active communication. The findings suggested that managing interpretation is related to managing a group of visitors. The degree of understanding of visitors within a group is diverse. This may have an influence on interpretation and explanation made by tour guides. Having known about visitors' backgrounds, tour guides are able to select a suitable scenario to be interpreted. Selecting the right scenario and story, visitors may also have a chance to provoke discussion and question their guides face to face. However, according to the author's experiences and the interviews from APSARA and NGOs, the organisations have not carried out survey about visitors' perceptions of interpretive facilities and visitor 
centres. They have not focused on how much visitors understand and learn about the site through interpretive facilities. This means the organisations do not exactly have direct communication with visitors. Therefore, the organisations are difficult to get feedback for improving visitors' understanding through facilities provided on site.

Financial support for the development of the interpretive structure is under the supervision of site managers. Tour guides seem to spend nothing during their process of interpretation. However, site managers need to have a clear budget plan for improving visitors' facilities at the site. The findings revealed that because APSARA used to plan a budget for conservation purpose they did not have enough funds to establish a visitor centre. Similarly, NGOs can run their exhibition centres by looking for international funds from overseas. An advance technology is another driver shaping the quality of interpretation. Some museums and sites in developed countries spend a lot of money for improving interpretive facilities which are believed to enhance the quality of visits. These findings imply that financial concerns are also a part of management of interpretation.

A slightly different role can be seen between the management of interpretation by organisations and tour guides. Literature revealed that site managers are responsible for planning and implementation to improve interpretive facilities (Hall \& McArthur, 1993; Landorf, 2009). APSARA and the Ministry of Tourism are good examples for this. However, the findings indicate that tour guides seem to use tour contents which they learned from the training courses and contribute to visitors. It is likely that tour guides have much involvement in implementation because they get influential ideas from tour guides of the organisations in order to serve the policy for the development of the site (Ap \& Wong, 2001; Christie \& Mason, 2003). Therefore, organisations have both roles in planning and implementation whereas tour guides have been involved in implementation for the purpose of managing interpretation.

APSARA and the Ministry of Tourism are in a high level of decision making with regard to interpretation. The current study revealed that these two organisations have a great deal of influence on both interpretation at sites as well as tour guides. These organisations should demonstrate good cooperation with tour guides before making a decision on developing interpretative facilities. This can be explained by the fact that tour guides have a closer relationship with visitors than APSARA and the Ministry of 
Tourism. Tour guides probably have some idea about visitors' demand for interpretation. Thus, tour guides should become a part of policy maker groups who decide on the management of interpretation.

6-4-3-The impacts of multiple stakeholders on interpretation management

Contradictions and conflicts are often found at heritage sites. These conflicts occur because of the problematic relationship between site managers (conservationists) and tourism developers (Aas, et al., 2005). The threats cannot be minimised unless these stakeholders have good cooperation and discussions. If an agreement can be found, these stakeholders will achieve the development of the site in a way that preserves the cultural resources and benefits to all stakeholders. According to the present study, there is no consensus among the relevant stakeholders in managing interpretation at Angkor Wat, especially tour guides and APSARA.

The findings suggested that tour guides are not happy with an introduction of a new audio tour guide project. Interviews with tour guides indicated that they were very concerned about redundancy which may be caused by placing audio tour guides at Angkor Wat. Although a few guides acknowledged that audio tour guides will not provide detailed information and explanation as real tour guides do, they still hold the opinion that the audio guides should not be introduced at Angkor Wat. In addition to that, an officer from the Ministry of Tourism supported the tour guides by stating that the use of interpretative facilities should not affect tour guides' careers. In a response to the tour guides' concerns, an APSARA officer made a point that the distribution of the audio tour guides at Angkor Wat offers visitors a plurality of heritage interpretation. So that tourists have choices to select tour guides or audio guides during a tour at Angkor Wat. It is likely a contradiction caused by the two perspectives from tour guides and the officer of APSARA. Even the officer from the Ministry of Tourism disagrees with the ideas of APSARA officer. If these conflicts cannot be resolved, they may impact on the development of the interpretation project at Angkor Wat.

Decision making was also found to be a controversial issue between the tour guides and the APSARA. Tour guides revealed that they are rarely invited by the APSARA to be involved in meetings. None of the tour guides' concerns have been raised and discussed 
for example in a meeting about the development of the interpretive facility project (see section 5-4-2). These actions seem that APSARA makes decisions for the site on their own. Centralisation could be a reason that leads to the sole decision making of APSARA. According to Aas et al. (2005), communication between stakeholders was perceived to be complicated because no one is really responsible for their actions at the sites. In addition to that, the private sector had no opportunity to discuss any issues with APSARA. The current findings may be in line with the study of Aas et al. (2005) because the authors conducted the research in Laos where political ideology and cultural contexts are relatively similar to Cambodia. It is believed that the management of interpretation at Angkor Wat will not be successful if the site managers fail to take an involvement of relevant stakeholders into account (Leask, 2010). 


\section{Chapter 7: Conclusion}

\section{7-1-Introduction}

This concluding chapter summarises the key aspects that were discussed in the previous chapters. The following section will be a discussion of the development of a conceptual framework. The studies' contribution to academic research and real practices will be presented. This is followed by limitations of the study and future research about interpretation management.

\section{7-2-The summary of the research}

The study of multiple stakeholders managing interpretation at a world heritage site contributes to the literature on heritage interpretation and tourism management. The current research also adds to the wider literature on visitor attractions and management for which interpretation is used as an educational tool to reduce visitor impacts at historical sites. The findings also make a contribution to the literature on stakeholders taking part in managing interpretation at a UNESCO World Heritage Site. In addition, a comparison between managing interpretation by organisations and tour guides are addressed in the study.

Another advantage of the current study is found in the research method and the selection of a constructivist perspective which is appropriate for investigating the management of interpretation. The development of the conceptual framework to examine the research questions provided a structure for data collection and identification of individual stakeholders taking part in interpretation management. To analyse the data, coding and categorising key themes were undertaken. The key themes were arranged according to the research questions.

The research method also confirms the trustworthiness of the findings. Adopting a social constructivist approach has allowed multiple voices to be examined. The approach allowed the researcher to identify the influential factors on the interpretation. Face-to-face, semi-structured interviews provided the participants with an opportunity to have an open discussion based around the questions. Primary and secondary data were both used in data analysis in processing the research questions. 
The findings of the research contribute to the literature on managing interpretation and tourism management at world heritage sites. The objectives of individual stakeholders for managing interpretation were identified. The research also found that organisations and tour guides have different responsibilities in interpretation management. Organisations were concerned about a lack of interpretive facilities provided at Angkor Wat. This interpretive infrastructure was used to enhance visitor experiences and promote conservation at the site. Furthermore, guide training courses were revealed to be significant tool to develop the capacity of tour guides. Tour guides, on the other hand, linked the management of interpretation with the management of visitors within group tours. The findings suggested that the effectiveness of interpretation partly depends on effective tactics in managing a group of visitors

Conflicts between stakeholders were identified. The findings revealed that tour guides had no power in decision making about the development of interpretation at the site. This means APSARA solely decided on how to improve interpretation at Angkor Wat temple whereas the Ministry of Tourism focused on organising the guide training courses. It seems that the communication between the two organisations have not been going well to develop interpretation for the site. Introducing an audio guide project at Angkor Wat temple has created misunderstanding between APSARA and tour guides. The project was planned for improving interpretive facilities at the temple but tour guides and the officer from the Ministry of Tourism were not happy with the project because it may affect tour guides' careers.

\section{7-3-The conceptual framework}

A conceptual framework (see figure 3, p. 38) which was developed from the literature provides an overview of the management of interpretation at a world heritage site. The framework illustrates the overlap of site management and interpretation management. According to the literature, interpretation is used as a management tool for controlling visitors' behaviour and promoting visitors' experiences at heritage attractions. The framework also provides a comprehensive understanding of the involvement of stakeholders in managing interpretation at heritage sites. Understanding the stakeholders' contributions to data collection assists in addressing the research questions. 
A structure of findings (see figure 4, p. 87) illustrates different levels of organisations in managing interpretation at Angkor Wat temple. Compared to the conceptual framework, the structure of findings provided more specific answers which addressed the research questions. The structure of findings provided detail about how individual organisations manage interpretation at Angkor Wat temple. Different objectives and responsibilities of the stakeholders were found in their interpretation management. Additionally, the structure shows the relationship between the stakeholders.

The conceptual framework and a structure of findings contribute to a discussion chapter. Literature that formed the conceptual framework was discussed with the findings of the current research. Some findings confirmed and contrasted the previous studies whereas others suggested areas for future research. Having gone through the discussion chapter, although the conceptual framework was used as guidance for the current research, changes had been made to the framework according to the findings presented in the research. The conceptual framework suggested that some stakeholders take part in managing interpretation including the international community, and the public and private sector. However, responsibilities of the international community were found less in the interpretation management at Angkor Wat temple. Instead, APSARA and tour guides were found to be as key players. Hence, the conceptual framework needs to be revisited after a discussion chapter to ensure any changes.

\section{7-4-Contribution of the study}

\section{7-4-1-Contribution to academic research}

The current study has provided insight into the relationship between organisations and tour guides in managing interpretation at a world heritage site as opposed to looking at one group's perspective individually as has been done in most previous studies. It further examined the conflicts between the stakeholders and the objectives of interpretation at a heritage site. Looking at the big picture, interpretation is used as a means to deal with visitor impact. Thus, the study of managing interpretation provides a chance to understand visitor management that needs support from diverse forms of interpretation. 
This study adds another insight into heritage management. In addition to sustainable tourism management and cultural tourism, the current research broadens scope of research into the area of heritage management. The selection of a case study about Angkor Wat temple, a world heritage site, provided an understanding about the benefits of interpretation for managing heritage sites where site managers are concerned about conservation and sustainable development. These concerns are taken into account by both national to international communities.

The current research has provided an idea how to recruit participants from tour companies through tour guides. Because one of the research questions was to explore decision-making in interpretation management, tour companies were suggested as interviewees by tour guides. Although the outcomes from the interviews have not involved in data analysis, the selection process of tour companies is a new way to recruit participants. Tour companies have a close connection with tour guides and the companies also have strong influence on organising efficient time for interpretation. The selection method helped the researcher to understand the relationship between tour guides and tour companies. This method also allowed for additional data to be collected.

\section{7-4-2- Contribution and practical implications}

Heritage interpretation plays an important role in promoting cultural tourism but little attention has been paid to multiple stakeholders managing interpretation at heritage sites. The present study contributes to an understanding of stakeholders' objectives and the relationships between stakeholders in interpretation management. This research is also valuable for those who wish to understand the partnership between the heritage industry and cultural tourism development.

It is common to have conflict between stakeholders when they take part in managing interpretation at a world heritage site. Some conflicts stated by site managers and tour guides were identified in the current research. Identifying these conflicts could help the two parties to find appropriate ways to solve the problems. In addition, both parties could understand each other's objectives and they would be willing to improve their interpretation management. 


\section{APSARA Authority}

Understanding about interpretation management at Angkor Wat temple provides an important example for a future study of interpretation at other temples in the Angkor area where interpretation is needed. Site managers and relevant institutions can use the current research as a guideline to discover the structure of managing interpretation at other heritage sites. The present study also provides site managers an opportunity to adopt and develop the research framework of interpretation management.

Interpretive centres were found important for Angkor Wat temple. The current study highlighted the important role of such centres where visitors can learn about the history and architecture of Khmer culture. Visitors are likely to appreciate authentic experiences at the site and their satisfaction would become a good marketing strategy that encourages visitors to further explore the culture. It would be worthwhile to have visitor centres explaining the features of Angkor Wat temple so that visitors may consider extending their holiday or plan a subsequent visit.

\section{Ministry of Tourism}

The findings suggested that guide training courses are necessary to enhance tour guides' capacity in knowledge as well as language. The Ministry of Tourism and APSARA should consider providing additional training courses which aim to develop guides' skills of interpretation. Testing tour guides' knowledge about the sites and their interpretive language skills should be strengthened in order to enhance the quality of guides.

NGOs

Interpretation management has implications for conservation. The effectiveness of heritage interpretation management is not only to promote visitor experiences but also to minimise the negative impacts to sites. A reduction of visitor impact is a component of conservation policy which would help site managers to think about a structure of heritage management framework. APSARA and UNESCO should consider the 
interpretation management as a part of the heritage management framework for Angkor Wat temple.

\section{Tour guides}

The Cambodian Ministry of Tourism should reconsider the tour guide qualification structure. According to the current research, tour guides would be happy to take part in further seminars or training courses that can help them develop their professional skills. The research findings could inform the Ministry of Tourism about a need for guide training courses to enhance tour guides' qualification. Also, the status of tour guides could be promoted through their experiences on the site and participation in the training courses. When the quality of the guides is improved, they would receive higher pay which motivates tour guides to efficiently work in their career. However, it should be acknowledged that some tour operators might not hire these qualified tour guides because they will increase the cost of package tours. Hence, tour guide training in some Asian countries is still a controversial topic, specifically with regard to their quality and salaries.

\section{Relationships between multiple stakeholders}

It is impossible to develop interpretation management without building relationships among individual stakeholders. A tie between policy makers and implementers is found to be very important to achieve an organisation's goals. To improve policy relating to heritage interpretation, Ministry of Tourism and APSARA could collaborate with tour guides who work closely with visitors and understand visitors' demand for interpretation, both verbal and non-verbal. An effective form of interpretation could be discussed as to how to improve visitors' experiences while preserving the site in a sustainable manner. As a result, the visitors' appreciation about the interpretation would promote conservation and cultural tourism in the country. 


\section{7-5-Limitations}

It is necessary to identify the limitations of this research (see section 3-5-2) because they provide a chance for future researchers to examine the management of interpretation. The method to recruit tour guides was not adequate because most of interviewees were Cambodian tour guides. In addition to Cambodian tour guides, foreign tour guides may reveal other issues in managing their interpretation such as culture, communication with locals, and knowledge of the visiting sites. It would be better to use another method to recruit tour guides to select both national and international ones.

On-site observation on a guiding tour would complement the interviews with tour guides. The present research selected semi-structured interviews as a means to collect data. The researcher could collect further data by going into the field for observing the tour guides. This observation would help the researcher to follow up on what he discovered by interviewing tour guides and get more insight into how they conduct.

It was hard to arrange for the interviews with participants because the current research was conducted in the high tourist season in Cambodia. This particularly affected the interviews with tour guides. The researcher needed to be flexible with tour guides because they were normally very busy guiding tours during the day. The arrangement for the interviews with tour guides was in the evening after tour guides had completed their work. The interviews are not expected to get sufficient responses because due to tour guide tiredness. Thus, tour guides did not concentrate on the questions. It would be better if the interviews were conducted at an appropriate time so that tour guides could pay more attention to the questions.

Few tour operators were selected for examining their influence on tour guides. Only three recommended tour operators were interviewed. This number was smaller compared to ten interviewed tour guides. The number of tour operators to be interviewed should be increased so that the researcher could gain a clearer understanding of the relationship between the management of interpretation and the organised itinerary.

The interviewees were reluctant to provide certain pieces of information because that would reveal the name of the organisation where they were employed. Before 
conducting the interviews, the researcher handed in an information sheet which stated the confidentiality of data to interviewees. Because the name of the institution was stated in the sheet and would be used in the report, interviewees were still unwilling to answer some questions which participants considered sensitive with regard to government policy.

\section{7-6-Further research}

The current research leaves gaps for future research on the management of interpretation at a World Heritage Site. Future scholars have an opportunity to address the limitations discussed above. The current research about management of interpretation at a World Heritage Site was conducted from the supply-side perspective. Future researchers could further this study by examining visitors' perceptions about the interpretation provided by site managers and tour guides and hence reveal issues relating to the demand-side perspective.

Semi-structured interviews were adopted for the current research. However, other methods of enquiry could be considered for future research methodology. Conducting visitor surveys may provide sufficient data about interpretation because the survey could be done with independent and dependent visitors. Additionally, observation would be a good research method if the researcher had adequate time to conduct the field-work.

It is suggested that future research could focus on historical sites which are owned by the private sectors to offer a point of comparison to the current study. This study took place at Angkor Wat temple which is operated by the government. The management of visitor interpretation may not be the same to one run by the private sector because of their different objectives in managing sites. Additionally, financial concerns for conservation and development of the visiting places may also differ between the two sectors.

The interviews in the current research were conducted with local tour guides who know a lot of back-ground information about the history and culture of the destination. However, international guides should not be ignored. The future researchers could pay attention to these groups because their language, communication with the community 
and their knowledge of the culture of the visiting places may influence their management of interpretation. As a result, visitors may have different experiences through interpretation provided by foreign guides.

An investigation into tour itineraries could be made. The itinerary organised by tour operators may have a relationship with the length of the interpretation process. According to the itinerary, some tour guides have to be flexible with suggested amount of time indicated by the tour operators. It may be hard for visitors to have an authentic experience because tour guides are not able to offer lengthier interpretation due to the itinerary. Thus, tour guides need to have good time management skills and a good selection of interpretive topics. Future researchers could further the area of research by focusing on the influence of itinerary on interpretation. 


\section{References:}

Aas, C., Ladkin, A., \& Fletcher, J. (2005). Stakeholder collaboration and heritage management. Annals of Tourism Research, 32(1), 28-48.

Ang, C., Thompson, A., \& Prenowitz, E. (1998). Angkor: A Manual for the Past, Present and Future. Phnom Penh: APSARA: UNESCO.

Ap, J., \& Wong, K. K. F. (2001). Case study on tour guiding: professionalism, issues and problems. Tourism Management, 22(5), 551-563.

Araoz, G. (2005). Some Background Musings on the Need for an ICOMOS Ename Charter for the Interpretation of Cultural Heritage Sites. The George Wright Forum.

Beck, W. (2006). Narratives of World Heritage in travel guidebooks. International Journal of Heritage Studies, 12(6), 521-535.

Bramwell, B., \& Lane, B. (1993). Interpretation and sustainable tourism: the potential and the pitfalls. Journal of Sustainable Tourism, 1(2), 71-80.

Brochu, L., \& Merriman, T. (2002). Personal interpretation: Connecting your audience to heritage resources: Interp Press, [Fort Collins].

Butts, D. (1993). Institutional Arrangments for Cultural Heritage Management in New Zealand: Legislation, Management, and Protection. In C. M. Hall (Ed.), Heritage Management in New Zealand and Australia.

Carr, A. (2004). Mountain places, cultural spaces: The interpretation of culturally significant landscapes. Journal of Sustainable Tourism, 12(5), 432-459.

Carter, B., \& Grimwade, G. (1997). Balancing use and preservation in cultural heritage management. International Journal of Heritage Studies, 3(1), 45-53.

Christie, M. F., \& Mason, P. A. (2003). Transformative tour guiding: Training tour guides to be critically reflective practitioners. Journal of Ecotourism, 2(1), 1-16.

Cohen, E. (1985). The tourist guide: The origins, structure and dynamics of a role. Annals of Tourism Research, 12(1), 5-29.

Creswell, J. W. (2007). Qualitative inquiry \& research design: Choosing among five approaches. Thousand Oaks: Sage Publications, Inc.

Cros, H., Leask, A., \& Fyall, A. (2007). Too much of a good thing? Visitor congestion management issues for popular World Heritage tourist attractions. Journal of Heritage Tourism, 2 (3 (Special)), 225-238.

Dahles, H. (2002). The Politics of Tour Guiding:: Image Management in Indonesia. Annals of Tourism Research, 29(3), 783-800.

Davies, D., \& Dodd, J. (2002). Qualitative research and the question of rigor. Qualitative Health Research, 12(2), 279-289. 
de Rojas, C., \& Camarero, C. (2008). Visitors' experience, mood and satisfaction in a heritage context: evidence from an interpretation center. Tourism Management, 29(3), 525-537.

Fallon, L. D., \& Kriwoken, L. K. (2003). Community involvement in tourism infrastructure--the case of the Strahan Visitor Centre, Tasmania. Tourism Management, 24(3), 289-308.

Finn, M., Elliott-White, M., \& Walton, M. (2000). Tourism and leisure research methods: data collection, analysis, and interpretation. London: Pearson Education.

Garrod, B., \& Fyall, A. (2000). Managing heritage tourism. Annals of Tourism Research, 27(3), 682-708.

Garrod, B., Fyall, A., \& Leask, A. (2002). Scottish visitor attractions: managing visitor impacts. Tourism Management, 23(3), 265-279.

Garrod, B., Fyall, A., \& Leask, A. (2006). Managing visitor impacts at visitor attractions: an international assessment. Current issues in tourism, 9(2), 125-151.

Glaize, M. (1993). Les monuments du groupe d'Angkor. Saigon: J. Maisonneuve.

Guba, E. G., \& Lincoln, Y. S. (1994). Competing paradigms in qualitative research. Handbook of qualitative research, 2, 163-194.

Hall, M. (1999). Rethinking collaboration and partnership: A public policy perspective. Journal of Sustainable Tourism, 7(3-4), 274-289.

Hall, M., \& McArthur, S. (1993). Visitor Management and Interpretation at Heritage Sites. In M. Hall \& S. McArthur (Eds.), Heritage Management in New Zealand and Australia: Oxford University Press.

Hawkins, D. E. (2004). Sustainable tourism competitiveness clusters: application to World Heritage sites network development in Indonesia. Asia Pacific Journal of Tourism Research, 9(3), 293-307.

Hay-Edie, T., Howard, P., Martin, G., \& McCandless, S. (2011). The roles of local, national and international designations in conserving biocultural diversity on a landscape scale. International Journal of Heritage Studies, 17(6), 527-536.

Ho, P., \& McKercher, B. (2004). Managing heritage resources as tourism products. Asia Pacific Journal of Tourism Research, 9(3), 255-266.

House, J. (2007). Angkor Management Plan: APSARA Authority.

Hughes, M., \& Morrison-Saunders, A. (2002). Impact of trail-side interpretive signs on visitor knowledge. Journal of Ecotourism, 1(2), 122-132.

Io, M. U., \& Hallo, L. (2011). Tour guides' interpretation of the Historic Center of Macao as a World Cultural Heritage site. Journal of Tourism and Cultural Change, 9(2), 140-152.

Jamieson, W. (2006). Interpretation and Tourism. In W. Jamieson (Ed.), Community Destination Management in Developing Economies (pp. 87). New York: The Haworth Hospitality Press. 
Knudson, D. M., Cable, T. T., \& Beck, L. (1995). Interpretation of cultural and natural resources: ERIC.

Kuo, I. (2002). The effectiveness of environmental interpretation at resource-Sensitive tourism destinations. International Journal of Tourism Research, 4(2), 87-101.

Landorf, C. (2009). Managing for sustainable tourism: a review of six cultural World Heritage Sites. Journal of Sustainable Tourism, 17(1), 53-70.

Leask, A. (2010). Progress in visitor attraction research: Towards more effective management. Tourism Management, 31(2), 155-166.

Leask, A., Fyall, A., \& Garrod, B. (2002). Heritage Visitor Attractions: managing revenue in the new millennium. International Journal of Heritage Studies, 8(3), 247-265.

Leask, A., \& Yeoman, I. (1999). Heritage visitor attractions: an operations management perspective: Thomson Learning Emea.

Light, D. (1995). Visitors' use of interpretive1 media at heritage sites. Leisure Studies, 14(2), 132-149.

Mason, P. (2005). Visitor Management in Protected Areas: From 'Hard'to 'Soft'Approaches? Current issues in tourism, 8(2), 181-194.

McKercher, B., \& Du Cros, H. (2002). Cultural tourism: The partnership between tourism and cultural heritage management: Routledge.

McKercher, B., Ho, P. S. Y., \& du Cros, H. (2005). Relationship between tourism and cultural heritage management: Evidence from Hong Kong. Tourism Management, 26(4), 539548.

Millar, S. (1989). Heritage management for heritage tourism. Tourism Management, 10(1), 914.

Ministry of Tourism. (2009). Tourism charter: Phnom Penh: Ministry of Tourism.

Ministry of Tourism. (2011). Tourism Statistic Report: First Quarter 2011. Phnom Penh: Ministry of Tourism.

Mitsche, N., Reino, S., Knox, D., \& Bauernfeind, U. (2008). Enhancing Cultural Tourism eServices through Heritage Interpretation. eResearch, 418-429

Moscardo, G. (1996). Mindful visitors:: Heritage and tourism. Annals of Tourism Research, 23(2), 376-397.

Moscardo, G. (1998). Interpretation and Sustainable Tourism. The Journal of Tourism Studies, 9(1).

Moscardo, G., \& Ballantyne, R. (2008). Interpretation and Attractions. In A. Fyall, B. Garrod, A. Ladkin \& S. Wanhill (Eds.), Managing Visitor Attractions (2 ed.).

Munro, J. K., Morrison-Saunders, A., \& Hughes, M. (2008). Environmental interpretation evaluation in natural areas. Journal of Ecotourism, 7(1), 1-14. 
Orams, M. B. (1996). Using interpretation to manage nature-based tourism. Journal of Sustainable Tourism, 4, 81-94.

Patton, M. Q. (2002). Qualitative research and evaluation methods. Thousand Oaks: Sage Publications, Inc.

Pizam, A. (1999). The American group tourist as viewed by British, Israeli, Korean, and Dutch tour guides. Journal of Travel Research, 38(2), 119.

Poon, A. (1993). Tourism, technology and competitive strategies. Wellingford: CAB international.

Poria, Y., Biran, A., \& Reichel, A. (2009). Visitors' preferences for interpretation at heritage sites. Journal of Travel Research, 48(1), 92.

Randall, C., \& Rollins, R. B. (2009). Visitor perceptions of the role of tour guides in natural areas. Journal of Sustainable Tourism, 17(3), 357-374.

Reisinger, Y., \& Steiner, C. (2006). Reconceptualising interpretation: The role of tour guides in authentic tourism. Current issues in tourism, 9(6), 481-498.

Shackley, M. (1998). Introduction-World Cultural Heritage Sites. In M. Shackley (Ed.), Visitor Management Case Studies from World Heritage Sites (pp. 8-9): ButterworthHeinemann.

Sihanouk, N. (1995). Royal Decree establishing APSARA Authority.

Silverman, D. (2009). Doing qualitative research. London: Sage Publications Ltd.

Smith, V. L. (2001). The culture brokers. In V. L. Smith \& M. Brent (Eds.), Hosts and guests revisited: tourism issues of the 21st century (pp. 275-282). New York: Cognizant Communication Corporation.

Stake, R. E. (2005). Qualitative case studies. In N. K. Denzin \& Y. S. Lincoln (Eds.), The Sage handbook of qualitative research (Vol. 3, pp. 443-466). Thousand Oaks, CA: Sage Thousand Oaks, CA.

Tilden, F. (1957). Interpreting Our Heritage: The University of North Carolina Press.

Timothy, D. (2007). Managing Heritage and Cultural Tourism Resources (Vol. 1): Ashgate Publishing Limited.

Timothy, D., \& Boyd, S. (2003). Heritage Tourism: Pearson Education Limited.

Timothy, D., \& Prideaux, B. (2004). Issues in heritage and culture in the Asia Pacific region. Asia Pacific Journal of Tourism Research, 9(3), 213-223.

Yale, P. (1991). From tourist attractions to heritage tourism: ELM publications.

Yu, X., Weiler, B., \& Ham, S. (2002). Intercultural communication and mediation: A framework for analysing the intercultural competence of Chinese tour guides. Journal of Vacation Marketing, 8(1), 75-87.

Yu, X., Weiler, B., \& Ham, S. (2004). Cultural mediation in guided tour experiences: A case study of Australian guides of Chinese tour groups. New Frontiers in Tourism Research. 


\title{
Appendix A: Information sheet
}

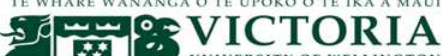 \\ Information Sheet}

EN UNIVESITY OF WELLINGTON

\author{
"Managing Visitor Interpretation at a World Heritage Site, a Supply Side Perspective of \\ Angkor Wat, Cambodia"
}

Dear participant,

I am a Master of Tourism Management student at Victoria University of Wellington and am doing my thesis research on the Management of Visitor Interpretation at World Heritage Site using Angkor Wat as a case study.

Thank you for showing an interest in this project. Please read this information sheet carefully before deciding whether or not to participate. If you decide to participate I thank you. If you decide not to take part, I thank you for considering my request.

\section{The project}

This project is part of the Master of Tourism Management at Victoria University of Wellington. The research objectives aim to look at organisational structure of interpretation management at Angkor Wat, to identify aims and objectives of stakeholders in managing interpretation and to understand how they achieve their goals, and to find out factors that influence stakeholders' perspectives and decision making in managing interpretation.

\section{Definition of Interpretation}

Interpretation is defined as the full range of potential activities intended to heighten public awareness and enhance understanding of natural and cultural heritage sites. These can include print and electronic publications, public lectures, on-site and directly related off-site installations, educational programmes, community activities, and ongoing research, training, and evaluation of the interpretation process itself (ICOMOS Ename Charter, 2008).

This project intends to find some participants whose tasks related to interpretation of Angkor Wat, a world heritage site. These participants are from UNESCO, Office of Tourism, APSARA Authority, international conservation teams such as GACP, WMF, I.Ge.S, tour operators, and tour guides.

Ethical approval for the proposed research has been granted by the Victoria University of Wellington Human Ethics Committee. You will be provided with a Consent Form, which will inform you about your rights and give you the opportunity to state how the data collected from you should be handled. 


\section{Participation in the project}

Should you agree to take part in this project, you will be asked to participate in an interview of 45-60 minutes duration. You will be asked to sign a consent form and the interview will be recorded if you allow. You have the rights to check interview notes. Please be aware that you may withdraw from participation in the project within two weeks after the interview and data collected will be destroyed.

\section{What you need to do}

The interview will be in depth and semi-structured. I will be asking you about objectives, views, responsibilities, experiences, expectations and decision-making that is relevant to the management of the visitor interpretation at Angkor Wat. The nature of some interview questions has not been determined in advance but will depend on the way in which the interview develops. You may decline to answer questions that you feel uncomfortable with or withdraw from the project immediately.

\section{Confidentiality of data}

All information and opinion will be presented in an aggregate form. Your identities such as your name and contacts will be entirely confidential. They will not be revealed to anyone and will neither be used in the interview transcription nor written in this Master thesis. However, your institution name will be identified instead. Please be aware that even though every effort will be made to keep your identity confidential, it may be possible for some to deduct your identity from the mentioning of your organisation or your statement. The data collected will be securely stored in such a way that only I and my supervisor will be able to access it. All raw data and audio recordings will be destroyed within two years after the conclusion of the research.

\section{Result of the research}

The thesis report will be available in the University Library and may be used for publication in academic or professional journal and for dissemination at academic or professional conferences.

You can indicate on the consent form if you wish to receive an electronic copy of the interview transcript and research report at the conclusion of the research.

If you have any questions about the project, either now or in the future, please feel free to contact me.

\section{Chanvirak Sarm}

Master Student at VUW

E-mail: sarmchan@myvuw.ac.nz

Tel: (64) 2102313056

\section{Dr. Julia Albrecht}

Lecturer, Victoria Management School, VUW

E-mail: Julia.albrecht@vuw.ac.nz

Tel: (64) 44635726 


\section{Appendix B: Consent form}

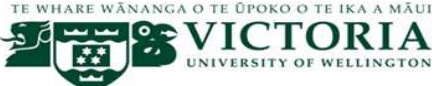

\section{Consent Form}

\section{"Managing Interpretation at a World Heritage Site, A Supply Side Perspective of Angkor Wat, Cambodia"}

I have read the Information Sheet concerning this project and understand what it is about. All my questions have been answered to my satisfaction. I understand that I am free to request further information at any stage.

I know that:

- My participation in the project is entirely voluntary;

- In the event that the line of questioning during the interview develops in such a way that I feel hesitant or uncomfortable I may decline to answer any particular question(s) and/or may withdraw from the project. All relevant notes and audio recordings will be destroyed immediately;

- I have the rights to check interview notes at the end of the interview.

- I am free to withdraw from the project within two weeks after the interview and all data collected will be destroyed;

- All information and opinions will be presented in an aggregate form; my identity such as my name and other contacts will remain confidential but the name of the organisation I work for will be identified;

- The interview may be recorded. Only the researcher and supervisor are able to access the data. The data collected will be retained in secure storage and security code will be used to protect the transcript file for two years, after which they will be destroyed;

- The result of this research will be used for a student Master thesis project and may be published in academic journals or presented in academic conferences.

I agree to take part in this project

Name of participant

(Name of the organisation if applicable)

Signature of participant

(Date)

I would like (please tick box as required)

Q 9 the transcript of this interview.

Q 9 a summary of the project results.

Your mail or e-mail address to be sent the document to. 


\section{Researchers' consent:}

I confirm that I will act in accordance with all confidentiality requirements as mentioned in the information sheet of this project.

\section{Chanvirak Sarm}

Master of Tourism Management, Victoria University of Wellington

Signature 


\section{Appendix C: Interview questions}

\section{Questions for semi-structured interviews}

"Managing Interpretation at a World Heritage Site, A Supply Side Perspective of Angkor Wat"

\section{Section 1: Introduction}

-Information sheet

-Consent form

\section{Section 2: Participant background (For all participants)}

-Can you tell briefly about your background?

-How long have you been working for this organisation/as a tour guide?

\section{Section 3: Objectives for managing interpretation by multiple stakeholders}

\section{UNESCO:}

-Does the UNESCO have any involvement in the management of visitors at Angkor Wat? If so, can you describe your involvement to me?

-In general are you aware of interpretation of a world heritage site? What should it achieve?

-Do you know about the International Ename Charter? Do you work with it? If so how?

-If yes, what does it mean to Angkor Wat in terms of conservation and visitation?

-Does the UNESCO have any guidelines regarding interpretation at Angkor Wat?

-Why does/doesn't the UNESCO distribute the guidelines to relevant stakeholders? How?

-Can you tell me what works well and what does not work well with multi stakeholders? (Challenging working)

-What are the objectives of the interpretation policy at Angkor Wat?

-What are the requirements to achieve these objectives in the future? 


\section{GACP, WMF and APSARA:}

-What do you think the role of interpretation at Angkor Wat is?

-Does the organization has an interpretive centre? What are the roles of the centre? How does it work?

-How many kinds of interpretation do you provide to the public?

-How do they use interpretive signage?

-Who are the stakeholders involved in developing interpretation?

-How does the organization deal with relevant stakeholders in terms of improving interpretation? For example: a guide training course, seminars and so on.

-What are the objectives of the interpretive signs or boards?

-What are the requirements to achieve the objectives in the future?

-Does the admission fee benefit interpretation? How?

-Have the staff been trained for the purpose of improving interpretation skills?

\section{Ministry of Tourism:}

-How often does the organisation offer a guide training course? How long is the course?

-Why they have to be trained? What skills do they need to study?

-Do you think that the interpretation provided by tour guides contributes to conservation and quality of visit? In what way?

-How the training courses benefit the quality of the interpretation?

-What are the objectives of the interpretations?

-What are the requirements to achieve the objectives?

-How does the organisation plan to develop the interpretation programme for tour guides?

-How many stakeholders do you work with for the improvement of interpretation programme? Working with these stakeholders, do you feel that everything going smooth? Why? What are the results of having them working together?

\section{Site managers (APSARA Authority):}

-What are the interpretive facilities provided on the site? What are their roles?

-What are the benefits of having these interpretive signs on the site? How do you manage them?

-Does the development of interpretation benefit from admission fee?

-Have you and your staff been trained about how to manage visitor interpretation at the sites? Do you think that training courses beneficial? 
-What are the objectives of the interpretations?

-What are the requirements to achieve the objectives?

-How many stakeholders do you work with for the improvement of interpretation programme? Working with these stakeholders, do you feel that everything going smooth? Why? What are the result of having them working together?

\section{Tour operators:}

-Why do you include Angkor Wat in your itinerary? Is it important?

-How long for the visit at Angkor Wat? At what time? Why?

-What does interpretation mean to you as tour operator?

-Angkor Wat is the hot spot for all visitors to Angkor region, have your visitors experienced such negative things like crowded, difficult to listen to the tour guides and feel unhappy with the site in particular?

-How do you deal with these issues? For example provide them with ear phone set or allocate appropriate time or just select special scene for visitors at Angkor Wat?

-Have you provided instruction for visiting Angkor Wat to the tour guides? Or do you allow them to interpret everything by themselves?

-What are the objectives of the interpretations?

-What are the requirements to achieve the objectives?

-How many stakeholders do you work with for the improvement of interpretation? Working with these stakeholders, do you feel that everything going smooth? Why? What are the results of having them working together?

\section{Tour guides:}

-What do you interpret to the visitors at Angkor Wat? And how do you manage interpretation at the site? Have you prepared at home what need or not to be interpreted?

-How long do you usually spend in Angkor Wat? Which part of Angkor Wat you spend longer time than others?

-How do you deal with the visitors if they do not understand your interpretation.

-How many courses have you participated so far? Do the courses provide some detail about interpretation?

-What does interpretation mean to you as tour guides?

-What are the objectives of the interpretations?

-What are the requirements to achieve the objectives?

-How many stakeholders do you work with for the improvement of interpretation? Working with these stakeholders, do you feel that everything going smooth? Why? What are the result of having them working together? 


\section{Section 4: Influential factors on managing interpretation}

\section{UNESCO:}

-What are the factors that influence on your perspectives of interpretation of a world heritage site?

-What are the key factors that encourage you to take part in the interpretation policy or planning?

-What are the key factors that lead to a decision on managing of interpretation at a world heritage site?

-How do visitors to Angkor Wat affect the conservation project? In what way?

-How does tourism contribute to the conservation project?

-Does UNESCO have any guidelines or projects for balancing conservation and visitor management at Angkor Wat in particular?

-Will International Ename Charter on Interpretation be promoted in Angkor Wat? Why?

-In what way that you can promote this charter effectively? How?

\section{GACP, WMF, Office of Tourism, APSARA, Site managers:}

-What are the factors that influence on your planning on the interpretation for a world heritage site? For example, fund and human resources.

-What are the key factors that encourage you to take part in the interpretation project?

-What are the key factors that lead to a decision on managing of the interpretation at a world heritage site?

\section{Tour operator and tour guide:}

-What are the influential factors that affect interpretation?

-What are the motives that encourage you to participate in the interpretation

programmes?

-What are the key factors influence on your decision making in managing interpretation

\section{Section 5: Conclusion (For all participants)}

-Can you tell me one thing I should take away from this interview regarding the management of interpretation at Angkor Wat? What is it?

-Is there anything else you would like to add?

-If you do in the future, please feel free to contact me.

Thanks you very much for your time and participation. It is great to talk to you! 


\section{Appendix D: Pseudonyms of research participants (22 participants)}

I-APSARA Authority

1-Reahu: Adviser to Director General of APSARA

2-Mara: Cultural heritage expert

3-Dara: Deputy Director of Tourism Department

4-Devi: Director of Conservation and Prevention Department

II-Ministry of Tourism

5-Tom: Director of Training and Development Department

III-UNESCO

6-Jim: Culture Specialist

$I V-N G O S$

7-John: Project manager from GACP

8-Vana: Project manager from I.Ge.S.

9-Naga: Project manager from WMF

V-Tour companies

10-Kanha: Manager of BFT Angkor Travel

11-Raja: Tour guide organiser from APEX Tour

12-Yana: Itinerary manager from Angkor TK

VI-Tour guides

13-Kakada: French speaking guide

14-Seiha: French speaking guide

15-Tola: English speaking guide

16-Minea: English speaking guide

17-Vicheka: Japanese speaking guide

18-Mesa: Japanese speaking guide

19-Thanu: Spanish speaking guide

20-Sophea: Spanish speaking guide

21-Pheak: Thai speaking guide

22-Makara: Chinese speaking guide 


\section{Appendix E: Other documents}

1- APSARA legal framework

2- Tour guide regulation

3- Angkor Management Plan

4- Heritage booklet for children (gathered from APSARA library)

(gathered from Ministry of Tourism)

(gathered from APSARA library)

(gathered from APSARA library) 


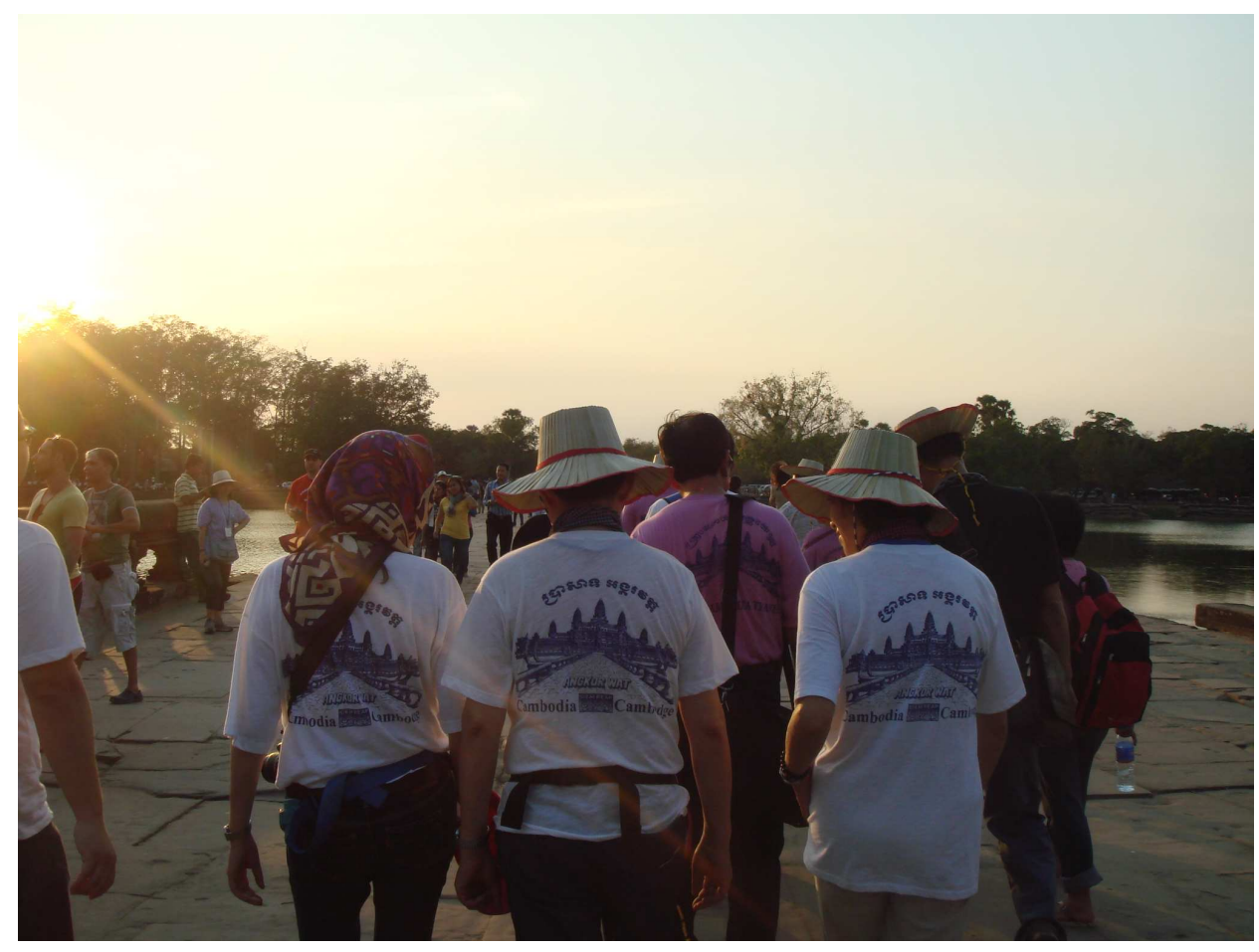

